\title{
New theoretical yields of intermediate mass stars ${ }^{\star}$
}

\author{
L.B. van den Hoek ${ }^{1}$ and M.A.T. Groenewegen ${ }^{2}$ \\ 1 Astronomical Institute "Anton Pannekoek", Kruislaan 403, NL 1098 SJ Amsterdam, The Netherlands \\ 2 Max-Planck-Institut für Astrophysik, Karl-Schwarzschild-Straße 1, D-85748 Garching, Germany
}

Received July 29; accepted September 25, 1996

\begin{abstract}
We present theoretical yields of $\mathrm{H},{ }^{4} \mathrm{He},{ }^{12} \mathrm{C}$, ${ }^{13} \mathrm{C},{ }^{14} \mathrm{~N}$, and ${ }^{16} \mathrm{O}$ for stars with initial masses between 0.8 and $8 M_{\odot}$ and initial metallicities $Z=0.001,0.004$, $0.008,0.02$, and 0.04 . We use the evolutionary tracks of the Geneva group up to the early asymptotic giant branch (AGB) in combination with a synthetic thermal-pulsing AGB evolution model to follow in detail the chemical evolution and mass loss up to the end of the AGB including the first, second, and third dredge-up phases. Most of the relations used are metallicity dependent to make a realistic comparison with stars of different initial abundances. The effect of Hot Bottom Burning (HBB) is included in an approximate way.

The free parameters in our calculations are the mass loss scaling parameter $\eta_{\mathrm{AGB}}$ for stars on the AGB (using a Reimers law), the minimum core mass for dredge-up $M_{\mathrm{c}}^{\min }$, and the third dredge-up efficiency $\lambda$. As derived from previous extensive modeling, $\eta_{\mathrm{AGB}}=4, M_{\mathrm{c}}^{\min }=$ $0.58 M_{\odot}$, and $\lambda=0.75$ including HBB are in best agreement with observations of AGB stars both in the Galactic disk and Magellanic Clouds.

The influence of specific model assumptions and adopted parameter values on the resulting AGB yields is examined and compared with earlier theoretical work. We compare the abundances predicted during the final stages of the AGB with those observed in planetary nebulae in the Galactic disk and show that the model with the aforementioned parameters is in good agreement with the observations. The metallicity dependent yields of intermediate mass stars presented in this paper are well suited for use in galactic chemical evolution models.
\end{abstract}

Key words: stars: abundances, evolution, AGB - ISM: abundances — galaxies: abundances

Send offprint requests to: L.B. van den Hoek (bobby@astro.uva.nl)

* Tables also available at CDS via anonymous ftp 130.79 .

128.5 or on WWW a http://cdsweb.u-strasbg.fr/abstract.html

\section{Introduction}

Presumably all main sequence stars with initial masses between $\sim 0.9$ and $\sim 8 M_{\odot}$ pass through a double-shell burning phase at the end of their lifetime, also referred to as the asymptotic giant branch (AGB) phase. During this phase, intermediate mass stars lose most of their envelope mass while they contribute substantially to the interstellar abundances of $\mathrm{He}, \mathrm{C}, \mathrm{N}$, and s-process elements (e.g. Renzini \& Voli 1981; Iben \& Renzini 1983; Dopita \& Meatheringham 1991).

The most quoted work with respect to the yields of intermediate mass stars is that of Renzini \& Voli (1981; hereafter RV) who calculated the amount of matter returned to the ISM by AGB stars in the form of e.g. He, $\mathrm{C}, \mathrm{N}$, and $\mathrm{O}$. Their well known results have been widely used to compare the predicted abundances in the ejecta of AGB stars with the abundances observed in planetary nebulae (see Clegg 1991 and references therein) and have been often applied in Galactic chemical evolution models (e.g. Matteucci et al. 1989; Rocca-Volmerange \& Schaeffer 1990).

In this paper, we use a synthetic evolution model similar in approach to that presented by RV to follow the chemical evolution of stars on the AGB. However, our model differs substantially from that described by RV, both in the various aspects of AGB evolution considered as well as in the parameters that best fit the observations (in particular the mass loss rate on the AGB). The model has been described in detail by Groenewegen \& de Jong (1993; hereafter GJ) and applied to various observational aspects of AGB evolution, both for AGB stars in the Galactic disk and Magellanic Clouds (GJ; Groenewegen et al. 1995, hereafter GHJ).

An important aspect of AGB evolution largely neglected in previous studies is the metallicity dependence of the evolutionary algorithms used. Observations show that the luminosity function and relative number ratios of carbon and oxygen-rich AGB stars in the Large and Small Magellanic Clouds are different (see e.g. GJ). One of the explanations for this is the different metallicity in these galaxies. In the actual model, we use a nearly complete 
metallicity dependent treatment of the evolution of AGB stars covering the first, second, and third dredge up. In addition, in GJ/GHJ take into account several new physical ingredients including the variation of the luminosity during the interpulse period, the fact that the first few pulses are not yet at full amplitude, and the detailed inclusion of mass loss and chemical evolution prior to the AGB.

Before reaching the AGB phase, the main sequence stellar composition has changed during the first dredge-up (experienced by all stars on the red giant branch (RGB)) and during the second dredge-up (experienced by stars with initial mass larger than some certain critical mass). The first dredge up occurs when the convective envelope moves inwards as a star becomes a red giant for the first time so that helium and CNO processed material are brought to the surface. Several tenths of solar masses can be lost in this phase for low mass stars (e.g. Sweigart et al. 1990; Rood 1973).

The second dredge-up is associated with the formation of the electron-degenerate $\mathrm{CO}$ core after central helium exhaustion and occurs on the early-AGB (hereafter E-AGB). In this case, helium and nitrogen may be dredged up towards the stellar surface. We use the comprehensive set of metallicity dependent stellar evolution tracks provided by the Geneva group (e.g. Schaller et al. 1992) to describe the evolution prior to the AGB. However, to study in detail the influence of the first and second dredge up on the AGB yields, we also consider a metallicity dependent theoretical treatment of these phases (cf. Sect. 3) according to the recipes outlined in GJ. In both cases, the stellar evolution prior to the AGB is coupled consistently to the thermal pulsing AGB phase.

During the third dredge up, carbon is dredged up to the stellar surface by convection of the carbon-rich pocket formed after each helium shell flash (or thermal pulse (TP)). By mixing additional carbon to the envelope, the star may undergo a transition from M-star (oxygenrich), to S-star (carbon roughly equal to oxygen), and C-star (carbon outnumbering oxygen). For stars with $m \gtrsim 3-4 M_{\odot}$, this transition is affected by HBB when both carbon already present and newly dredged-up carbon are processed at the base of the convective envelope according to the CNO cycle. We account for the effect of HBB in an approximate way since the details of this process are not well understood. Abundance variations during the AGB of individual elements heavier than oxygen are not taken into account.

The free parameters in our calculations are the mass loss scaling parameter $\eta_{\text {AGB }}$ for stars on the AGB (using a Reimers law), the minimum core mass for dredge-up $M_{\mathrm{c}}^{\mathrm{min}}$, and the third dredge-up efficiency $\lambda$. We will discuss the effect of these parameters as well as the effect of HBB on the stellar yields in Sect. 4. For AGB stars both in the Galactic disk and Magellanic Clouds, models with $\eta_{\mathrm{AGB}}=4, M_{\mathrm{c}}^{\mathrm{min}}=0.58 M_{\odot}$, and $\lambda=0.75$ including $\mathrm{HBB}$ are in best agreement with the observations. Part of the argumentation for this specific set of parameter values can be found in GJ and GHJ and references therein. For this set, we compute the stellar yields of $\mathrm{H},{ }^{4} \mathrm{He},{ }^{12} \mathrm{C},{ }^{13} \mathrm{C},{ }^{14} \mathrm{~N}$, and ${ }^{16} \mathrm{O}$ of AGB stars with initial mass between 0.8 and 8 $M_{\odot}$, and initial metallicity $Z=0.001,0.004,0.008,0.02$ and 0.04 , as presented at the end of this paper.

This paper is organized as follows. In Sect. 2, we define the stellar yields used throughout this paper. In Sect. 3, we briefly describe the basic ingredients of the synthetic evolution model related to the chemical evolution of stars on the AGB. In Sect. 4, resulting stellar yields are presented and their dependence on the main model assumptions is examined. In Sect. 5, we discuss the preferred set of stellar yields with respect to earlier theoretical work and compare the abundances predicted during the final stages of the AGB with those observed in planetary nebulae (PNe) in the Galactic disk.

\section{Definition of stellar yields}

The element yield $p_{j}$ of a star of initial mass $m$ is defined as the newly formed and ejected mass of element $j$ integrated over the stellar lifetime $\tau(m)$ and normalized to the initial mass (e.g. Maeder 1992):

$$
m p_{j}(m)=\int_{0}^{\tau(m)} E(m, t) \cdot\left(Z_{j}(t)-Z_{j}(0)\right) \mathrm{d} t
$$

where $E(m, t)$ denotes the stellar mass-loss rate and $Z_{j}(t)$ the abundance by mass of element $j$ in the ejecta at stellar age $t$. Note that negative yields may occur e.g. in the case of hydrogen consumption.

In general, stellar yields depend on the initial stellar abundances in different manners. First, abundances in the stellar envelope $Z_{j}(t)$ are related in a complex manner to the initial abundances of distinct elements (e.g. helium and/or oxygen). This is particularly true for stars on the AGB as we will discuss below. To first order, we take this important effect into account by the dependence of the evolutionary algorithms used on the initial stellar metallicity $Z(0)$, i.e. integrated over elements heavier than helium. Second, stellar lifetimes $\tau(m)$, remnant masses $m_{\text {rem }}(m)$, and mass-loss rates $E(m, t)$ vary strongly with initial stellar metallicity (e.g. Schaller et al. 1992). Third, stellar yields are defined with respect to the initial stellar abundances $Z_{j}(0)$ (cf. Eq. 1).

To allow for a direct comparison of the derived element yields for pre-AGB and AGB evolution phases (see below), we adopt the initial abundances as used in the stellar evolution tracks presented by the Geneva group (i.e. Schaller et al. 1992; Schaerer et al. 1993a,b; Charbonnel et al. 1993; Meynet et al. 1994). In brief, the Geneva group calculated the initial helium abundance from:

$Y=Y_{0}+\frac{\Delta Y}{\Delta Z} Z$ 
assuming a primordial helium abundance $Y_{0}$ of 0.24 (e.g. Audouze 1987; Steigman 1989) and $\Delta Y / \Delta Z=3$ (e.g. Pagel et al. 1986; Pagel \& Kaztauskas 1992) for stars in the Galactic disk. Accordingly, these tracks imply a revised solar metallicity of $Z_{\odot}=0.0188$ with $Y_{\odot}=0.299$ (see Schaller et al. 1992). Initial abundances of C, N, and $\mathrm{O}$ were taken according to the relative ratios (cf. Anders \& Grevesse 1989) used in the opacity tables by Rogers \& Iglesias (1992). The hydrogen content was calculated from $X=1-Y-Z$. Table 1 lists the adopted initial abundances of $\mathrm{H},{ }^{4} \mathrm{He},{ }^{12} \mathrm{C},{ }^{13} \mathrm{C},{ }^{14} \mathrm{~N}$, and ${ }^{16} \mathrm{O}$ at metallicities $Z(0)=$ $0.001,0.004,0.008,0.02$, and 0.04 . Note that abundances are given by mass throughout this paper.

Table 1. Initial element abundances adopted

\begin{tabular}{llllll}
\hline Element & $Z=0001$ & 0.004 & 0.008 & 0.02 & 0.04 \\
\hline $\mathrm{H}$ & 0.756 & 0.744 & 0.728 & 0.68 & 0.62 \\
${ }^{4} \mathrm{He}$ & 0.243 & 0.252 & 0.264 & 0.30 & 0.34 \\
${ }^{12} \mathrm{C}$ & $2.24(-4)$ & $9.73(-4)$ & $1.79(-3)$ & $4.47(-3)$ & $9.73(-3)$ \\
${ }^{13} \mathrm{C}$ & $0.04(-4)$ & $0.16(-4)$ & $0.29(-4)$ & $0.72(-4)$ & $1.56(-4)$ \\
${ }^{14} \mathrm{~N}$ & $0.70(-4)$ & $2.47(-4)$ & $5.59(-4)$ & $1.40(-3)$ & $2.47(-3)$ \\
${ }^{16} \mathrm{O}$ & $5.31(-4)$ & $2.11(-3)$ & $4.24(-3)$ & $1.06(-2)$ & $2.11(-2)$ \\
\hline
\end{tabular}

In this paper, we distinguish stellar yields e.g. for the pre-AGB and AGB phases (cf. Sect. 4). In this case, the total mass of element $j$ ejected during mass-loss phase $i$ (with age boundaries $t_{1}^{i}(m)$ and $t_{\mathrm{u}}^{i}(m)$ in Eq. 1) can be written as:

$\Delta m_{j}^{i}=\Delta m^{i} Z_{j}(0)+m p_{j}^{i}(m)$

where $\Delta m^{i}=\Sigma_{j} \Delta m_{j}^{i}$ is the total mass ejected during phase $i$. Similarly, mean abundances of element $j$ within the ejecta returned to the ISM during phase $i$ can be written as:

$<Z_{j}^{i}>=\frac{m p_{j}^{i}}{\Delta m^{i}}+Z_{j}(0)$.

The lifetime-integrated stellar yield of element $j$ in terms of the stellar yields for distinct mass-loss phases $i$ is given by $m p_{j}=m \Sigma_{i} p_{j}^{i}$. Since $\Sigma_{j} \mathrm{p}_{j}=0$ and $\Sigma_{j} Z_{j}=1$ according to Eq. (1), the total stellar mass ejected can be expressed as: $\Delta m^{\mathrm{ej}}=\Sigma_{i} \Delta m^{i}=\Sigma_{i} \Sigma_{j} \Delta m_{j}^{i}=m-m_{\mathrm{rem}}(m)$ where $m_{\text {rem }}(m)$ is the stellar remnant mass. In this manner, Eq. (1) also can be written as:

$m p_{j}(m)=\Delta m_{j}-\left(m-m_{\mathrm{rem}}\right) Z_{j}(0)$.

\section{Chemical evolution in the synthetic model}

We briefly repeat that part of the synthetic evolution model that is related to the chemical evolution on the AGB. Full details on the model can be found in GJ. The evolution model is started at the first TP, taking into account the changes in mass and abundances prior to the first TP, and is terminated when the envelope mass has been lost due to mass loss or if the core reaches the Chandrasekhar mass. The latter situation never occurs in the best fitting models for the Galaxy and the Large Magellanic Cloud (see GHJ, GJ).

\subsection{First dredge-up}

The first dredge-up occurs when the convective envelope moves inwards as a star becomes a red giant for the first time. Description of the mass loss during the RGB can be found in GJ. The convective motion dredges up material that was previously located near the hydrogen burning shell. The increase in the helium abundance, $\Delta Y$, is given by (cf. Sweigart et al. 1990):

$$
\Delta Y= \begin{cases}-0.0170 m+0.0425 & \text { for } m<2, Y=0.3 \\ -0.0068 m+0.0221 & \text { for } 2 \leq m<3.25 \\ & Y=0.3 \\ -0.0220 m+0.0605 & \text { for } m<2.2, Y=0.2 \\ -0.0078 m+0.0293 & \text { for } 2.2 \leq m<3.75 \\ 0 & Y=0.2 \\ 0 & \text { else. }\end{cases}
$$

Results are linearly interpolated for a given $Y$ while the small dependence of $\Delta \mathrm{Y}$ on $\mathrm{Z}$ for a given $\mathrm{Y}$ is neglected. The change in hydrogen is opposite to the change in helium:

$\Delta X=-\Delta Y$.

Changes in ${ }^{12} \mathrm{C},{ }^{14} \mathrm{~N}$, and ${ }^{16} \mathrm{O}$ are calculated from:

$\Delta^{12} \mathrm{C}={ }^{12} \mathrm{C}(g-1)$

$\Delta^{14} \mathrm{~N}=-1.167 \Delta^{12} \mathrm{C}$

$\Delta^{16} \mathrm{O}=-0.01{ }^{16} \mathrm{O}$

$g= \begin{cases}0.64-0.05(m-3) & \text { for } m<3 \\ 0.64 & \text { for } m \geq 3\end{cases}$

The number ratio ${ }^{12} \mathrm{C} /{ }^{13} \mathrm{C}$ after the first dredge-up does not vary much with mass or composition (Sweigart et al. 1989) and is set to 23.

\subsection{Second dredge-up}

The second dredge-up is related to the formation of the electron-degenerate CO core after central helium exhaustion in stars more massive than a critical mass (see Becker \& Iben 1979, 1980) which depends both on the core mass and main-sequence abundances. The base of the convective envelope moves inward through matter pushed outwards by the He-burning shell. The treatment of the second dredge-up follows that of RV closely. No mass loss is assumed during second dredge-up. 
Following GJ (and references therein), the abundances after the second dredge-up can be obtained from the abundances prior to the second dredge-up and the abundances of the material that is dredged up using the relation:

$X^{\text {after }}=a X^{\text {prior }}+b X^{\text {du }}$

where the coefficients $a$ and $b$ are functions of the total mass as well as the core mass before and after second dredge-up and are given by Eq. (30) in GJ. The abundances prior to the second dredge-up are known and the abundances of the dredged up material are given by RV and Iben \& Truran (1978):

$$
\begin{aligned}
Y^{\mathrm{du}} & =1-Z \\
{ }^{14} \mathrm{~N}^{\mathrm{du}} & =14\left({ }^{12} \mathrm{C} / 12+{ }^{13} \mathrm{C} / 13+{ }^{14} N / 14+{ }^{16} \mathrm{O} / 16\right) \\
{ }^{12} \mathrm{C}^{\mathrm{du}} & ={ }^{13} \mathrm{C}^{\mathrm{du}}={ }^{16} \mathrm{O}^{\mathrm{du}}=0 .
\end{aligned}
$$

The hydrogen abundance after second dredge-up was calculated from $X=1-Y-Z$, with $Y$ and $Z$ the helium and metal abundance after second dredge-up. This was done to ensure that $X+Y+Z \equiv 1$ at all times.

\subsection{Third dredge-up}

As discussed above, the pre-AGB evolution with respect to mass loss and chemical evolution during the first and second dredge-up is either calculated according to the recipes in GJ (see previous subsections), or is taken from the theoretical evolution tracks provided by the Geneva group. In the latter case, we use the stellar surface abundances as well as the stellar mass at the end of these tracks.

The synthetic AGB evolution model starts at the first thermal pulse. In brief, we account for the dependence of core mass on initial stellar metallicity and assume that third dredge-up occurs only if the core mass is larger than a critical value $M_{\mathrm{c}}^{\min }$. In GJ we argued that a value of $M_{\mathrm{c}}^{\min } \sim 0.58 M_{\odot}$ is required to fit the low-luminosity tail of the observed carbon star luminosity function in the LMC (see below).

The time scale on which thermal pulses occur is a function of core mass as discovered by Paczynski (1975). In GJ and GHJ, we use the core-mass-interpulse relation presented in Boothroyd \& Sackmann (1988) where the increase in core mass during the interpulse period $\left(t_{\mathrm{ip}}\right)$ is given by:

$\Delta M_{\mathrm{c}}=\int_{o}^{t_{\mathrm{ip}}} \frac{\mathrm{d} M_{\mathrm{c}}}{\mathrm{d} t} \mathrm{~d} t$

A certain fraction of this amount is assumed to be dredged up:

$\Delta M_{\text {dredge }}=\lambda \Delta M_{\mathrm{c}}$.

The free dredge-up parameter $\lambda$ is assumed to be a constant. In GJ we found that a value of $\lambda=0.75$ is required to fit the peak of the observed carbon stars LF in the LMC (see below).

In principle, the composition of the dredged-up material is determined by the detailed chemical evolution of the core. For simplicity, we assume that the composition of the material dredged-up after a TP is: ${ }^{4} \mathrm{He}=0.76,{ }^{12} \mathrm{C}=$ 0.22 , and ${ }^{16} \mathrm{O}=0.02$ (cf. Boothroyd \& Sackmann 1988). The carbon is formed through incomplete helium burning in the triple $\alpha$ process and the oxygen through the ${ }^{12} \mathrm{C}(\alpha, \gamma){ }^{16} \mathrm{O}$ reaction.

Newly dredged-up material can be processed at the base of the convective envelope in the CNO-cycle, a process referred to as hot bottom burning (HBB) and extensively discussed by RV. To a large extent, HBB determines the composition of the material in the stellar envelope of thermal pulsing AGB stars. The process of HBB is able to slow down or even prevent the formation of carbon stars (e.g. Groenewegen \& de Jong 1994a). Since ${ }^{12} \mathrm{C}$ is converted into ${ }^{13} \mathrm{C}$ and ${ }^{14} \mathrm{~N}$, it also gives rise to the formation of ${ }^{13} \mathrm{C}$-rich carbon stars (usually referred to as J-type carbon stars) and ${ }^{14} \mathrm{~N}$-rich objects (e.g. Richer et al. 1979).

RV treated HBB in considerable detail as a function of the mixing length parameter (e.g. $\alpha=0,1.0,1.5,2$ ). In GJ (see for details their Appendix A) it was decided to approximate in a semi-analytical way the results of RV for their $\alpha=2$ case as it gave the largest effect of HBB. Since then new results regarding HBB have been obtained, both theoretically (Boothroyd et al. 1993, 1995) and observationally for AGB stars in the Magellanic Clouds (Plez et al. 1993; Smith et al. 1995). These results suggest that HBB is a common phenomenon that occurs at a level roughly consistent with that predicted by RV in case $\alpha=2$. In particular, Boothroyd et al. (1995) estimate that the initial stellar mass above which HBB takes place is $\sim 4.5 M_{\odot}$ which is similar to the value of $\sim 3.3 M_{\odot}$ predicted by RV $(\alpha=2)$. Observations indicate that virtually all stars brighter than $M_{\text {bol }} \approx-6$ mag undergo envelope burning (Smith et al. 1995). These luminosities are reached for stars with initial masses slightly below $4 M_{\odot}$ and larger (Boothroyd et al. 1993).

During the thermal pulsing AGB, stars lose most of their mass: typically $\sim 0.4 M_{\odot}$ for a $1 M_{\odot}$ star and $\sim 4.8 M_{\odot}$ for a $6 M_{\odot}$ star (at solar initial metallicity; see GJ). Clearly, stellar yields for intermediate mass stars are dominated by the mass loss and chemical evolution during this phase. After gradual ejection of their outer envelope, most AGB stars leave a white dwarf remnant usually accompanied by the formation of a planetary nebula $(\mathrm{PN})$.

\subsection{Tuning, calibration, and uncertainties of the synthetic evolution model}

We briefly discuss assumptions and uncertainties involved with the synthetic evolution model described above. In GJ and GHJ we used observations of AGB stars in the LMC and Galaxy to constrain the synthetic AGB model. The 
main model parameters are the minimum core mass for third dredge-up $M_{\mathrm{c}}^{\mathrm{min}}$, the third dredge-up efficiency $\lambda$, and the scaling law for mass loss on the AGB $\eta_{\mathrm{AGB}}$.

In GJ the following observational constraints were considered: the luminosity function of carbon stars, the observed number ratio of carbon to oxygen-rich AGB stars, the birth rate of AGB stars, the abundances observed in $\mathrm{PNe}$, the initial-final mass relation, and the frequency of carbon stars in clusters of a given mass. Values of $M_{\mathrm{c}}^{\min }=0.58 M_{\odot}$ and $\lambda=0.75$ were determined predominantly by fitting the carbon star LF. A value of $\eta_{\mathrm{AGB}}=4$ (assuming a Reimers mass loss law) was derived by fitting the high-luminosity tail of this LF. This set of model parameters resulted in a birthrate of AGB stars consistent with other determinations and predicts that carbon stars can form only from main-sequence stars more massive than $1.2 M_{\odot}$, consistent with observations of carbon stars in LMC clusters. In Groenewegen \& de Jong (1994a) we showed that the model with the aforementioned parameters predicts the correct observed abundances in LMC PNe. In Groenewegen \& de Jong (1994b) we considered two alternative mass loss formula to the Reimers one. We found that the mass loss formula proposed by Vassiliadis \& Wood (1993) could less well explain the observed abundances while a scaled version of the law proposed by Blöcker \& Schönberner (1993) could equally well fit the observations.

In GHJ we applied the synthetic evolution model to carbon stars in the Galactic disk. As there yet exists no reliable carbon star LF, we used observations of carbon stars in open clusters and in binaries to determine $M_{\mathrm{c}}^{\min }$ $=0.58 M_{\odot}$. Using similar constraints as for AGB stars in the LMC, values of $\lambda=0.75$ and $\eta_{\mathrm{AGB}}=4$ were found in optimal agreement with the observations. Thus, models for the observed luminosity function of carbon stars in both the Galactic disk and LMC do favour a high mass loss coefficient $\eta_{\mathrm{AGB}} \approx 3-5$. This range in $\eta_{\mathrm{AGB}}$ is consistent with additional constraints such as the initial-final mass relation for $\mathrm{C}+\mathrm{O}$ white dwarfs in the solar neighbourhood (see Weidemann \& Koester 1983; Weidemann 1990). In conclusion, a wide range of observations of AGB stars both in the LMC and Galactic disk can be explained by one and the same set of model parameters, i.e. $M_{\mathrm{c}}^{\min }=0.58 M_{\odot}$, $\lambda=0.75$, and $\eta_{\mathrm{AGB}}=4$. In the following, we will refer to this set of parameters as the standard model.

It should be noted that observations indicate that some stars do not obey the standard model predictions. In particular, the ${ }^{12} \mathrm{C} /{ }^{13} \mathrm{C}$ ratio after the first dredge-up is often lower than predicted in stars of low mass, down to ${ }^{12} \mathrm{C} /{ }^{13} \mathrm{C} \approx 10$. Rotationally induced mixing (e.g. Sweigart \& Mengel 1979; Charbonnel 1995; Denissenkov \& Weiss 1996) or initial abundances different from those adopted here (see Sect. 4) may play a role.

Clearly, the assumptions of a fixed critical core mass as well as of a constant dredge-up efficiency and mass loss parameter for all AGB stars (independent of their ini- tial mass and AGB phase) are first order approximations. There is much debate whether or not material is dredged up at every thermal pulse, and how much. Furthermore, it seems possible that the dredge-up process is turned off when a star becomes a carbon star (e.g. Lattanzio 1989). Notwithstanding, this simple three parameter model can explain essentially all present-day observations of AGB stars so there appears no need for a more complicated model (although this does not prove that our model assumptions are correct). We will investigate the sensitivity of the stellar yields on the adopted values of $\mathrm{M}_{\mathrm{c}}^{\mathrm{min}}, \lambda$, and $\eta_{\mathrm{AGB}}$ in Sect. 4.

An additional source of uncertainty is associated with the number of atoms (and isotopes) taken into account, i.e. $\mathrm{H}, \mathrm{He},{ }^{12} \mathrm{C},{ }^{13} \mathrm{C},{ }^{14} \mathrm{~N}$ and ${ }^{16} \mathrm{O}$. The first and second dredge-up abundance changes are either taken directly from the model tracks of the Geneva group, or, in the synthetic model, through parametrisation of other model calculations. All these works include a much larger chemical network than considered here. The third dredge-up is simplified in the sense that only the ${ }^{12} \mathrm{C}(\alpha, \gamma){ }^{16} \mathrm{O}$ is included and that the abundances of ${ }^{12} \mathrm{C},{ }^{16} \mathrm{O}$ and $\mathrm{He}$ in the convective zone after a TP are taken from Boothroyd \& Sackmann (1988) and are assumed to be constant. In particular, we do not consider s-process reactions which take place in the convective inter-shell. The most important effect of this process on the species we consider is through the ${ }^{13} \mathrm{C}(\alpha, \mathrm{n}){ }^{16} \mathrm{O}$ reaction. However, the amount of matter burnt in this reaction is probably small (Marigo et al. 1996) and apparently depends on the amount of semi-convection assumed in the models (Busso et al. 1992, 1995).

Other uncertainties concern the detailed inclusion of HBB. In particular, the temperature structure of the envelope, the fraction of dredged up material processed in the CNO cycle, and the amount of envelope matter mixed down and processed at the bottom of the envelope may vary among AGB stars differing in initial mass, composition, and age. Nevertheless, although the details on HBB are poorly understood yet, good agreement is obtained between the standard model predictions including HBB and observations related to HBB in massive AGB stars. We will investigate the effect of HBB on the stellar yields by introducing the parameter $m_{\mathrm{HBB}}$, which defines the core mass at which HBB is assumed to operate (according to the recipes outlined in the Appendix in GJ). The default value used in the standard model is $m_{\mathrm{HBB}}=0.8 M_{\odot}$ which de facto is the value used in GJ and GHJ. Other values of $m_{\mathrm{HBB}}$ are discussed below.

\section{Results}

In Tables 2-21, we present theoretical yields $p_{j}$ for AGB stars in the mass range $0.8-8 M_{\odot}$ in case of the standard model $\left(\eta_{\mathrm{AGB}}=4, M_{\mathrm{c}}^{\min }=0.58 M_{\odot}, \lambda=0.75\right.$, and $\left.m_{\mathrm{HBB}}=0.8 M_{\odot}\right)$ including first, second, and third 
dredge-up as well as HBB. We distinguish pre-AGB, AGB, final AGB, and total element yields at initial metallicities $Z=0.001,0.004,0.008,0.02$, and 0.04 . Pre-AGB yields are the yields up to the end of the E-AGB. AGB yields are the yields on the TP-AGB except for the last $2.510^{4} \mathrm{yr}$. The final AGB yields are the yields on the TP-AGB integrated over the last $2.510^{4} \mathrm{yr}$. This distinction is made to compare with the abundances in $\mathrm{PNe}$ (note that final AGB yields have been omitted if the AGB lifetime is much smaller than $2.510^{4} \mathrm{yr}$ ). In several cases, $\sim 8 M_{\odot}$ stars have final AGB yields that are negligible (because such massive stars do not always go through the PN stage). For such stars, the final AGB yields were omitted in Table 4.

Pre-AGB evolution is based on the Geneva group (e.g. Schaller et al. 1992). These uniform grids of stellar models are based on up-to-date physical input (e.g. opacities, nuclear reaction rates, mixing schemes, etc.) and cover the relevant initial stellar mass range from 0.8 to $8 M_{\odot}$ as well as initial metallicity from $Z=0.001-0.04$. For stars with $m \lesssim 1.7 M_{\odot}$ these tracks have been computed up to the He flash, for $2<m<5 M_{\odot}$ up to the E-AGB, and for $m>7 M_{\odot}$ until the end of central C-burning. Recently, Charbonnel et al. (1996) presented new grids of models covering the evolution (from the zero age main sequence up to the end of the E-AGB) of low mass stars with initial masses between 0.8 and $1.7 M_{\odot}$ born with metallicities $Z=0.02$ and 0.001 . We note that these stars were not evolved through the helium core flash but instead were evolved from constructed zero-age horizontal branch models (see Charbonnel et al. 1996).

For stars with initial mass above $1.25 M_{\odot}$, the Geneva tracks used are with overshooting and standard mass loss rates (see e.g. Schaller et al. ). For stars below $1.25 M_{\odot}$, the tracks used are without overshooting (for $m=1.25 M_{\odot}$ we include yields both for tracks with and without overshooting). The two $M_{\mathrm{ini}}=1.3 M_{\odot}$ lines in the tables refer to the $1.25 M_{\odot}$ models both for tracks with (lower table lines) and without (upper lines) overshooting. Perhaps the tracks with overshooting are preferred (see Schaller et al. 1992).

We neglect the fact that the Geneva tracks for stars with $m \lesssim 1.7 M_{\odot}$ and $Z=0.004,0.008$, and 0.04 end at the helium flash and do not extent to the end of the EAGB. However, these low mass stars do not experience the second dredge-up and are expected not to loose much mass on the horizontal branch and E-AGB, so that the influence on the yields is negligible (see Sect. 4.4). The 0.8 $M_{\odot}$ star yields are not included in the total yields tables because for such low-mass stars the final AGB (PN-phase) yields are relatively uncertain. It would be okay to sum up the pre-AGB and AGB yields for these stars and use this as the total yield.

In Tables 2-21, we list subsequently the initial mass $m_{\text {ini }}$, element yields $p_{j}$ of $\mathrm{H},{ }^{4} \mathrm{He},{ }^{12} \mathrm{C},{ }^{13} \mathrm{C},{ }^{14} \mathrm{~N},{ }^{16} \mathrm{O}$, integrated CNO-yield $Y_{\mathrm{CNO}}$, total element integrated yield
$Y_{\text {tot }}$ (elements heavier than helium), the total amount of mass returned $\Delta m_{\mathrm{ej}}$, and the stellar mass $m_{\mathrm{end}}$ at the end of each phase.

We consider resulting stellar yields for various choices of the Reimers mass loss coefficient $\eta_{\mathrm{AGB}}=1-5$, third dredge-up efficiency $\lambda=0.6-0.9$, critical core mass for dredge up $M_{\mathrm{c}}^{\min }=0.56-0.62 M_{\odot}$, and minimum core mass for $\mathrm{HBB} m_{\mathrm{HBB}}=0.8$ and $0.9 M_{\odot}$ (see Sect. 3). We examine the impact of these quantities as well as of the adopted pre-AGB evolution model on the predicted yields.

\subsection{Dependence on mass loss}

Figure 1 shows resulting AGB yields for various values of the Reimers mass-loss parameter $\eta_{\mathrm{AGB}}=1-5$. The other parameters are as for the standard model (unless stated otherwise). Low mass AGB stars $\left(m \lesssim 4 M_{\odot}\right)$ predominantly contribute to helium and carbon. High mass AGB stars are important contributors to helium and nitrogen (see below). For the standard model, element yields are smaller by factors typically $2-3$ compared to the $\eta_{\mathrm{AGB}} \sim 1$ case. Resulting yields increase with decreasing values of $\eta_{\mathrm{AGB}}$ (i.e. smaller mass-loss rates) as a lower value of $\eta$ results in longer AGB lifetimes and therefore more thermal pulses (assuming that the amount of dredged-up matter during a thermal pulse is roughly constant). For large values of $\eta_{\mathrm{AGB}} \gtrsim 5$, the effect of increasing $\eta_{\mathrm{AGB}}$ on both the AGB lifetimes and number of thermal pulses becomes negligible and the predicted yields remain approximately constant.

\subsection{Dependence on initial metallicity}

In general, carbon and oxygen yields increase with decreasing initial metallicity $Z$ (cf. Fig. 1 ). This is due to the fact that dredge-up with subsequent CNO-burning affects more strongly the composition of envelopes with relatively low initial abundances (see e.g. RV). In addition, the core mass at the first thermal pulse is larger at low metallicities (GJ). Therefore, the amount of material dredged-up from the core to the envelope is substantially larger in initially low $-Z$ AGB stars. In contrast, nitrogen yields slightly increase with metallicity as nitrogen is formed during CNOburning by consumption of $\mathrm{C}$ and $\mathrm{O}$. For hydrogen and helium, the sensitivity of the yields to initial metallicity are mainly due to the effect of dredge-up, i.e. post dredgeup processing of $\mathrm{H}$ and $\mathrm{He}$ is usually low. Note that even small changes in the yields of AGB stars due to variations in initial metallicity can significantly affect the enrichment of the ISM (after weighing by the initial mass function and star formation rate at the time these stars were formed).

We like to emphasize that AGB yields of intermediate mass stars are strongly dependent on the abundances of distinct elements (e.g. C, N, and O) in the galactic ISM from which these stars are formed. In other words, stars with initial element abundances substantially 
different from those listed in Table 1 have AGB yields distinct from the yields given in Tables 2-21. We will return to this important point below when model predictions are confronted with abundances observed in PNe in the Galactic disk.

\subsection{Dependence on the amount of $H B B$}

As discussed before, HBB may prevent or slow down the formation of carbon stars by the possible destruction of newly dredged up carbon at the base of the convective envelope. Figure 2 illustrates that for low mass AGB stars $\left(m<4 M_{\odot}\right)$, the effect of HBB is negligible due to the low temperature at the bottom of their envelopes (GJ). For high mass AGB stars, the effect of HBB depends on the amount of matter exposed to the high temperatures at the bottom of their envelopes, the net result being the conversion of carbon and oxygen to nitrogen. Yields of $\mathrm{H}$, $\mathrm{He}$, and total CNO are not affected by HBB since basically two reaction chains of the $\mathrm{CNO}$-cycle are involved, i.e. the $\mathrm{CN}$ and $\mathrm{ON}$-cycle.

We compare in Fig. 2 the resulting yields in case $m_{\mathrm{HBB}}=0.9$ (figure labelled $\mathrm{HBB}$ ) and $1.3 M_{\odot}($ no HBB), respectively. A choice of $m_{\mathrm{HBB}} \approx 1.3 M_{\odot}$ or larger results in no $\mathrm{HBB}$ as none of the AGB stars in our model reach such high core masses. In case of HBB, the strong decrease of the carbon and strong increase in the nitrogen yield can be seen at masses at $m \gtrsim 4-5 M_{\odot}$. In the no HBB case, the stellar yields of carbon are seen to dominate the total CNO-yields over the entire mass range.

The effect of changing $m_{\mathrm{HBB}}$ from 0.8 to $0.9 M_{\odot}$ is that HBB operates in stars of initial mass $\gtrsim 5 M_{\odot}$ instead of $\gtrsim 4 M_{\odot}$. Since $m_{\mathrm{HBB}}=0.9 M_{\odot}$ provides a reasonable upper limit to the minimum stellar mass experiencing HBB, we have included in Tables $22-30{ }^{12} \mathrm{C},{ }^{13} \mathrm{C},{ }^{14} \mathrm{~N}$, and ${ }^{16} \mathrm{O}$ yields for stars more massive than $4 M_{\odot}$ in case of the standard model with $m_{\mathrm{HBB}}=0.9 M_{\odot}$ (pre-AGB are as given at the corresponding metallicities in Tables 2-21). These yields include the minimum effect of HBB as inferred from the observations and are somewhat smaller than those given by the standard model (i.e. $m_{\mathrm{HBB}}=$ $\left.0.8 M_{\odot}\right)$.

As discussed earlier, the default choice of $m_{\mathrm{HBB}}=$ $0.8 M_{\odot}$ is based on our implementation of the RV $\alpha=2$ model but appears consistent with recent observations of HBB in AGB stars both in the SMC and LMC as well as recent model calculations on massive AGB stars. In any case, HBB is required to explain observations. More observations are needed to investigate any dependence of HBB on metallicity.

\subsection{Dependence on third dredge up efficiency}

We consider in Fig. 2 AGB yields for third dredge-up efficiencies $\lambda=0.6$ and 0.9 (i.e. the range allowed for by the observations; GJ). Stellar yields increase substan- tially when $\lambda$ is increased, i.e. enhancing the amount of carbon and helium that is dredged-up and added to the stellar envelope after each thermal pulse. In addition, the composition of dredged-up material may be strongly affected by HBB, in particular for high mass stars. In other words, increasing $\lambda$ leads to an increase in the carbon yields for low mass stars and to an increase in nitrogen for high mass stars. Furthermore, helium yields increase for all stars with initial masses above $\approx 1.5 M_{\odot}$ which corresponds to the limit of $M_{\mathrm{c}}^{\min }=0.58 M_{\odot}$.

\subsection{Dependence on critical core mass for dredge up}

Yields for extreme values of the minimal core mass for third dredge-up $M_{\mathrm{c}}^{\text {min }}=0.56$ and $0.60 M_{\odot}$, respectively, are shown in last two columns of Fig. 2. The effects of varying $M_{\mathrm{c}}^{\mathrm{min}}$ are limited to relatively low mass AGB stars $\left(\lesssim 2 M_{\odot}\right)$. A larger value of $M_{\mathrm{c}}^{\mathrm{min}}$ implies a higher initial mass for stars that can turn into carbon stars. This results in negative carbon yields (corresponding to the depletion of carbon during first dredge-up) over a larger range in initial mass (helium yields decrease over this mass range as well). A value of $M_{\mathrm{c}}^{\mathrm{min}}$ as small as $\sim 0.56 M_{\odot}$ would imply that all AGB stars end as carbon stars while $M_{\mathrm{c}}^{\min } \gtrsim$ $0.61 M_{\odot}$ would inhibit carbon star formation. Clearly, the third dredge-up and the precise values of $M_{\mathrm{c}}^{\mathrm{min}}$ and $\lambda$ are of crucial importance for the formation of carbon stars. We like to emphasize that the parameter value ranges consistent with the observations are rather narrow and are mutually correlated (e.g. in case of $M_{\mathrm{c}}^{\min }$ and $\lambda$ ).

\subsection{Dependence on pre-AGB evolution}

In GJ and GHJ the description of the pre-thermal pulsing AGB evolution was taken from recipes in the literature or fits made to published results. An alternative approach is to directly use stellar evolution tracks, as is done in this study (see above).

In Fig. 3, we compare for $Z=0.02$ and 0.001 the resulting AGB yields in the case of pre-AGB evolution according to the evolution tracks described above with those computed following the recipes from GJ/GHJ. In both cases, the initial stellar composition has been adopted from the Geneva group to comply with the stellar evolution tracks prior to the AGB.

Differences between the two sets of yields are found to be very small except for hydrogen and helium where the GJ/GHJ approach predicts higher yields for massive stars. This is traced back to differences in the treatment of the second dredge-up process. We list in Table 32 the corresponding total AGB yields of $\mathrm{H}$ and $\mathrm{He}$ for the synthetic GJ/GHJ model (initial metallicities as before). These modified yields can be used when the effect of 2nd dredge up is expected to be more pronounced than that given by the Geneva group (see below). The larger yields also imply higher helium abundances which has 


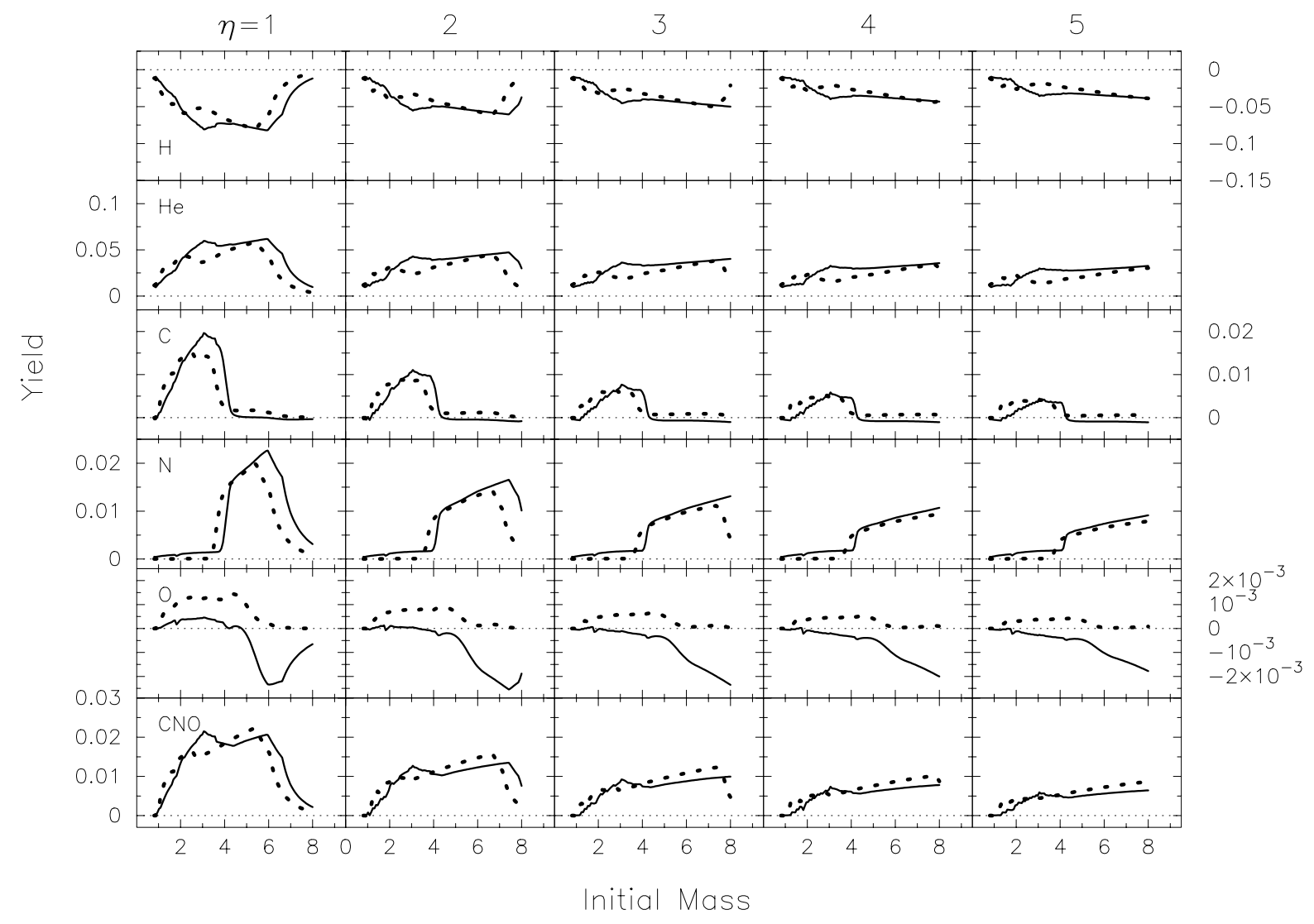

Fig. 1. Stellar yields of $\mathrm{H},{ }^{4} \mathrm{He},{ }^{12} \mathrm{C},{ }^{14} \mathrm{~N},{ }^{16} \mathrm{O}$, and total $\mathrm{CNO}$ vs. initial stellar mass for $\eta_{\mathrm{AGB}}=1-5$ and initial compositions $(Z, Y)=(0.02,0.32$; solid line $)$ and $(0.001,0.24$; dotted $)$. Parameters values are further as for the standard model (i.e. $\left.\eta_{\mathrm{AGB}}=4\right)$

interesting consequences for the predicted helium abundances in planetary nebulae (see Sect. 5).

We find that pre-AGB evolution for stars born with metallicity $Z=0.02$ is in general unimportant for the total yields of AGB stars, except in case of helium and hydrogen. This confirms our earlier statement that the thermal pulsing AGB is the most important phase in determining the yields of intermediate mass stars (even though initial stellar abundances, effects of overshooting, mixing, and pre-AGB evolution can play a significant role).

\subsection{Conclusion}

We conclude that the resulting AGB yields are most sensitive to the mass loss parameter $\eta_{\mathrm{AGB}}$, the effect of $\mathrm{HBB}$, and the initial stellar abundances. Variations in the remaining model parameters result in stellar yields not substantially different from those predicted by the standard model with $\eta_{\mathrm{AGB}}=4, M_{\mathrm{c}}^{\mathrm{min}}=0.58 M_{\odot}, \lambda=0.75$, and $m_{\mathrm{HBB}}=0.8 M_{\odot}$. Stellar yields for model parameters distinct from that used for the standard model (e.g. $\eta_{\mathrm{AGB}}$, HBB, or initial abundances) are available upon request. We like to emphasize that small differences in the predicted AGB yields may be important when integrating over the initial mass function in galactic chemical evolution models.

\section{Discussion}

\subsection{Comparison with $R V$}

We compare in Fig. 3 the yields predicted by the standard model with those given by RV for stars formed with initial metallicities $Z=0.02(Y=0.28)$ and $Z=0.004(Y=0.232)$, respectively. We take into account the observational fact that HBB takes place in stars more massive than $\sim 3.5 M_{\odot}$. Accordingly, we use the yields given by $\mathrm{RV}$ in case $Z=0.02$ with $\alpha=2.0$ for $m>3.3 M_{\odot}$ and $\alpha=0.0$ for $m \lesssim 3 M_{\odot}$ (i.e. their Tables $3 \mathrm{e}$ and $3 \mathrm{a}$, respectively). Similarly, we use their yields in case $Z=0.004$ with $\alpha=1.5$ for $m>3.25 M_{\odot}$ and $\alpha=0.0$ for $m<3 M_{\odot}$ (i.e. their tables $3 \mathrm{i}$ and $3 \mathrm{~h}$ ). For $Z=0.004 \mathrm{RV} \operatorname{did}$ not tabulate results for $\alpha=2$.

Figure 3 shows that the standard model (pre-AGB evolution as described in Sect. 3) results in yields which differ from the selected yields of RV within a factor $2-3$. The standard model predicts larger yields predominantly for AGB stars with $m \lesssim 4 M_{\odot}$ in case of carbon and oxygen, 


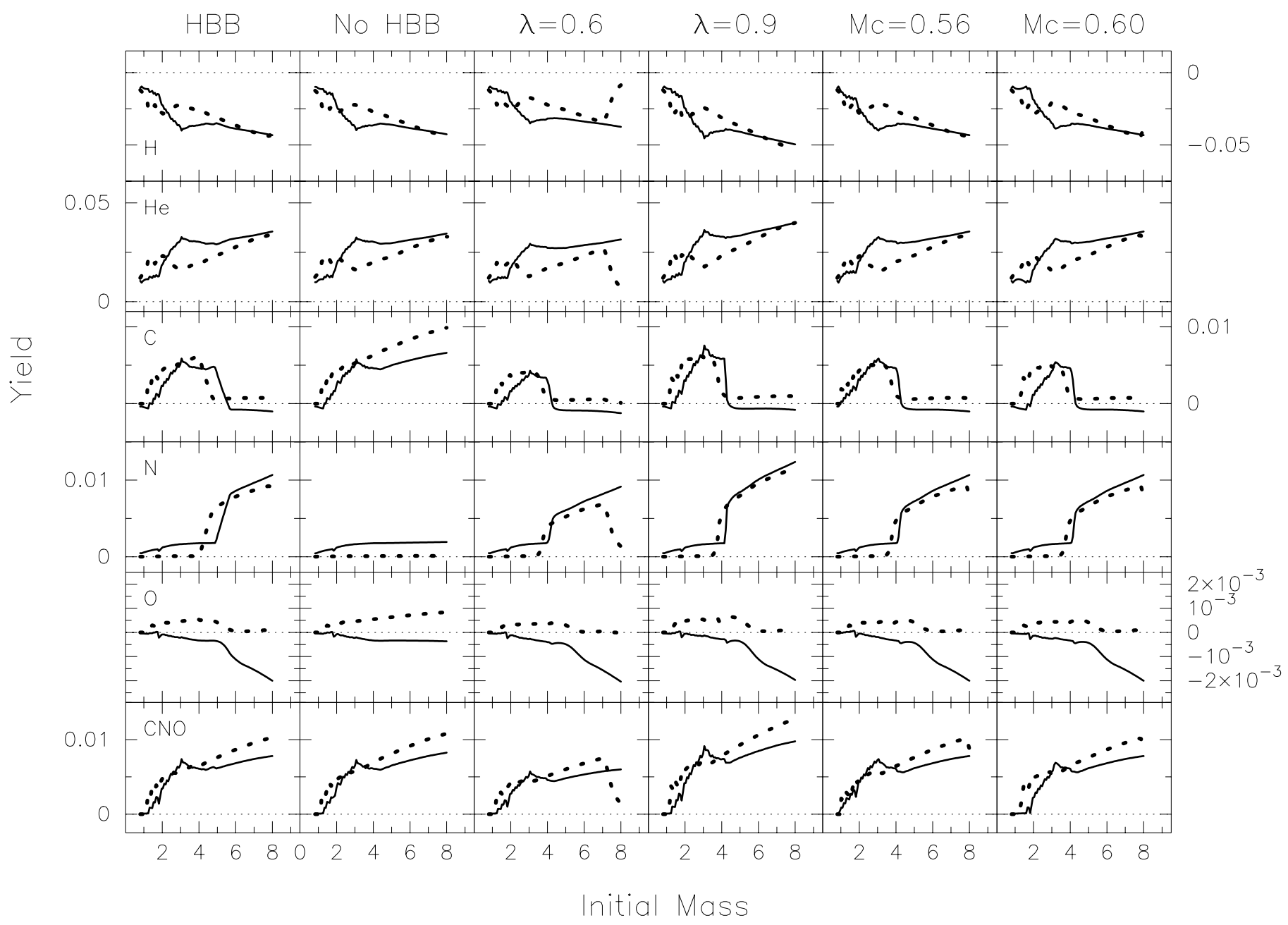

Fig. 2. Stellar yields of $\mathrm{H},{ }^{4} \mathrm{He},{ }^{12} \mathrm{C},{ }^{14} \mathrm{~N},{ }^{16} \mathrm{O}$, and total CNO vs. initial stellar mass for the standard model: effect of varying 1 ) the amount of HBB (first two columns), 2) the dredge-up efficiency (center columns), and 3) the critical core mass for dredge-up (last two columns)

and for AGB stars more massive than $\sim 3.25 M_{\odot}$ in case of nitrogen. In this comparison, we have neglected the effect on the resulting yields of differences (up to $\sim 25 \%$ ) in the initial $\mathrm{C}, \mathrm{N}$, and $\mathrm{O}$ abundances between the standard model and that of RV.

It was derived in GJ that $\eta_{\mathrm{AGB}} \gtrsim 3$ is needed to fit the observed initial-final mass relation for stars in the Galactic disk (see Weidemann \& Koester 1983). However, the selected yields of RV were computed for $\eta_{\mathrm{AGB}}=0.33$ while for the standard model $\eta_{\mathrm{AGB}}=4$. Therefore, due to the high mass loss rates of AGB stars much fewer thermal pulses on the AGB occur in the standard model compared to the RV models. The main part of the observed differences between the yields predicted by the standard model and those of RV are probably due to this effect (apart from differences in the detailed description of evolution along the AGB, in particular the efficiency of third dredge-up).

In conclusion, we find that the selected yields given by RV differ from those predicted by the standard model by a factor $2-3$. In particular, for high mass AGB stars $\left(m \gtrsim 3.5 M_{\odot}\right)$, the effect of HBB on the nitrogen yields for the selected RV models is much larger than that for the standard model. This suggests that values of the mixing length parameter $\alpha<2$ may be more appropriate for massive AGB stars as we will argue below.

\subsection{AGB stars and the enrichment of the galactic ISM}

We have presented the yields of intermediate mass AGB stars for appropriate ranges in mass, initial composition, mass loss parameter $\eta_{\mathrm{AGB}}$, and effects of second dredge-up and HBB. We have shown that the yields of such stars are determined by their final stages and are important for the carbon and nitrogen enrichment of the Galactic disk ISM. In particular, AGB stars account probably for more than $90 \%$ of the interstellar nitrogen in the disk (depending on the shape of the IMF at low and intermediate mass stars). 


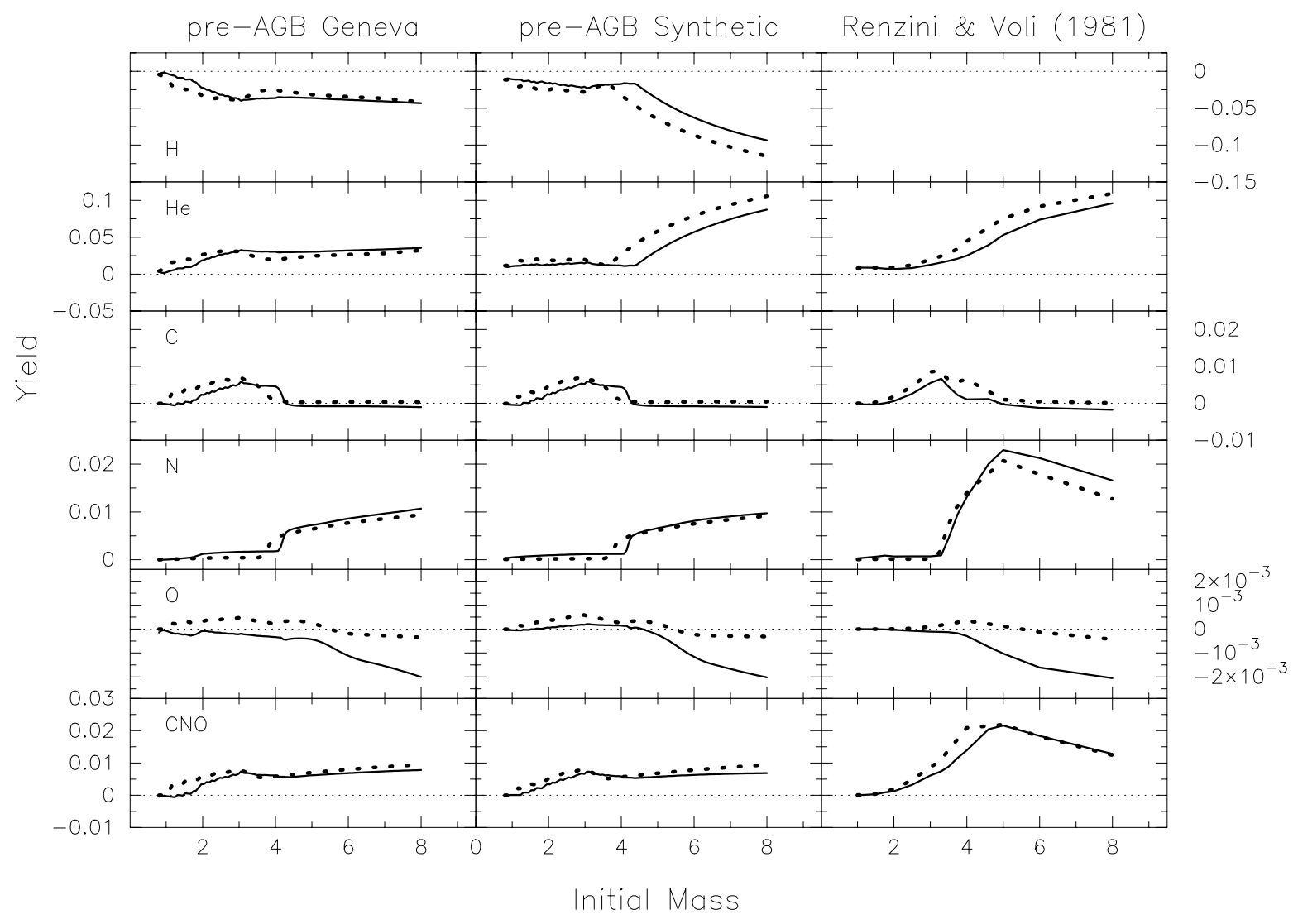

Fig. 3. Stellar yields including $\mathrm{HBB}$ vs. initial stellar mass of $\mathrm{H},{ }^{4} \mathrm{He},{ }^{12} \mathrm{C},{ }^{14} \mathrm{~N}$, ${ }^{16} \mathrm{O}$, and total CNO in case of the standard model for different treatments of pre-AGB evolution (left and center panels) and initial metallicities $Z=0.02$ (solid line) and 0.004 (dotted line; yields for $Z=0.001$ are similar). The yields presented by RV (their case $\alpha=2$ ) at initial compositions $(Z, Y)=(0.02,0.32$; solid lines) and $(0.004,0.24$; dotted) are shown for comparison (hydrogen yields are not given explicitly by RV)

From the results presented in GJ and GHJ, we argued that the standard model with $\eta_{\mathrm{AGB}} \sim 4$ provides a reasonable approximation of the yields of intermediate mass AGB stars in the Galactic disk and the Large Magellanic Cloud. These systems have a metallicity that differ by only a factor of 2 (e.g. Russell \& Dopita 1992). In galaxies with a substantial lower metallicity, one may expect a lower value of $\eta_{\mathrm{AGB}}$ to be more appropriate. We like to emphasize that using a fixed value of $\eta_{\mathrm{AGB}}$ does not necessarily mean identical mass loss rates as two stars of the same initial mass evolve differently in the synthetic model due to the explicit metallicity dependence of the recipes used.

Direct observational information on the metallicity dependence of mass loss and element yields in AGB stars is rare. In Groenewegen et al. (1995), the spectral energy distributions and $8-13 \mu \mathrm{m}$ spectra of three long-period variables (one each in the SMC, LMC and Galaxy) with roughly the same period were fitted. From the derived ratios of the dust optical depths in these stars, it was argued that the mass loss rates of AGB stars in the Galaxy, LMC, and SMC are roughly in the ratio of 4:3:1. This corroborates that $\eta_{\mathrm{AGB}}$ could be similar for AGB stars in the Galaxy and LMC. Furthermore, this suggests that for AGB stars in low metallicity systems like the SMC ( $Z \leq 0.004)$, values of $\eta_{\mathrm{AGB}} \approx 1-2$ may be more appropriate.

\subsection{Comparison with $P N$ abundances observed in the Galactic disk}

In GHJ, we compared the mean abundances in the envelopes of AGB stars predicted by the standard model with the abundances observed in PNe in the Galactic disk. Here we repeat part of this analysis with improved model input and put emphasis on the differences in the description of pre-AGB evolution between the Geneva models and that outlined in GJ. In particular, we consider in more detail the effects of second dredge-up and $\mathrm{HBB}$ on the predicted abundances and address the uncertainties involved.

In the model, the abundances within $\mathrm{PNe}$ are estimated by averaging the abundances in the ejecta of AGB stars over the final $\tau_{\mathrm{PN}}=25000 \mathrm{yr}$ (e.g. Pottasch 1995). We neglect any changes in the ejected shell abundances 
during the post-AGB phase, e.g. due to a late thermal pulse (Schönberner 1983), which is expected to be a rare event, or due to selective element depletion by dust formation. The latter process may affect the composition both in the wind of an AGB star and during the post-AGB phase (e.g. Bond 1992; van Winckel et al. 1992) but is neglected here for simplicity.

We assume an upper mass limit of $8 M_{\odot}$ for stars that ultimately can become a PN (with final core mass less than $\sim 1.2 M_{\odot}$ ) and ignore the possibility that not all our model AGB stars will become PNe. In fact, some of the low-mass AGB stars may evolve so slowly during the postAGB phase that the material previously collected in the wind is dispersed before the central star has become hot enough to ionize this material. Also, the upper mass limit for AGB stars is matter of debate and may range between 6 and $\sim 9 M_{\odot}$, depending on the critical mass for carbon ignition in an electron degenerate core and on details of the stellar mass-loss scenario (cf. GJ; Vassiliadis \& Wood 1993; Hashimoto et al. 1993). Furthermore, we assume a constant value of $\tau_{\mathrm{PN}}=25000 \mathrm{yr}$. In reality, the time during which the mass accumulated in a $\mathrm{PN}$ has been swept up on the AGB may depend on the mass and initial composition of the progenitor. Nevertheless, we do not expect that these simplifications will alter our qualitative conclusions given below.

The observed PNe abundances are taken from various sources, i.e. mainly from Aller \& Cryzack (1983), Zuckerman \& Aller (1986), Aller \& Keyes (1987), and Kaler et al. (1990). The few halo PNe are excluded as the present comparison concentrates on AGB stars in the Galactic disk. Errors in the observed abundances are typically 0.015 in $\mathrm{He} / \mathrm{H}$ and about $0.2-0.25$ dex in all other ratios considered in Fig. 4.

The PNe nowadays observed in the Galactic disk probably originate from AGB stars covering a wide range in initial mass, i.e. $\sim 0.85-8 M_{\odot}$. This means that the progenitors of these $\mathrm{PNe}$ were formed at galactic ages ranging from about $10-15 \mathrm{Gyr}$ to $50 \mathrm{Myr}$ ago (see e.g. Schaller et al. 1992). Therefore, the initial element abundances of these PN progenitors are expected to differ considerably since the enrichment of the Galactic disk ISM over this time interval has been substantial (e.g. Twarog 1980; Edvardsson et al. 1993). When comparing the abundances predicted in the envelopes of final stage AGB stars with those observed in $\mathrm{PNe}$, we take this important effect into account by incorporating a self-consistent model for the chemical evolution of the Galactic disk (van den Hoek et al. 1997; GHJ). Since the metallicity dependent AGB yields and the resulting chemical evolution of the Galactic disk are mutually dependent, an iterative solution method was applied. The adopted star formation history (SFR) and initial mass function (IMF) in this model were derived using observational constraints to the abundanceabundance variations with age of stars in the solar neighbourhood, the metallicity and age distributions of long- living stars as well as constraints to the current space density and formation rate of several post-main-sequence star populations.

Resulting abundance-ratios (by number) in $\mathrm{PNe}$ are shown in Fig. 4 in case of the standard model assuming pre-AGB evolution according to the Geneva tracks (Tables $2-21)$. We verified that the resulting abundances are insensitive to the adopted PN lifetime up to $\tau_{\mathrm{PN}}=50000 \mathrm{yr}$. In general, good agreement is found between the observed and predicted PN abundances despite the uncertainties involved. We find that the overall trend of the observations is reproduced well by the standard model independent of the adopted chemical enrichment history of the Galactic disk. However, some discrepancies are present between the standard model (with pre-AGB evolution according to the Geneva tracks) and the observations, in particular at large values of $\mathrm{He} / \mathrm{H} \gtrsim 0.15$.

For comparison, we show in Fig. 4 the PN abundances predicted by the standard model with pre-AGB evolution according to the recipes outlined in Sect. 3. In this case, the enhanced effect of second dredge-up can account for massive AGB stars with $\mathrm{He} / \mathrm{H}$ up to $\sim 0.18$ in their envelopes. This suggests that second dredge-up has been relatively important at least for some of the PNe in our sample with $\mathrm{He} / \mathrm{H} \lesssim 0.15$. Alternatively, a substantial fraction of the hydrogen contained in the outer envelope may have turned into helium. Since PNe may evolve from a $\mathrm{H}$ and/or He-shell burning AGB star, this will determine the distribution of $\mathrm{He} / \mathrm{H}$ abundance ratios observed for a given progenitor mass. We have included in Table 32 the yields of $\mathrm{H}$ and $\mathrm{He}$ for the standard model with second dredge-up as described by RV (cf. Sect. 3.2) which provides reasonable agreement with the observed $\mathrm{PN}$ abundances of $\mathrm{He} / \mathrm{H}$ up to $\sim 0.2$, in particular for the more massive $\mathrm{PNe}$.

The effect of HBB on the predicted abundances can be seen in Fig. 4 by comparison of the standard model with $m_{\mathrm{HBB}}=0.8$ and $1.3 M_{\odot}$ (i.e. no HBB), respectively. Our results indicate that the standard model overestimates the effect of $\mathrm{HBB}$ on the resulting $\mathrm{N} / \mathrm{O}$ abundance ratios in $\mathrm{PNe}$ with progenitors mass $\gtrsim 5-6 M_{\odot}$. We note that the standard model takes into account the maximum effect of HBB as described by RV so that values of the mixing length parameter $\alpha<2$ in case of RV are probably more appropriate for massive AGB stars. On the other hand, models without $\mathrm{HBB}$ are inconsistent with the observed $\mathrm{N} / \mathrm{O}$ abundances as well as with independent observations discussed in Sect. 4.2. Therefore, the range of N/O abundances observed in the envelopes of post-AGB stars allows for variations in the importance of HBB roughly covering the range from $m_{\mathrm{HBB}}=0.8$ to $0.9 M_{\odot}$. In case of reduced $\mathrm{HBB}$ (i.e. $m_{\mathrm{HBB}}=0.9 M_{\odot}$ ), the CNO yields of massive stars in Tables 22-30 are more suitable than those given for the standard model.

The procedure to approximate the effect of HBB in a semi-analytical way has been described in the Appendix 

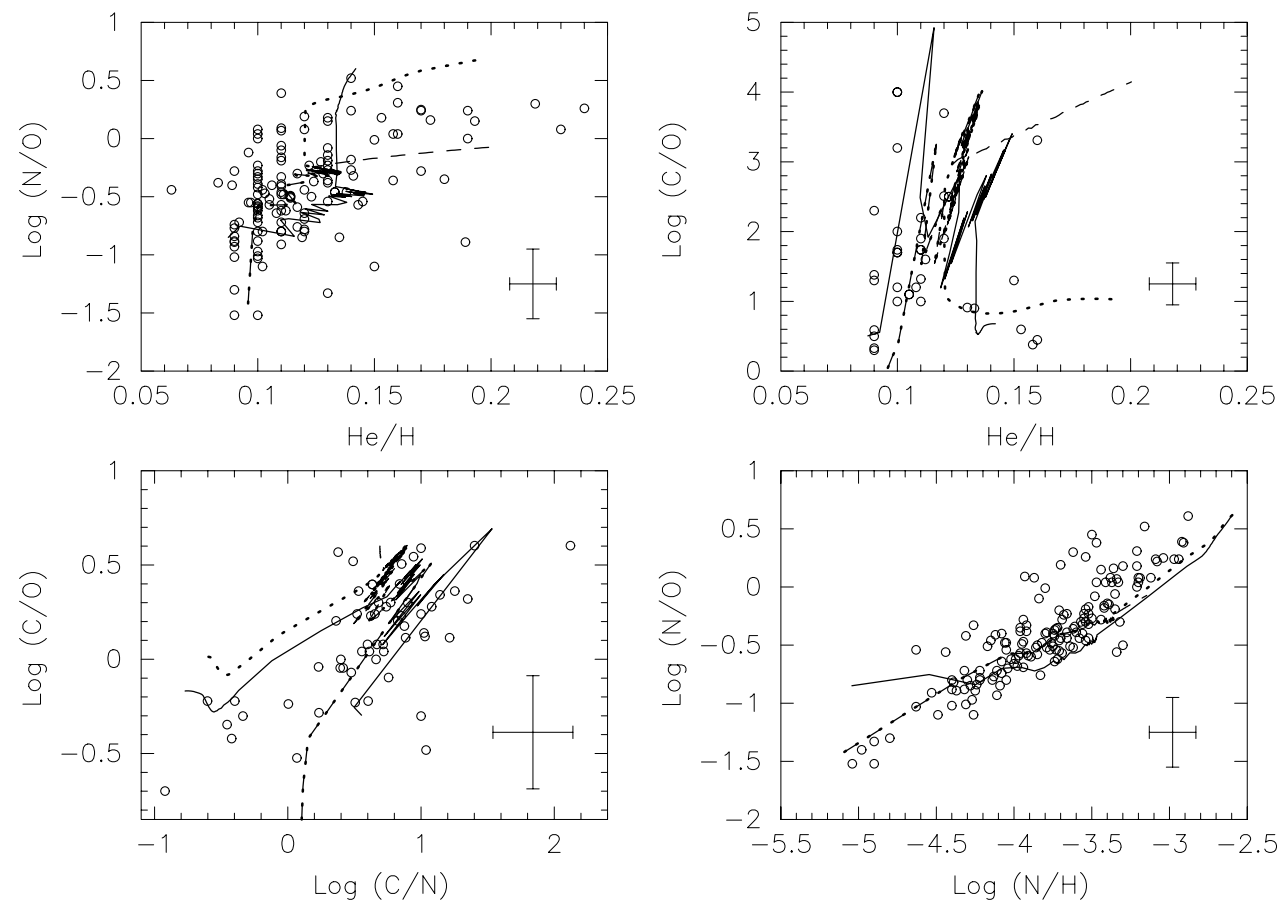

Fig. 4. Planetary nebulae abundances (by number) predicted by the standard model with pre-AGB evolution according to the Geneva tracks (solid curves) and according to the recipes outlined in Sect. 3 (dotted curves). The latter model without HBB is shown for comparison (dashed curves). Abundances observed in PNe in the Galactic disk are shown by open circles (data mainly from Aller \& Cryzack (1983), Zuckerman \& Aller (1986), Aller \& Keyes (1987), and Kaler et al. (1990)). Typical errors in the observations are indicated at the bottom right corner of each panel

of GJ. Here the basic parameters were determined by fitting the RV $\left(\alpha=2, \eta_{\mathrm{AGB}}=0.33\right)$ case for which the effect of HBB is largest. Thus, as the standard model has $\eta_{\mathrm{AGB}}=4$, possible effects of $\mathrm{HBB}$ varying with in particular mass loss were neglected. In fact, the temperature structure of the envelope is expected to change when the number of thermal pulses decreases with increasing values of $\eta_{\mathrm{AGB}}$. This may reduce the amount of HBB occuring in the convective envelope and affect the resulting abundances as observed for PNe with $\log (\mathrm{N} / \mathrm{O}) \lesssim-0.5$ and $\mathrm{He} / \mathrm{H} \gtrsim 0.15$ (cf. Fig. 4).

We emphasize that the resulting abundances of PNe do depend strongly on the initial element abundances of their progenitors, i.e. are very sensitive to the detailed chemical enrichment of the Galactic disk. A considerable part of the scatter observed in Fig. 4 is expected to be caused (in addition to experimental errors) by substantial variations in the initial abundances of PN progenitors due to the inhomogeneous chemical evolution of the Galactic disk ISM (e.g. van den Hoek \& de Jong 1997). Furthermore, the progenitors of the PNe nowadays observed in the solar neighbourhood probably have been formed over a large range in galactocentric distance (e.g. Wielen et al. 1996) and thus with a large range in initial metallicity according to the radial abundance gradients in the disk ISM (e.g. Shaver et al. 1983). Therefore, we expect the agreement between the predicted and observed PN abundance-ratios to improve further when averaging over a range in initial composition for a given progenitor mass.

We conclude that the abundance-ratios predicted by the standard model are consistent with the observed abundances in virtually all the PNe in our sample when we allow for plausible variations in strength of second dredge-up and HBB.

\subsection{Final remarks}

The primary application of the stellar yields presented in this paper is probably in galactic chemical evolution studies.

As models with the default parameters for the mass loss on the AGB, third dredge-up efficiency, and HBB fit many constrains in our galaxy and the LMC (GJ/GHJ), the corresponding yields (Tables 2-21) are probably the most appropriate ones to use. Possible alternatives are models with less HBB (Tables 22-30), or using the preAGB evolution from the synthetic model (Table 32). We argued in Sect. 5.2 that the scaling factor $\eta_{\mathrm{AGB}}$ of the Reimers law may be different for low metallicities. To simulate this effect one may want to use the yields for models with $\eta_{\mathrm{AGB}}=2$ for $Z=0.004$ and $\eta_{\mathrm{AGB}}=1$ for $Z=0.001$ (Tables 33-38). 
Acknowledgements. We like to thank the referee Georges Meynet for careful reading of the paper and encouraging remarks. It is a pleasure to thank Achim Weiss for his comments on an earlier version of this paper. The research of LBH and MG has been supported under grants 782-372-028 and 782-373030 by the Netherlands Foundation for Research in Astronomy (ASTRON) which is financially supported by the Netherlands Organisation for Scientific Research (NWO).

\section{References}

Aller L.H., Cryzack S.J., 1983, ApJS 51, 211

Aller L.H., Keyes C.D., 1987, ApJS 65, 405

Anders E., Grevesse N., 1989, Geochim. Cosmochim. Acta 53, 197

Audouze J., 1987, JAp\&A 8, 147

Becker S.A., Iben I., 1979, ApJ 232, 831

Becker S.A., Iben I., 1980, ApJ 237, 111

Blöcker T., Schönberner D., 1993, in: IAU symposium 155 on Planetary Nebulae, R. Weinberger, A. Acker (eds.). Reidel, Dordrecht, p. 479

Bond H.E., 1992, Nat. 356, 474

Boothroyd A. I., Sackmann I.-J., 1988, ApJ 328, 653

Boothroyd A. I., Sackmann I.-J., Ahern S.C., 1993, ApJ 416, 762

Boothroyd A. I., Sackmann I.-J., Wasserburg G.J., 1995, ApJ 442, L21

Busso M., Gallino R., Lambert D.L., Raiteri C.M., Smith V.V., 1992, ApJ 399, 218

Busso M., Lambert D.L., Beglio L., Gallino R., Raiteri C.M., Smith V.V., 1995, ApJ 446, 775

Charbonnel C., 1995, ApJ 453, L41

Charbonnel C., Meynet G., Maeder A., Schaerer D., 1996, A\&AS 115, 339

Clegg R.E.S., 1991, Evolution of Stars, IAU symposium 145, G. Michaud, A. Tutukov, Reidel (eds.). Dordrecht, p. 387

Denissenkov P.A., Weiss A., 1996, A\&A 308, 773

Dopita M.A., Meatheringham S.J., 1990, ApJ 357, 140

Dopita M.A., Meatheringham S.J., 1991, ApJ 367, 115

Edvardsson B., Andersen J., Gustafsson B., et al., 1993, A\&A 275,101

Groenewegen M.A.T., de Jong T., 1993, A\&A 267, 410 (GJ)

Groenewegen M.A.T., de Jong T., 1994a, A\&A 282, 127

Groenewegen M.A.T., de Jong T., 1994b, A\&A 283, 463

Groenewegen M.A.T., van den Hoek L.B., de Jong T., 1995, A\&A 293, 381 (GHJ)

Groenewegen M.A.T., Smith C.H., Wood P.R., Omont A., Fujiyoshi T., 1995, ApJ 449, L119
Hashimoto H., Iwamoto K., Nomoto K., 1993, ApJ 414, L105 van den Hoek L.B., de Jong T., 1997, A\&A 318, 231

van den Hoek L.B., Groenewegen M.A.T., Nomoto K., de Jong T., 1997 (in preparation)

Iben I., Renzini A., 1983, ARA\&A 21, 271 (IR)

Iben I., Truran J.W., 1978, ApJ 220, 980

Kaler J.B., Shaw R.A., Kwitter K.B., 1990, ApJ 359, 392

Lattanzio J.C., 1989, ApJ 344, L25

Maeder A., 1992, A\&A 264, 105

Marigo P., Bressan A., Chiosi C., 1996, A\&A (in press)

Matteucci F., Franco J., Francois P., Treyer M.A., 1989, Rev. Mex. Astron. Astrofis. 18, 145

Meynet G., Maeder A., Schaller G., Schaerer D., Charbonnel C., 1994, A\&AS 103, 97

Paczynski B., 1975, ApJ 202, 558

Pagel B.E.J., Terlevich R.J., Melnick J., 1986, PASP 98, 1005

Pagel B.E.J., Kazlauskas A., 1992, MNRAS 256, 49

Plez B., Smith V.V., Lambert D.L., 1993, ApJ 418, 812

Pottasch S.R., 1992, A\&AR 4, 215

Renzini A., Voli M., 1981, A\&A 94, 175 (RV)

Richer H.B., Olander N., Westerlund B.E., 1979, ApJ 230, 724

Rocca-Volmerange B., Schaeffer R., 1990, A\&A 233, 427

Rogers F.J., Iglesias C.A., 1992, ApJ 401, 361

Rood R.T., 1973, ApJ 184, 815

Russell S.C., Dopita M.A., 1992, ApJ 384, 508

Schaerer D., Meynet G., Maeder A., Schaller G., 1993a, A\&AS 98,523

Schaerer D., Charbonnel C., Meynet G., Maeder A., Schaller G., 1993b, A\&AS 102, 339

Schaller G., Schaerer D., Meynet G., Maeder A., 1992, A\&AS 96,269

Schönberner D., 1983, ApJ 272, 708

Shaver P.A., McGee R.X., Newton L.M., et al., 1983, MNRAS 204, 53

Smith V.V., Plez B., Lambert D.L., Lubowich D.A., 1995, ApJ 441,735

Steigman G., 1993, ApJ 413, L73

Schramm D.N., 1989, Comm. Ap. 14, 97

Sweigart A.V., Mengel J.G., 1979, ApJ 229, 642

Sweigart A.V., Greggio L., Renzini A., 1989, ApJS 69, 911

Sweigart A.V., Greggio L., Renzini A., 1990, ApJ 364, 527

Twarog B.A., 1980, ApJ 242, 242

Vassiliadis E., Wood P.R., 1993, ApJ 413, 641

Weidemann V., Koester D., 1983, A\&A 121, 77

Weidemann V., 1990, ARA\&A 28, 103

Wielen R., Fuchs B., Dettbarn C., 1996, A\&A (in press)

van Winckel H., Mathis J.S., Waelkens C., 1992, Nat 356, 500

Zuckerman B., Aller L.H., 1986, ApJ 301, 772 
Table 2. Pre-AGB yields for $Z_{\mathrm{ini}}=0.001, \eta_{\mathrm{AGB}}=4$, and $m_{\mathrm{HBB}}=0.8$

\begin{tabular}{|c|c|c|c|c|c|c|c|c|c|c|}
\hline$m_{\mathrm{ini}}$ & $\overline{\mathrm{H}}$ & ${ }^{4} \mathrm{He}$ & ${ }^{12} \mathrm{C}$ & ${ }^{13} \mathrm{C}$ & ${ }^{14} \mathrm{~N}$ & ${ }^{16} \mathrm{O}$ & $Y_{\mathrm{CNO}}$ & $\overline{Y_{\mathrm{TOT}}}$ & $\overline{\Delta m_{\mathrm{ej}}}$ & $m_{\text {end }}$ \\
\hline .9 & $-.676 \mathrm{E}-03$ & $.682 \mathrm{E}-03$ & $-.762 \mathrm{E}-06$ & $-.124 \mathrm{E}-05$ & $.838 \mathrm{E}-06$ & $.622 \mathrm{E}-07$ & $-.106 \mathrm{E}-05$ & $-.106 \mathrm{E}-05$ & .03 & .87 \\
\hline 1.0 & $-.726 \mathrm{E}-03$ & $.669 \mathrm{E}-03$ & $-.110 \mathrm{E}-05$ & $-.107 \mathrm{E}-05$ & $.126 \mathrm{E}-05$ & $.450 \mathrm{E}-07$ & $-.829 \mathrm{E}-06$ & $-.829 \mathrm{E}-06$ & .03 & .97 \\
\hline 1.3 & $-.173 \mathrm{E}-03$ & $.173 \mathrm{E}-03$ & $-.438 \mathrm{E}-06$ & $-.241 \mathrm{E}-06$ & $.506 \mathrm{E}-06$ & $.640 \mathrm{E}-08$ & $-.153 \mathrm{E}-06$ & $-.153 \mathrm{E}-06$ & .01 & 1.24 \\
\hline 1.5 & $-.176 \mathrm{E}-03$ & $.171 \mathrm{E}-03$ & $-.592 \mathrm{E}-06$ & $-.265 \mathrm{E}-06$ & $.695 \mathrm{E}-06$ & $.533 \mathrm{E}-08$ & $-.140 \mathrm{E}-06$ & $-.140 \mathrm{E}-06$ & .01 & 1.49 \\
\hline 1.7 & $-.388 \mathrm{E}-04$ & $.391 \mathrm{E}-04$ & $-.166 \mathrm{E}-06$ & $-.658 \mathrm{E}-07$ & $.197 \mathrm{E}-06$ & $-.294 \mathrm{E}-08$ & $-.322 \mathrm{E}-07$ & $-.322 \mathrm{E}-07$ & .00 & 1.70 \\
\hline 2.0 & $-.602 \mathrm{E}-04$ & $.581 \mathrm{E}-04$ & $-.253 \mathrm{E}-06$ & $-.977 \mathrm{E}-07$ & $.353 \mathrm{E}-06$ & $-.635 \mathrm{E}-07$ & $-.516 \mathrm{E}-07$ & $-.516 \mathrm{E}-07$ & .01 & 1.99 \\
\hline 2.5 & $-.317 \mathrm{E}-04$ & $.310 \mathrm{E}-04$ & $-.294 \mathrm{E}-06$ & $-.105 \mathrm{E}-06$ & $.398 \mathrm{E}-06$ & $-.624 \mathrm{E}-07$ & $-.530 \mathrm{E}-07$ & $-.530 \mathrm{E}-07$ & .01 & 2.49 \\
\hline 5.0 & $-.119 \mathrm{E}-04$ & $.274 \mathrm{E}-05$ & $-.190 \mathrm{E}-06$ & $-.880 \mathrm{E}-07$ & $.225 \mathrm{E}-06$ & $-.660 \mathrm{E}-08$ & $-.571 \mathrm{E}-07$ & $-.571 \mathrm{E}-07$ & .01 & 4.99 \\
\hline 7.0 & $-.777 \mathrm{E}-05$ & $.311 \mathrm{E}-05$ & $-.168 \mathrm{E}-06$ & $-.784 \mathrm{E}-07$ & $.206 \mathrm{E}-06$ & $-.117 \mathrm{E}-07$ & $-.476 \mathrm{E}-07$ & $-.476 \mathrm{E}-07$ & .02 & 6.98 \\
\hline
\end{tabular}

Table 3. AGB yields for $Z_{\mathrm{ini}}=0.001, \eta_{\mathrm{AGB}}=4$, and $m_{\mathrm{HBB}}=0.8$

\begin{tabular}{|c|c|c|c|c|c|c|c|c|c|c|}
\hline$m_{\text {ini }}$ & $\overline{\mathrm{H}}$ & ${ }^{4} \mathrm{He}$ & ${ }^{12} \mathrm{C}$ & ${ }^{13} \mathrm{C}$ & ${ }^{14} \mathrm{~N}$ & ${ }^{16} \mathrm{O}$ & $\overline{Y_{\mathrm{CNO}}}$ & $\overline{Y_{\mathrm{TOT}}}$ & $\Delta m_{\mathrm{ej}}$ & $m m_{\text {end }}$ \\
\hline .8 & $-.121 \mathrm{E}-01$ & $.121 \mathrm{E}-01$ & $-.187 \mathrm{E}-04$ & $-.107 \mathrm{E}-04$ & $.218 \mathrm{E}-04$ & $-.176 \mathrm{E}-05$ & $-.929 \mathrm{E}-05$ & $-.149 \mathrm{E}-07$ & .27 & .55 \\
\hline 1.0 & $-.133 \mathrm{E}-01$ & $.133 \mathrm{E}-01$ & $-.236 \mathrm{E}-04$ & $-.131 \mathrm{E}-04$ & $.276 \mathrm{E}-04$ & $-.215 \mathrm{E}-05$ & $-.113 \mathrm{E}-04$ & $-.170 \mathrm{E}-07$ & 41 & .59 \\
\hline 1.3 & $-.185 \mathrm{E}-01$ & $.168 \mathrm{E}-01$ & $.149 \mathrm{E}-02$ & $-.156 \mathrm{E}-04$ & $.332 \mathrm{E}-04$ & $.132 \mathrm{E}-03$ & $.164 \mathrm{E}-02$ & $.166 \mathrm{E}-02$ & .60 & .65 \\
\hline 1.7 & $-.180 \mathrm{E}-01$ & $.154 \mathrm{E}-01$ & $.230 \mathrm{E}-02$ & $-.174 \mathrm{E}-04$ & $.396 \mathrm{E}-04$ & $.204 \mathrm{E}-03$ & $.252 \mathrm{E}-02$ & $.254 \mathrm{E}-02$ & .91 & .79 \\
\hline 2.0 & $-.222 \mathrm{E}-01$ & $.187 \mathrm{E}-01$ & $.305 \mathrm{E}-02$ & $-.188 \mathrm{E}-04$ & $.701 \mathrm{E}-04$ & $.262 \mathrm{E}-03$ & $.337 \mathrm{E}-02$ & $.354 \mathrm{E}-02$ & 1.13 & .86 \\
\hline 2.5 & $-.181 \mathrm{E}-01$ & $.142 \mathrm{E}-01$ & $.341 \mathrm{E}-02$ & $-.193 \mathrm{E}-04$ & $.760 \mathrm{E}-04$ & $.293 \mathrm{E}-03$ & $.376 \mathrm{E}-02$ & $.388 \mathrm{E}-02$ & 1.50 & .99 \\
\hline 4.0 & $-.219 \mathrm{E}-01$ & $.166 \mathrm{E}-01$ & $.877 \mathrm{E}-03$ & $.180 \mathrm{E}-03$ & $.379 \mathrm{E}-02$ & $.344 \mathrm{E}-03$ & $.520 \mathrm{E}-02$ & $.528 \mathrm{E}-02$ & 2.71 & 1.27 \\
\hline 4.5 & $-.241 \mathrm{E}-01$ & $.183 \mathrm{E}-01$ & $.471 \mathrm{E}-03$ & $.480 \mathrm{E}-04$ & $.482 \mathrm{E}-02$ & $.417 \mathrm{E}-03$ & $.576 \mathrm{E}-02$ & $.584 \mathrm{E}-02$ & 3.14 & 1.34 \\
\hline 5.0 & $-.260 \mathrm{E}-01$ & $.197 \mathrm{E}-01$ & $.472 \mathrm{E}-03$ & $.414 \mathrm{E}-04$ & $.541 \mathrm{E}-02$ & $.338 \mathrm{E}-03$ & $.626 \mathrm{E}-02$ & $.635 \mathrm{E}-02$ & 3.57 & 1.41 \\
\hline 6.0 & $-.308 \mathrm{E}-01$ & $.236 \mathrm{E}-01$ & $.571 \mathrm{E}-03$ & $.625 \mathrm{E}-04$ & $.655 \mathrm{E}-02$ & $.355 \mathrm{E}-04$ & $.722 \mathrm{E}-02$ & $.728 \mathrm{E}-02$ & 4.43 & 1.56 \\
\hline 7.0 & $-.352 \mathrm{E}-01$ & $.272 \mathrm{E}-01$ & $.613 \mathrm{E}-03$ & $.748 \mathrm{E}-04$ & $.731 \mathrm{E}-02$ & $.465 \mathrm{E}-04$ & $.805 \mathrm{E}-02$ & $.808 \mathrm{E}-02$ & 5.28 & 1.70 \\
\hline 8.0 & $-.382 \mathrm{E}-01$ & $.295 \mathrm{E}-01$ & $.603 \mathrm{E}-03$ & $.859 \mathrm{E}-04$ & $.794 \mathrm{E}-02$ & $.960 \mathrm{E}-04$ & $.873 \mathrm{E}-02$ & $.878 \mathrm{E}-02$ & 6.13 & 1.84 \\
\hline
\end{tabular}

Table 4. Final AGB yields for $Z_{\text {ini }}=0.001, \eta_{\mathrm{AGB}}=4$, and $m_{\mathrm{HBB}}=0.8$

\begin{tabular}{|c|c|c|c|c|c|c|c|c|c|c|}
\hline$m_{\text {ini }}$ & $\overline{\mathrm{H}}$ & ${ }^{4} \mathrm{He}$ & ${ }^{12} \mathrm{C}$ & ${ }^{13} \mathrm{C}$ & ${ }^{14} \mathrm{~N}$ & ${ }^{16} \mathrm{O}$ & $Y_{\mathrm{CNO}}$ & $Y_{\mathrm{TOT}}$ & $\Delta m_{\mathrm{ej}}$ & $m_{\mathrm{end}}$ \\
\hline .8 & $-.374 \mathrm{E}-03$ & $.374 \mathrm{E}-03$ & $-.579 \mathrm{E}-06$ & $-.330 \mathrm{E}-06$ & $.676 \mathrm{E}-06$ & $-.546 \mathrm{E}-07$ & $-.288 \mathrm{E}-06$ & $-.436 \mathrm{E}-09$ & .01 & .54 \\
\hline 1.0 & $-.744 \mathrm{E}-03$ & $.744 \mathrm{E}-03$ & $-.132 \mathrm{E}-05$ & $-.728 \mathrm{E}-06$ & $.154 \mathrm{E}-05$ & $-.120 \mathrm{E}-06$ & $-.628 \mathrm{E}-06$ & $-.100 \mathrm{E}-08$ & .02 & .57 \\
\hline 1.3 & $-.576 \mathrm{E}-02$ & $.433 \mathrm{E}-02$ & $.131 \mathrm{E}-02$ & $-.166 \mathrm{E}-05$ & $.271 \mathrm{E}-05$ & $.116 \mathrm{E}-03$ & $.143 \mathrm{E}-02$ & $.143 \mathrm{E}-02$ & .06 & .59 \\
\hline 1.7 & $-.549 \mathrm{E}-02$ & $.426 \mathrm{E}-02$ & $.113 \mathrm{E}-02$ & $-.294 \mathrm{E}-05$ & $.610 \mathrm{E}-05$ & $.999 \mathrm{E}-04$ & $.123 \mathrm{E}-02$ & $.123 \mathrm{E}-02$ & .15 & .64 \\
\hline 2.0 & $-.725 \mathrm{E}-02$ & $.550 \mathrm{E}-02$ & $.158 \mathrm{E}-02$ & $-.313 \mathrm{E}-05$ & $.106 \mathrm{E}-04$ & $.138 \mathrm{E}-03$ & $.172 \mathrm{E}-02$ & $.175 \mathrm{E}-02$ & .19 & .68 \\
\hline 2.5 & $-.631 \mathrm{E}-02$ & $.461 \mathrm{E}-02$ & $.154 \mathrm{E}-02$ & $-.327 \mathrm{E}-05$ & $.118 \mathrm{E}-04$ & $.135 \mathrm{E}-03$ & $.168 \mathrm{E}-02$ & $.170 \mathrm{E}-02$ & .25 & .74 \\
\hline 4.0 & $-.485 \mathrm{E}-02$ & $.357 \mathrm{E}-02$ & $.211 \mathrm{E}-03$ & $.432 \mathrm{E}-04$ & $.930 \mathrm{E}-03$ & $.871 \mathrm{E}-04$ & $.127 \mathrm{E}-02$ & $.128 \mathrm{E}-02$ & .36 & .91 \\
\hline 4.5 & $-.502 \mathrm{E}-02$ & $.369 \mathrm{E}-02$ & $.114 \mathrm{E}-03$ & $.130 \mathrm{E}-04$ & $.109 \mathrm{E}-02$ & $.970 \mathrm{E}-04$ & $.132 \mathrm{E}-02$ & $.133 \mathrm{E}-02$ & .40 & .95 \\
\hline 5.0 & $-.513 \mathrm{E}-02$ & $.377 \mathrm{E}-02$ & $.108 \mathrm{E}-03$ & $.112 \mathrm{E}-04$ & $.116 \mathrm{E}-02$ & $.736 \mathrm{E}-04$ & $.135 \mathrm{E}-02$ & $.136 \mathrm{E}-02$ & .43 & .98 \\
\hline 6.0 & $-.559 \mathrm{E}-02$ & $.413 \mathrm{E}-02$ & $.120 \mathrm{E}-03$ & $.147 \mathrm{E}-04$ & $.130 \mathrm{E}-02$ & $.109 \mathrm{E}-04$ & $.145 \mathrm{E}-02$ & $.145 \mathrm{E}-02$ & .50 & 1.06 \\
\hline 7.0 & $-.600 \mathrm{E}-02$ & $.447 \mathrm{E}-02$ & $.121 \mathrm{E}-03$ & $.163 \mathrm{E}-04$ & $.137 \mathrm{E}-02$ & $.165 \mathrm{E}-04$ & $.153 \mathrm{E}-02$ & $.153 \mathrm{E}-02$ & .57 & 1.13 \\
\hline
\end{tabular}


Table 5. Total yields for $Z_{\mathrm{ini}}=0.001, \eta_{\mathrm{AGB}}=4$, and $m_{\mathrm{HBB}}=0.8$

\begin{tabular}{|c|c|c|c|c|c|c|c|c|c|c|}
\hline$m_{\mathrm{ini}}$ & $\mathrm{H}$ & ${ }^{4} \mathrm{He}$ & ${ }^{12} \mathrm{C}$ & ${ }^{13} \mathrm{C}$ & ${ }^{14} \mathrm{~N}$ & ${ }^{16} \mathrm{O}$ & $\mathrm{Y}_{\mathrm{CNO}}$ & $\mathrm{Y}_{\mathrm{TOT}}$ & $\Delta m_{\mathrm{ej}}$ & $m_{\text {end }}$ \\
\hline 1.3 & $-.244 \mathrm{E}-01$ & $.213 \mathrm{E}-01$ & $.281 \mathrm{E}-02$ & $-.175 \mathrm{E}-04$ & $.364 \mathrm{E}-04$ & $.249 \mathrm{E}-03$ & $.308 \mathrm{E}-02$ & $.309 \mathrm{E}-02$ & .67 & .59 \\
\hline 1.3 & $-.247 \mathrm{E}-01$ & $.215 \mathrm{E}-01$ & $.281 \mathrm{E}-02$ & $-.178 \mathrm{E}-04$ & $.371 \mathrm{E}-04$ & $.249 \mathrm{E}-03$ & $.308 \mathrm{E}-02$ & $.309 \mathrm{E}-02$ & .69 & .59 \\
\hline 1.7 & $-.235 \mathrm{E}-01$ & $.197 \mathrm{E}-01$ & $.343 \mathrm{E}-02$ & $-.204 \mathrm{E}-04$ & $.459 \mathrm{E}-04$ & $.304 \mathrm{E}-03$ & $.375 \mathrm{E}-02$ & $.377 \mathrm{E}-02$ & 1.06 & .64 \\
\hline 2.0 & $-.295 \mathrm{E}-01$ & $.242 \mathrm{E}-01$ & $.463 \mathrm{E}-02$ & $-.220 \mathrm{E}-04$ & $.811 \mathrm{E}-04$ & $.400 \mathrm{E}-03$ & $.509 \mathrm{E}-02$ & $.529 \mathrm{E}-02$ & 1.32 & .68 \\
\hline 2.5 & $-.244 \mathrm{E}-01$ & $.188 \mathrm{E}-01$ & $.495 \mathrm{E}-02$ & $-.227 \mathrm{E}-04$ & $.882 \mathrm{E}-04$ & $.429 \mathrm{E}-03$ & $.544 \mathrm{E}-02$ & $.559 \mathrm{E}-02$ & 1.76 & .74 \\
\hline 7.0 & $-.412 \mathrm{E}-01$ & $.316 \mathrm{E}-01$ & $.734 \mathrm{E}-03$ & $.910 \mathrm{E}-04$ & $.869 \mathrm{E}-02$ & $.629 \mathrm{E}-04$ & $.958 \mathrm{E}-02$ & $.961 \mathrm{E}-02$ & 5.87 & 1.13 \\
\hline 8.0 & $-.382 \mathrm{E}-01$ & $.295 \mathrm{E}-01$ & $.603 \mathrm{E}-03$ & $.858 \mathrm{E}-04$ & $.794 \mathrm{E}-02$ & $.960 \mathrm{E}-04$ & $.872 \mathrm{E}-02$ & $.878 \mathrm{E}-02$ & 6.17 & 1.84 \\
\hline
\end{tabular}

Table 6. Pre-AGB yields for $Z_{\mathrm{ini}}=0.004, \eta_{\mathrm{AGB}}=4$, and $m_{\mathrm{HBB}}=0.8$

\begin{tabular}{|c|c|c|c|c|c|c|c|c|c|c|}
\hline$m_{\text {ini }}$ & $\overline{\mathrm{H}}$ & ${ }^{4} \mathrm{He}$ & ${ }^{12} \mathrm{C}$ & ${ }^{13} \mathrm{C}$ & ${ }^{14} \mathrm{~N}$ & ${ }^{16} \mathrm{O}$ & $\overline{Y_{\mathrm{CNO}}}$ & $\overline{Y_{\mathrm{TOT}}}$ & $\Delta m_{\mathrm{ej}}$ & $m_{\mathrm{end}}$ \\
\hline .8 & $-.480 \mathrm{E}-04$ & $.385 \mathrm{E}-04$ & $.128 \mathrm{E}-05$ & $-.205 \mathrm{E}-07$ & $.330 \mathrm{E}-06$ & $.276 \mathrm{E}-05$ & $.436 \mathrm{E}-05$ & $.436 \mathrm{E}-05$ & .00 & .80 \\
\hline .9 & $-.132 \mathrm{E}-03$ & $.114 \mathrm{E}-03$ & $.291 \mathrm{E}-05$ & $-.189 \mathrm{E}-07$ & $.109 \mathrm{E}-05$ & $.684 \mathrm{E}-05$ & $.108 \mathrm{E}-04$ & $.108 \mathrm{E}-04$ & .00 & .90 \\
\hline 1.0 & $-.178 \mathrm{E}-03$ & $.154 \mathrm{E}-03$ & $.337 \mathrm{E}-05$ & $-.220 \mathrm{E}-07$ & $.176 \mathrm{E}-05$ & $.868 \mathrm{E}-05$ & $.138 \mathrm{E}-04$ & $.138 \mathrm{E}-04$ & .01 & .99 \\
\hline 1.3 & $-.883 \mathrm{E}-04$ & $.774 \mathrm{E}-04$ & $.140 \mathrm{E}-05$ & $-.136 \mathrm{E}-07$ & $.118 \mathrm{E}-05$ & $.429 \mathrm{E}-05$ & $.687 \mathrm{E}-05$ & $.687 \mathrm{E}-05$ & .00 & 1.25 \\
\hline 1.3 & $-.704 \mathrm{E}-04$ & $.648 \mathrm{E}-04$ & $.127 \mathrm{E}-05$ & $-.720 \mathrm{E}-08$ & $.100 \mathrm{E}-05$ & $.378 \mathrm{E}-05$ & $.606 \mathrm{E}-05$ & $.606 \mathrm{E}-05$ & .00 & 1.25 \\
\hline 1.5 & $-.575 \mathrm{E}-03$ & $.507 \mathrm{E}-03$ & $.788 \mathrm{E}-05$ & $-.109 \mathrm{E}-06$ & $.960 \mathrm{E}-05$ & $.286 \mathrm{E}-04$ & $.461 \mathrm{E}-04$ & $.461 \mathrm{E}-04$ & .03 & 1.47 \\
\hline 1.7 & $-.455 \mathrm{E}-03$ & $.405 \mathrm{E}-03$ & $.586 \mathrm{E}-05$ & $-.102 \mathrm{E}-06$ & $.863 \mathrm{E}-05$ & $.224 \mathrm{E}-04$ & $.369 \mathrm{E}-04$ & $.369 \mathrm{E}-04$ & .02 & 1.68 \\
\hline 2.0 & $-.243 \mathrm{E}-03$ & $.215 \mathrm{E}-03$ & $.291 \mathrm{E}-05$ & $-.590 \mathrm{E}-07$ & $.470 \mathrm{E}-05$ & $.106 \mathrm{E}-04$ & $.182 \mathrm{E}-04$ & $.182 \mathrm{E}-04$ & .01 & 1.99 \\
\hline 2.5 & $-.255 \mathrm{E}-03$ & $.238 \mathrm{E}-03$ & $.275 \mathrm{E}-05$ & $-.512 \mathrm{E}-07$ & $.564 \mathrm{E}-05$ & $.106 \mathrm{E}-04$ & $.189 \mathrm{E}-04$ & $.189 \mathrm{E}-04$ & .02 & 2.48 \\
\hline 3.0 & $-.340 \mathrm{E}-03$ & $.295 \mathrm{E}-03$ & $.400 \mathrm{E}-05$ & $-.660 \mathrm{E}-07$ & $.827 \mathrm{E}-05$ & $.154 \mathrm{E}-04$ & $.276 \mathrm{E}-04$ & $.276 \mathrm{E}-04$ & .03 & 2.97 \\
\hline 4.0 & $-.141 \mathrm{E}-03$ & $.129 \mathrm{E}-03$ & $.315 \mathrm{E}-05$ & $-.355 \mathrm{E}-07$ & $.523 \mathrm{E}-05$ & $.115 \mathrm{E}-04$ & $.199 \mathrm{E}-04$ & $.199 \mathrm{E}-04$ & .03 & 3.97 \\
\hline 5.0 & $-.926 \mathrm{E}-04$ & $.761 \mathrm{E}-04$ & $.226 \mathrm{E}-05$ & $-.196 \mathrm{E}-07$ & $.344 \mathrm{E}-05$ & $.806 \mathrm{E}-05$ & $.138 \mathrm{E}-04$ & $.138 \mathrm{E}-04$ & .03 & 4.97 \\
\hline 7.0 & $-.192 \mathrm{E}-03$ & $.160 \mathrm{E}-03$ & $.490 \mathrm{E}-05$ & $-.431 \mathrm{E}-07$ & $.740 \mathrm{E}-05$ & $.172 \mathrm{E}-04$ & $.296 \mathrm{E}-04$ & $.296 \mathrm{E}-04$ & .08 & 6.92 \\
\hline
\end{tabular}

Table 7. AGB yields for $Z_{\text {ini }}=0.004, \eta_{\mathrm{AGB}}=4$, and $m_{\mathrm{HBB}}=0.8$

\begin{tabular}{|c|c|c|c|c|c|c|c|c|c|c|}
\hline$m_{\text {ini }}$ & $\mathrm{H}$ & ${ }^{4} \mathrm{He}$ & ${ }^{12} \mathrm{C}$ & ${ }^{13} \mathrm{C}$ & ${ }^{14} \mathrm{~N}$ & ${ }^{16} \mathrm{O}$ & $Y_{\mathrm{CNO}}$ & $Y_{\mathrm{TOT}}$ & $\Delta m_{\mathrm{ej}}$ & $m_{\mathrm{end}}$ \\
\hline .8 & $-.108 \mathrm{E}-01$ & $.108 \mathrm{E}-01$ & $-.753 \mathrm{E}-04$ & $.564 \mathrm{E}-05$ & $.879 \mathrm{E}-04$ & $-.649 \mathrm{E}-05$ & $.117 \mathrm{E}-04$ & $-.144 \mathrm{E}-07$ & .25 & .57 \\
\hline .9 & $-.110 \mathrm{E}-01$ & $.110 \mathrm{E}-01$ & $-.811 \mathrm{E}-04$ & $.593 \mathrm{E}-05$ & $.947 \mathrm{E}-04$ & $-.689 \mathrm{E}-05$ & $.126 \mathrm{E}-04$ & $210 \mathrm{E}-09$ & .29 & .61 \\
\hline 1.0 & $-.119 \mathrm{E}-01$ & $.119 \mathrm{E}-01$ & $-.950 \mathrm{E}-04$ & $.673 \mathrm{E}-05$ & $.111 \mathrm{E}-03$ & $-.791 \mathrm{E}-05$ & $.147 \mathrm{E}-04$ & $-.698 \mathrm{E}-08$ & .38 & .62 \\
\hline 1.3 & $-.155 \mathrm{E}-01$ & $.144 \mathrm{E}-01$ & $.890 \mathrm{E}-03$ & $.770 \mathrm{E}-05$ & $.138 \mathrm{E}-03$ & $.730 \mathrm{E}-04$ & $.111 \mathrm{E}-02$ & $.109 \mathrm{E}-02$ & .57 & .68 \\
\hline 1.5 & $-.176 \mathrm{E}-01$ & $.157 \mathrm{E}-01$ & $.164 \mathrm{E}-02$ & $.864 \mathrm{E}-05$ & $.167 \mathrm{E}-03$ & $.135 \mathrm{E}-03$ & $.195 \mathrm{E}-02$ & $.193 \mathrm{E}-02$ & .80 & .70 \\
\hline 1.7 & $-.205 \mathrm{E}-01$ & $.174 \mathrm{E}-01$ & $.272 \mathrm{E}-02$ & $.941 \mathrm{E}-05$ & $.194 \mathrm{E}-03$ & $.224 \mathrm{E}-03$ & $.315 \mathrm{E}-02$ & $.311 \mathrm{E}-02$ & 1.03 & .67 \\
\hline 2.0 & $-.288 \mathrm{E}-01$ & $.239 \mathrm{E}-01$ & $.411 \mathrm{E}-02$ & $.103 \mathrm{E}-04$ & $.314 \mathrm{E}-03$ & $.287 \mathrm{E}-03$ & $.472 \mathrm{E}-02$ & $.493 \mathrm{E}-02$ & 1.29 & .70 \\
\hline 2.5 & $-.318 \mathrm{E}-01$ & $.263 \mathrm{E}-01$ & $.469 \mathrm{E}-02$ & $.112 \mathrm{E}-04$ & $.375 \mathrm{E}-03$ & $.296 \mathrm{E}-03$ & $.537 \mathrm{E}-02$ & $.545 \mathrm{E}-02$ & 1.66 & .82 \\
\hline 3.0 & $-.334 \mathrm{E}-01$ & $.267 \mathrm{E}-01$ & $.583 \mathrm{E}-02$ & $.117 \mathrm{E}-04$ & $.400 \mathrm{E}-03$ & $.380 \mathrm{E}-03$ & $.662 \mathrm{E}-02$ & $.671 \mathrm{E}-02$ & 2.10 & .86 \\
\hline 3.5 & $-.228 \mathrm{E}-01$ & $.183 \mathrm{E}-01$ & $.380 \mathrm{E}-02$ & $.916 \mathrm{E}-04$ & $.367 \mathrm{E}-03$ & $.239 \mathrm{E}-03$ & $.450 \mathrm{E}-02$ & $.455 \mathrm{E}-02$ & 2.31 & 1.16 \\
\hline 4.0 & $-.207 \mathrm{E}-01$ & $.161 \mathrm{E}-01$ & $.645 \mathrm{E}-03$ & $.215 \mathrm{E}-03$ & $.354 \mathrm{E}-02$ & $.199 \mathrm{E}-03$ & $.459 \mathrm{E}-02$ & $.462 \mathrm{E}-02$ & 2.67 & 1.30 \\
\hline 4.5 & $-.237 \mathrm{E}-01$ & $.185 \mathrm{E}-01$ & $.223 \mathrm{E}-03$ & $.801 \mathrm{E}-04$ & $.460 \mathrm{E}-02$ & $.266 \mathrm{E}-03$ & $.517 \mathrm{E}-02$ & $.520 \mathrm{E}-02$ & 3.11 & 1.36 \\
\hline 5.0 & $-.263 \mathrm{E}-01$ & $.206 \mathrm{E}-01$ & $.215 \mathrm{E}-03$ & $.724 \mathrm{E}-04$ & $.522 \mathrm{E}-02$ & $.194 \mathrm{E}-03$ & $.570 \mathrm{E}-02$ & $.573 \mathrm{E}-02$ & 3.54 & 1.43 \\
\hline 6.0 & $-.290 \mathrm{E}-01$ & $.224 \mathrm{E}-01$ & $.284 \mathrm{E}-03$ & $.916 \mathrm{E}-04$ & $.636 \mathrm{E}-02$ & $-.166 \mathrm{E}-03$ & $.657 \mathrm{E}-02$ & $.661 \mathrm{E}-02$ & 4.38 & 1.57 \\
\hline 7.0 & $-.312 \mathrm{E}-01$ & $.239 \mathrm{E}-01$ & $.297 \mathrm{E}-03$ & $.103 \mathrm{E}-03$ & $.718 \mathrm{E}-02$ & $-.242 \mathrm{E}-03$ & $.734 \mathrm{E}-02$ & $.738 \mathrm{E}-02$ & 5.22 & 1.70 \\
\hline 8.0 & $-.357 \mathrm{E}-01$ & $.277 \mathrm{E}-01$ & $.248 \mathrm{E}-03$ & $.113 \mathrm{E}-03$ & $.791 \mathrm{E}-02$ & $-.316 \mathrm{E}-03$ & $.795 \mathrm{E}-02$ & $.798 \mathrm{E}-02$ & 6.17 & 1.84 \\
\hline
\end{tabular}


Table 8. Final AGB yields for $Z_{\text {ini }}=0.004, \eta_{\mathrm{AGB}}=4$, and $m_{\mathrm{HBB}}=0.8$

\begin{tabular}{|c|c|c|c|c|c|c|c|c|c|c|}
\hline$m_{\mathrm{ini}}$ & $\mathrm{H}$ & ${ }^{4} \mathrm{He}$ & $12 \mathrm{C}$ & ${ }^{13} \mathrm{C}$ & ${ }^{14} \mathrm{~N}$ & $16 \mathrm{O}$ & $Y_{\mathrm{CNO}}$ & $\overline{Y_{\mathrm{TOT}}}$ & $\Delta m_{\mathrm{ej}}$ & $m_{\text {end }}$ \\
\hline .8 & $-.545 \mathrm{E}-04$ & $.545 \mathrm{E}-04$ & $-.380 \mathrm{E}-06$ & $.284 \mathrm{E}-07$ & $.443 \mathrm{E}-06$ & $-.327 \mathrm{E}-07$ & $.591 \mathrm{E}-07$ & $-.725 \mathrm{E}-10$ & .00 & .57 \\
\hline .9 & $-.107 \mathrm{E}-02$ & $.107 \mathrm{E}-02$ & $-.788 \mathrm{E}-05$ & $.577 \mathrm{E}-06$ & $.920 \mathrm{E}-05$ & $-.670 \mathrm{E}-06$ & $.122 \mathrm{E}-05$ & $.437 \mathrm{E}-09$ & .03 & .58 \\
\hline 1.0 & $-.397 \mathrm{E}-02$ & $.313 \mathrm{E}-02$ & $.769 \mathrm{E}-03$ & $.688 \mathrm{E}-06$ & $.114 \mathrm{E}-04$ & $.628 \mathrm{E}-04$ & $.844 \mathrm{E}-03$ & $.840 \mathrm{E}-03$ & .05 & .58 \\
\hline 1.3 & $-.478 \mathrm{E}-02$ & $.388 \mathrm{E}-02$ & $.815 \mathrm{E}-03$ & $.119 \mathrm{E}-05$ & $.214 \mathrm{E}-04$ & $.666 \mathrm{E}-04$ & $.905 \mathrm{E}-03$ & $.899 \mathrm{E}-03$ & .10 & .59 \\
\hline 1.5 & $-.334 \mathrm{E}-02$ & $.274 \mathrm{E}-02$ & $.534 \mathrm{E}-03$ & $.107 \mathrm{E}-05$ & $.208 \mathrm{E}-04$ & $.438 \mathrm{E}-04$ & $.600 \mathrm{E}-03$ & $.596 \mathrm{E}-03$ & .10 & .60 \\
\hline 1.7 & $-.335 \mathrm{E}-02$ & $.251 \mathrm{E}-02$ & $.771 \mathrm{E}-03$ & $.564 \mathrm{E}-06$ & $.119 \mathrm{E}-04$ & $.631 \mathrm{E}-04$ & $.847 \mathrm{E}-03$ & $.843 \mathrm{E}-03$ & .07 & .60 \\
\hline 2.0 & $-.368 \mathrm{E}-02$ & $.277 \mathrm{E}-02$ & $.813 \mathrm{E}-03$ & $.593 \mathrm{E}-06$ & $.187 \mathrm{E}-04$ & $.634 \mathrm{E}-04$ & $.896 \mathrm{E}-03$ & $.907 \mathrm{E}-03$ & .08 & .62 \\
\hline 2.5 & $-.576 \mathrm{E}-02$ & $.441 \mathrm{E}-02$ & $.121 \mathrm{E}-02$ & $.111 \mathrm{E}-05$ & $.382 \mathrm{E}-04$ & $.898 \mathrm{E}-04$ & $.134 \mathrm{E}-02$ & $.135 \mathrm{E}-02$ & .18 & .64 \\
\hline 3.0 & $-.649 \mathrm{E}-02$ & $.479 \mathrm{E}-02$ & $.154 \mathrm{E}-02$ & $.101 \mathrm{E}-05$ & $.358 \mathrm{E}-04$ & $.117 \mathrm{E}-03$ & $.170 \mathrm{E}-02$ & $.170 \mathrm{E}-02$ & .21 & .66 \\
\hline 3.5 & $-.491 \mathrm{E}-02$ & $.372 \mathrm{E}-02$ & $.103 \mathrm{E}-02$ & $.293 \mathrm{E}-04$ & $.514 \mathrm{E}-04$ & $.756 \mathrm{E}-04$ & $.118 \mathrm{E}-02$ & $.119 \mathrm{E}-02$ & .33 & .83 \\
\hline 4.0 & $-.488 \mathrm{E}-02$ & $.365 \mathrm{E}-02$ & $.194 \mathrm{E}-03$ & $.527 \mathrm{E}-04$ & $.925 \mathrm{E}-03$ & $.655 \mathrm{E}-04$ & $.124 \mathrm{E}-02$ & $.124 \mathrm{E}-02$ & .39 & .91 \\
\hline 4.5 & $-.511 \mathrm{E}-02$ & $.383 \mathrm{E}-02$ & $.832 \mathrm{E}-04$ & $.180 \mathrm{E}-04$ & $.110 \mathrm{E}-02$ & $.765 \mathrm{E}-04$ & $.128 \mathrm{E}-02$ & $.128 \mathrm{E}-02$ & .42 & .94 \\
\hline 5.0 & $-.533 \mathrm{E}-02$ & $.401 \mathrm{E}-02$ & $.775 \mathrm{E}-04$ & $.154 \mathrm{E}-04$ & $.118 \mathrm{E}-02$ & $.552 \mathrm{E}-04$ & $.132 \mathrm{E}-02$ & $.133 \mathrm{E}-02$ & .45 & .98 \\
\hline 6.0 & $-.552 \mathrm{E}-02$ & $.411 \mathrm{E}-02$ & $.872 \mathrm{E}-04$ & $.184 \mathrm{E}-04$ & $.132 \mathrm{E}-02$ & $-.217 \mathrm{E}-04$ & $.141 \mathrm{E}-02$ & $.141 \mathrm{E}-02$ & .52 & 1.05 \\
\hline 7.0 & $-.565 \mathrm{E}-02$ & $.417 \mathrm{E}-02$ & $.842 \mathrm{E}-04$ & $.195 \mathrm{E}-04$ & $.140 \mathrm{E}-02$ & $-.292 \mathrm{E}-04$ & $.147 \mathrm{E}-02$ & $.147 \mathrm{E}-02$ & .58 & 1.12 \\
\hline 8.0 & $-.609 \mathrm{E}-02$ & $.455 \mathrm{E}-02$ & $.724 \mathrm{E}-04$ & $.208 \mathrm{E}-04$ & $.147 \mathrm{E}-02$ & $-.329 \mathrm{E}-04$ & $.153 \mathrm{E}-02$ & $.154 \mathrm{E}-02$ & .64 & 1.20 \\
\hline
\end{tabular}

Table 9. Total yields for $Z_{\mathrm{ini}}=0.004, \eta_{\mathrm{AGB}}=4$, and $m_{\mathrm{HBB}}=0.8$

\begin{tabular}{|c|c|c|c|c|c|c|c|c|c|c|}
\hline$m_{\text {ini }}$ & $\mathrm{H}$ & ${ }^{4} \mathrm{He}$ & ${ }^{12} \mathrm{C}$ & ${ }^{13} \mathrm{C}$ & ${ }^{14} \mathrm{~N}$ & ${ }^{16} \mathrm{O}$ & $Y_{\mathrm{CNO}}$ & $\bar{Y}_{\mathrm{TOT}}$ & $\Delta m_{\mathrm{ej}}$ & $m_{\text {end }}$ \\
\hline .9 & $-.122 \mathrm{E}-01$ & $.122 \mathrm{E}-01$ & $-.861 \mathrm{E}-04$ & $.649 \mathrm{E}-05$ & $.105 \mathrm{E}-03$ & $-.722 \mathrm{E}-06$ & $.247 \mathrm{E}-04$ & $.108 \mathrm{E}-04$ & .33 & .58 \\
\hline 1.0 & $-.161 \mathrm{E}-01$ & $.152 \mathrm{E}-01$ & $.678 \mathrm{E}-03$ & $.739 \mathrm{E}-05$ & $.124 \mathrm{E}-03$ & $.636 \mathrm{E}-04$ & $.873 \mathrm{E}-03$ & $.854 \mathrm{E}-03$ & .43 & .58 \\
\hline 1.3 & $-.203 \mathrm{E}-01$ & $.184 \mathrm{E}-01$ & $.171 \mathrm{E}-02$ & $.888 \mathrm{E}-05$ & $.160 \mathrm{E}-03$ & $.144 \mathrm{E}-03$ & $.202 \mathrm{E}-02$ & $.199 \mathrm{E}-02$ & .66 & .59 \\
\hline 1.3 & $-.203 \mathrm{E}-01$ & $.183 \mathrm{E}-01$ & $.171 \mathrm{E}-02$ & $.888 \mathrm{E}-05$ & $.160 \mathrm{E}-03$ & $.143 \mathrm{E}-03$ & $.202 \mathrm{E}-02$ & $.199 \mathrm{E}-02$ & .66 & .59 \\
\hline 1.5 & $-.215 \mathrm{E}-01$ & $.189 \mathrm{E}-01$ & $.219 \mathrm{E}-02$ & $.961 \mathrm{E}-05$ & $.198 \mathrm{E}-03$ & $.207 \mathrm{E}-03$ & $.260 \mathrm{E}-02$ & $.257 \mathrm{E}-02$ & .93 & .60 \\
\hline 1.7 & $-.243 \mathrm{E}-01$ & $.203 \mathrm{E}-01$ & $.350 \mathrm{E}-02$ & $.988 \mathrm{E}-05$ & $.215 \mathrm{E}-03$ & $.309 \mathrm{E}-03$ & $.403 \mathrm{E}-02$ & $.399 \mathrm{E}-02$ & 1.12 & .60 \\
\hline 2.0 & $-.328 \mathrm{E}-01$ & $.269 \mathrm{E}-01$ & $.493 \mathrm{E}-02$ & $.108 \mathrm{E}-04$ & $.337 \mathrm{E}-03$ & $.361 \mathrm{E}-03$ & $.564 \mathrm{E}-02$ & $.586 \mathrm{E}-02$ & 1.38 & .62 \\
\hline 2.5 & $-.378 \mathrm{E}-01$ & $.309 \mathrm{E}-01$ & $.590 \mathrm{E}-02$ & $.123 \mathrm{E}-04$ & $.418 \mathrm{E}-03$ & $.396 \mathrm{E}-03$ & $.673 \mathrm{E}-02$ & $.682 \mathrm{E}-02$ & 1.86 & .64 \\
\hline 3.0 & $-.402 \mathrm{E}-01$ & $.318 \mathrm{E}-01$ & $.738 \mathrm{E}-02$ & $.126 \mathrm{E}-04$ & $.444 \mathrm{E}-03$ & $.512 \mathrm{E}-03$ & $.835 \mathrm{E}-02$ & $.843 \mathrm{E}-02$ & 2.34 & .66 \\
\hline 4.0 & $-.257 \mathrm{E}-01$ & $.199 \mathrm{E}-01$ & $.841 \mathrm{E}-03$ & $.267 \mathrm{E}-03$ & $.447 \mathrm{E}-02$ & $.276 \mathrm{E}-03$ & $.585 \mathrm{E}-02$ & $.587 \mathrm{E}-02$ & 3.09 & .91 \\
\hline 5.0 & $-.317 \mathrm{E}-01$ & $.247 \mathrm{E}-01$ & $.294 \mathrm{E}-03$ & $.878 \mathrm{E}-04$ & $.639 \mathrm{E}-02$ & $.257 \mathrm{E}-03$ & $.703 \mathrm{E}-02$ & $.707 \mathrm{E}-02$ & 4.02 & .98 \\
\hline 7.0 & $-.371 \mathrm{E}-01$ & $.282 \mathrm{E}-01$ & $.386 \mathrm{E}-03$ & $.123 \mathrm{E}-03$ & $.858 \mathrm{E}-02$ & $-.254 \mathrm{E}-03$ & $.884 \mathrm{E}-02$ & $.888 \mathrm{E}-02$ & 5.88 & 1.12 \\
\hline 8.0 & $-.422 \mathrm{E}-01$ & $.326 \mathrm{E}-01$ & $.328 \mathrm{E}-03$ & $.133 \mathrm{E}-03$ & $.939 \mathrm{E}-02$ & $-.321 \mathrm{E}-03$ & $.953 \mathrm{E}-02$ & $.957 \mathrm{E}-02$ & 6.81 & 1.20 \\
\hline
\end{tabular}

Table 10. Pre-AGB yields for $Z_{\mathrm{ini}}=0.008, \eta_{\mathrm{AGB}}=4$, and $m_{\mathrm{HBB}}=0.8$

\begin{tabular}{|c|c|c|c|c|c|c|c|c|c|c|}
\hline$m_{\text {ini }}$ & $\overline{\mathrm{H}}$ & ${ }^{4} \mathrm{He}$ & ${ }^{12} \mathrm{C}$ & ${ }^{13} \mathrm{C}$ & ${ }^{14} \mathrm{~N}$ & ${ }^{16} \mathrm{O}$ & $Y_{\mathrm{CNO}}$ & $Y_{\mathrm{TOT}}$ & $\Delta m_{\mathrm{ej}}$ & $m_{\mathrm{end}}$ \\
\hline .8 & $-.591 \mathrm{E}-03$ & $.491 \mathrm{E}-03$ & $.196 \mathrm{E}-04$ & $.250 \mathrm{E}-06$ & $.683 \mathrm{E}-05$ & $.482 \mathrm{E}-04$ & $.751 \mathrm{E}-04$ & $.751 \mathrm{E}-04$ & .01 & .79 \\
\hline .9 & $-.571 \mathrm{E}-03$ & $.471 \mathrm{E}-03$ & $.166 \mathrm{E}-04$ & $.293 \mathrm{E}-06$ & $.748 \mathrm{E}-05$ & $.438 \mathrm{E}-04$ & $.683 \mathrm{E}-04$ & $.683 \mathrm{E}-04$ & .01 & .89 \\
\hline 1.0 & $-.102 \mathrm{E}-02$ & $.814 \mathrm{E}-03$ & $.252 \mathrm{E}-04$ & $.482 \mathrm{E}-06$ & $.145 \mathrm{E}-04$ & $.713 \mathrm{E}-04$ & $.112 \mathrm{E}-03$ & $.112 \mathrm{E}-03$ & .02 & .98 \\
\hline 1.3 & $-.777 \mathrm{E}-03$ & $.657 \mathrm{E}-03$ & $.186 \mathrm{E}-04$ & $.418 \mathrm{E}-06$ & $.151 \mathrm{E}-04$ & $.600 \mathrm{E}-04$ & $.943 \mathrm{E}-04$ & $.943 \mathrm{E}-04$ & .02 & 1.23 \\
\hline 1.5 & $-.477 \mathrm{E}-03$ & $.387 \mathrm{E}-03$ & $.103 \mathrm{E}-04$ & $.243 \mathrm{E}-06$ & $.110 \mathrm{E}-04$ & $.373 \mathrm{E}-04$ & $.589 \mathrm{E}-04$ & $.589 \mathrm{E}-04$ & .02 & 1.48 \\
\hline 1.7 & $-.540 \mathrm{E}-03$ & $.434 \mathrm{E}-03$ & $.112 \mathrm{E}-04$ & $.268 \mathrm{E}-06$ & $.138 \mathrm{E}-04$ & $.421 \mathrm{E}-04$ & $.676 \mathrm{E}-04$ & $.676 \mathrm{E}-04$ & .02 & 1.68 \\
\hline 2.0 & $-.387 \mathrm{E}-03$ & $.330 \mathrm{E}-03$ & $.804 \mathrm{E}-05$ & $.160 \mathrm{E}-06$ & $.106 \mathrm{E}-04$ & $.292 \mathrm{E}-04$ & $.482 \mathrm{E}-04$ & $.482 \mathrm{E}-04$ & .02 & 1.98 \\
\hline 2.5 & $-.495 \mathrm{E}-03$ & $.420 \mathrm{E}-03$ & $.827 \mathrm{E}-05$ & $.199 \mathrm{E}-06$ & $.136 \mathrm{E}-04$ & $.310 \mathrm{E}-04$ & $.532 \mathrm{E}-04$ & $.532 \mathrm{E}-04$ & .02 & 2.48 \\
\hline 3.0 & $-.511 \mathrm{E}-03$ & $.448 \mathrm{E}-03$ & $.922 \mathrm{E}-05$ & $.232 \mathrm{E}-06$ & $.155 \mathrm{E}-04$ & $.343 \mathrm{E}-04$ & $.594 \mathrm{E}-04$ & $.594 \mathrm{E}-04$ & .03 & 2.97 \\
\hline 4.0 & $-.457 \mathrm{E}-03$ & $.392 \mathrm{E}-03$ & $.978 \mathrm{E}-05$ & $.261 \mathrm{E}-06$ & $.154 \mathrm{E}-04$ & $.357 \mathrm{E}-04$ & $.613 \mathrm{E}-04$ & $.613 \mathrm{E}-04$ & .04 & 3.96 \\
\hline 5.0 & $-.444 \mathrm{E}-03$ & $.354 \mathrm{E}-03$ & $.100 \mathrm{E}-04$ & $.274 \mathrm{E}-06$ & $.155 \mathrm{E}-04$ & $.362 \mathrm{E}-04$ & $.620 \mathrm{E}-04$ & $.620 \mathrm{E}-04$ & .05 & 4.95 \\
\hline 7.0 & $-.699 \mathrm{E}-03$ & $.573 \mathrm{E}-03$ & $.156 \mathrm{E}-04$ & $.437 \mathrm{E}-06$ & $.246 \mathrm{E}-04$ & $.558 \mathrm{E}-04$ & $.966 \mathrm{E}-04$ & $.966 \mathrm{E}-04$ & .12 & 6.88 \\
\hline
\end{tabular}


Table 11. AGB yields for $Z_{\mathrm{ini}}=0.008, \eta_{\mathrm{AGB}}=4$, and $m_{\mathrm{HBB}}=0.8$

\begin{tabular}{|c|c|c|c|c|c|c|c|c|c|c|}
\hline$m_{\text {ini }}$ & $\mathrm{H}$ & ${ }^{4} \mathrm{He}$ & ${ }^{12} \mathrm{C}$ & ${ }^{13} \mathrm{C}$ & ${ }^{14} \mathrm{~N}$ & ${ }^{16} \mathrm{O}$ & $Y_{\mathrm{CNO}}$ & $Y_{\mathrm{TOT}}$ & $\Delta m_{\mathrm{ej}}$ & $m_{\text {end }}$ \\
\hline .8 & $-.110 \mathrm{E}-01$ & $.110 \mathrm{E}-01$ & $-.147 \mathrm{E}-03$ & $.111 \mathrm{E}-04$ & $.172 \mathrm{E}-03$ & $-.139 \mathrm{E}-04$ & $.218 \mathrm{E}-04$ & $.225 \mathrm{E}-08$ & .27 & .56 \\
\hline .9 & $-.101 \mathrm{E}-01$ & $.101 \mathrm{E}-01$ & $-.144 \mathrm{E}-03$ & $.106 \mathrm{E}-04$ & $.168 \mathrm{E}-03$ & $-.134 \mathrm{E}-04$ & $.212 \mathrm{E}-04$ & $.175 \mathrm{E}-07$ & .28 & .62 \\
\hline 1.0 & $-.111 \mathrm{E}-01$ & $.111 \mathrm{E}-01$ & $-.171 \mathrm{E}-03$ & $.122 \mathrm{E}-04$ & $.200 \mathrm{E}-03$ & $-.156 \mathrm{E}-04$ & $.252 \mathrm{E}-04$ & $.666 \mathrm{E}-08$ & .37 & .63 \\
\hline 1.3 & $-.141 \mathrm{E}-01$ & $.132 \mathrm{E}-01$ & $.610 \mathrm{E}-03$ & $.142 \mathrm{E}-04$ & $.251 \mathrm{E}-03$ & $.408 \mathrm{E}-04$ & $.916 \mathrm{E}-03$ & $.879 \mathrm{E}-03$ & .56 & .69 \\
\hline 1.5 & $-.157 \mathrm{E}-01$ & $.141 \mathrm{E}-01$ & $.121 \mathrm{E}-02$ & $.160 \mathrm{E}-04$ & $.305 \mathrm{E}-03$ & $.842 \mathrm{E}-04$ & $.161 \mathrm{E}-02$ & $.156 \mathrm{E}-02$ & .79 & 71 \\
\hline 1.7 & $-.185 \mathrm{E}-01$ & $.158 \mathrm{E}-01$ & $.220 \mathrm{E}-02$ & $.176 \mathrm{E}-04$ & $.358 \mathrm{E}-03$ & $.156 \mathrm{E}-03$ & $.273 \mathrm{E}-02$ & $.267 \mathrm{E}-02$ & 1.03 & .67 \\
\hline 2.0 & $-.257 \mathrm{E}-01$ & $.214 \mathrm{E}-01$ & $.346 \mathrm{E}-02$ & $.198 \mathrm{E}-04$ & $.525 \mathrm{E}-03$ & $.165 \mathrm{E}-03$ & $.417 \mathrm{E}-02$ & $.435 \mathrm{E}-02$ & 1.27 & 72 \\
\hline 2.5 & $-.338 \mathrm{E}-01$ & $.283 \mathrm{E}-01$ & $.451 \mathrm{E}-02$ & $.218 \mathrm{E}-04$ & $.670 \mathrm{E}-03$ & $.145 \mathrm{E}-03$ & $.535 \mathrm{E}-02$ & $.540 \mathrm{E}-02$ & 1.71 & .77 \\
\hline 3.0 & $-.353 \mathrm{E}-01$ & $.289 \mathrm{E}-01$ & $.537 \mathrm{E}-02$ & $.223 \mathrm{E}-04$ & $.706 \mathrm{E}-03$ & $.185 \mathrm{E}-03$ & $.628 \mathrm{E}-02$ & $.633 \mathrm{E}-02$ & 2.12 & .85 \\
\hline 3.5 & $-.265 \mathrm{E}-01$ & $.222 \mathrm{E}-01$ & $.351 \mathrm{E}-02$ & $.219 \mathrm{E}-04$ & $.666 \mathrm{E}-03$ & $.627 \mathrm{E}-04$ & $.426 \mathrm{E}-02$ & $.429 \mathrm{E}-02$ & 2.31 & 1.16 \\
\hline 4.0 & $-.253 \mathrm{E}-01$ & $.211 \mathrm{E}-01$ & $.461 \mathrm{E}-03$ & $.236 \mathrm{E}-03$ & $.346 \mathrm{E}-02$ & $-.921 \mathrm{E}-05$ & $.414 \mathrm{E}-02$ & $.414 \mathrm{E}-02$ & 2.64 & 1.32 \\
\hline 4.5 & $-.264 \mathrm{E}-01$ & $.217 \mathrm{E}-01$ & $-.216 \mathrm{E}-04$ & $.895 \mathrm{E}-04$ & $.458 \mathrm{E}-02$ & $.615 \mathrm{E}-04$ & $.471 \mathrm{E}-02$ & $.471 \mathrm{E}-02$ & 3.07 & 1.38 \\
\hline 5.0 & $-.271 \mathrm{E}-01$ & $.218 \mathrm{E}-01$ & $-.521 \mathrm{E}-04$ & $.798 \mathrm{E}-04$ & $.519 \mathrm{E}-02$ & $.211 \mathrm{E}-05$ & $.522 \mathrm{E}-02$ & $.522 \mathrm{E}-02$ & 3.51 & 1.44 \\
\hline 6.0 & $-.301 \mathrm{E}-01$ & $.241 \mathrm{E}-01$ & $-.781 \mathrm{E}-05$ & $.976 \mathrm{E}-04$ & $.639 \mathrm{E}-02$ & $-.428 \mathrm{E}-03$ & $.606 \mathrm{E}-02$ & $.605 \mathrm{E}-02$ & 4.34 & 1.58 \\
\hline 7.0 & $-.328 \mathrm{E}-01$ & $.260 \mathrm{E}-01$ & $-.173 \mathrm{E}-04$ & $.109 \mathrm{E}-03$ & $.730 \mathrm{E}-02$ & $-.599 \mathrm{E}-03$ & $.680 \mathrm{E}-02$ & $.680 \mathrm{E}-02$ & 5.17 & 1.71 \\
\hline 8.0 & $-.430 \mathrm{E}-01$ & $.346 \mathrm{E}-01$ & $-.101 \mathrm{E}-03$ & $.134 \mathrm{E}-03$ & $.934 \mathrm{E}-02$ & $-.926 \mathrm{E}-03$ & $.845 \mathrm{E}-02$ & $.845 \mathrm{E}-02$ & 6.11 & 1.89 \\
\hline
\end{tabular}

Table 12. Final AGB yields for $Z_{\mathrm{ini}}=0.008, \eta_{\mathrm{AGB}}=4$, and $m_{\mathrm{HBB}}=0.8$

\begin{tabular}{|c|c|c|c|c|c|c|c|c|c|c|}
\hline$m_{\text {ini }}$ & $\overline{\mathrm{H}}$ & ${ }^{4} \mathrm{He}$ & ${ }^{12} \mathrm{C}$ & ${ }^{13} \mathrm{C}$ & ${ }^{14} \mathrm{~N}$ & ${ }^{16} \mathrm{O}$ & $\overline{Y_{\mathrm{CD}}}$ & $\overline{Y_{\mathrm{TOT}}}$ & $\overline{\Delta m_{\mathrm{ej}}}$ & $m_{\text {end }}$ \\
\hline .8 & $.000 \mathrm{E}+00$ & $.000 \mathrm{E}+00$ & $.000 \mathrm{E}+00$ & $.000 \mathrm{E}+00$ & $.000 \mathrm{E}+00$ & $.000 \mathrm{E}+00$ & $.000 \mathrm{E}+00$ & $.000 \mathrm{E}+00$ & .00 & .56 \\
\hline .9 & $-.139 \mathrm{E}-02$ & $.139 \mathrm{E}-02$ & $-.198 \mathrm{E}-04$ & $.146 \mathrm{E}-05$ & $.231 \mathrm{E}-04$ & $-.185 \mathrm{E}-05$ & $.293 \mathrm{E}-05$ & $.220 \mathrm{E}-08$ & .04 & .58 \\
\hline 1.0 & $-.149 \mathrm{E}-02$ & $.149 \mathrm{E}-02$ & $-.230 \mathrm{E}-04$ & $.165 \mathrm{E}-05$ & $.268 \mathrm{E}-04$ & $-.210 \mathrm{E}-05$ & $.338 \mathrm{E}-05$ & $-.844 \mathrm{E}-09$ & .05 & .58 \\
\hline 1.3 & $-.428 \mathrm{E}-02$ & $.354 \mathrm{E}-02$ & $.655 \mathrm{E}-03$ & $.239 \mathrm{E}-05$ & $.421 \mathrm{E}-04$ & $.467 \mathrm{E}-04$ & $.746 \mathrm{E}-03$ & $.736 \mathrm{E}-03$ & .10 & .59 \\
\hline 1.5 & $-.604 \mathrm{E}-02$ & $.460 \mathrm{E}-02$ & $.132 \mathrm{E}-02$ & $.210 \mathrm{E}-05$ & $.400 \mathrm{E}-04$ & $.946 \mathrm{E}-04$ & $.145 \mathrm{E}-02$ & $.144 \mathrm{E}-02$ & .12 & .59 \\
\hline 1.7 & $-.310 \mathrm{E}-02$ & $.232 \mathrm{E}-02$ & $.707 \mathrm{E}-03$ & $.109 \mathrm{E}-05$ & $.223 \mathrm{E}-04$ & $.509 \mathrm{E}-04$ & $.782 \mathrm{E}-03$ & $.774 \mathrm{E}-03$ & .07 & .60 \\
\hline 2.0 & $-.422 \mathrm{E}-02$ & $.319 \mathrm{E}-02$ & $.923 \mathrm{E}-03$ & $.151 \mathrm{E}-05$ & $.407 \mathrm{E}-04$ & $.598 \mathrm{E}-04$ & $.103 \mathrm{E}-02$ & $.104 \mathrm{E}-02$ & .11 & .61 \\
\hline 2.5 & $-.483 \mathrm{E}-02$ & $.371 \mathrm{E}-02$ & $.102 \mathrm{E}-02$ & $.160 \mathrm{E}-05$ & $.500 \mathrm{E}-04$ & $.594 \mathrm{E}-04$ & $.113 \mathrm{E}-02$ & $.113 \mathrm{E}-02$ & .14 & .63 \\
\hline 3.0 & $-.641 \mathrm{E}-02$ & $.482 \mathrm{E}-02$ & $.144 \mathrm{E}-02$ & $.193 \mathrm{E}-05$ & $.626 \mathrm{E}-04$ & $.854 \mathrm{E}-04$ & $.159 \mathrm{E}-02$ & $.159 \mathrm{E}-02$ & .21 & .64 \\
\hline 3.5 & $-.651 \mathrm{E}-02$ & $.505 \mathrm{E}-02$ & $.130 \mathrm{E}-02$ & $.315 \mathrm{E}-05$ & $.969 \mathrm{E}-04$ & $.652 \mathrm{E}-04$ & $.146 \mathrm{E}-02$ & $.146 \mathrm{E}-02$ & .35 & .80 \\
\hline 4.0 & $-.588 \mathrm{E}-02$ & $.464 \mathrm{E}-02$ & $.187 \mathrm{E}-03$ & $.632 \mathrm{E}-04$ & $.958 \mathrm{E}-03$ & $.308 \mathrm{E}-04$ & $.124 \mathrm{E}-02$ & $.124 \mathrm{E}-02$ & .42 & .90 \\
\hline 4.5 & $-.581 \mathrm{E}-02$ & $.452 \mathrm{E}-02$ & $.529 \mathrm{E}-04$ & $.209 \mathrm{E}-04$ & $.117 \mathrm{E}-02$ & $.473 \mathrm{E}-04$ & $.129 \mathrm{E}-02$ & $.129 \mathrm{E}-02$ & .44 & .93 \\
\hline 5.0 & $-.565 \mathrm{E}-02$ & $.434 \mathrm{E}-02$ & $.431 \mathrm{E}-04$ & $.171 \mathrm{E}-04$ & $.123 \mathrm{E}-02$ & $.277 \mathrm{E}-04$ & $.131 \mathrm{E}-02$ & $.131 \mathrm{E}-02$ & .47 & .97 \\
\hline 6.0 & $-.587 \mathrm{E}-02$ & $.447 \mathrm{E}-02$ & $.521 \mathrm{E}-04$ & $.199 \mathrm{E}-04$ & $.140 \mathrm{E}-02$ & $-.668 \mathrm{E}-04$ & $.140 \mathrm{E}-02$ & $.140 \mathrm{E}-02$ & .54 & 1.04 \\
\hline 7.0 & $-.601 \mathrm{E}-02$ & $.456 \mathrm{E}-02$ & $.475 \mathrm{E}-04$ & $.209 \mathrm{E}-04$ & $.148 \mathrm{E}-02$ & $-.886 \mathrm{E}-04$ & $.146 \mathrm{E}-02$ & $.146 \mathrm{E}-02$ & .60 & 1.11 \\
\hline 8.0 & $-.708 \mathrm{E}-02$ & $.542 \mathrm{E}-02$ & $.336 \mathrm{E}-04$ & $.240 \mathrm{E}-04$ & $.172 \mathrm{E}-02$ & $-.121 \mathrm{E}-03$ & $.166 \mathrm{E}-02$ & $.166 \mathrm{E}-02$ & .69 & 1.20 \\
\hline
\end{tabular}

Table 13. Total yields for $Z_{\mathrm{ini}}=0.008, \eta_{\mathrm{AGB}}=4$, and $m_{\mathrm{HBB}}=0.8$

\begin{tabular}{|c|c|c|c|c|c|c|c|c|c|c|}
\hline$m_{\text {ini }}$ & $\mathrm{H}$ & ${ }^{4} \mathrm{He}$ & ${ }^{12} \mathrm{C}$ & ${ }^{13} \mathrm{C}$ & ${ }^{14} \mathrm{~N}$ & ${ }^{16} \mathrm{O}$ & $Y_{\mathrm{CNO}}$ & $Y_{\mathrm{TOT}}$ & $\Delta m_{\mathrm{ej}}$ & $m_{\mathrm{end}}$ \\
\hline .9 & $-.121 \mathrm{E}-01$ & $.120 \mathrm{E}-01$ & $-.147 \mathrm{E}-03$ & $.124 \mathrm{E}-04$ & $.198 \mathrm{E}-03$ & $.285 \mathrm{E}-04$ & $.925 \mathrm{E}-04$ & $.683 \mathrm{E}-04$ & .33 & .58 \\
\hline 1.0 & $-.136 \mathrm{E}-01$ & $.134 \mathrm{E}-01$ & $-.169 \mathrm{E}-03$ & $.144 \mathrm{E}-04$ & $.241 \mathrm{E}-03$ & $.536 \mathrm{E}-04$ & $.140 \mathrm{E}-03$ & $.112 \mathrm{E}-03$ & .44 & .58 \\
\hline 1.3 & $-.191 \mathrm{E}-01$ & $.174 \mathrm{E}-01$ & $.128 \mathrm{E}-02$ & $.170 \mathrm{E}-04$ & $.306 \mathrm{E}-03$ & $.139 \mathrm{E}-03$ & $.174 \mathrm{E}-02$ & $.170 \mathrm{E}-02$ & .68 & .59 \\
\hline 1.3 & $-.192 \mathrm{E}-01$ & $.174 \mathrm{E}-01$ & $.128 \mathrm{E}-02$ & $.171 \mathrm{E}-04$ & $.308 \mathrm{E}-03$ & $.148 \mathrm{E}-03$ & $.176 \mathrm{E}-02$ & $.171 \mathrm{E}-02$ & .68 & .59 \\
\hline 1.5 & $-.222 \mathrm{E}-01$ & $.191 \mathrm{E}-01$ & $.253 \mathrm{E}-02$ & $.183 \mathrm{E}-04$ & $.356 \mathrm{E}-03$ & $.216 \mathrm{E}-03$ & $.312 \mathrm{E}-02$ & $.306 \mathrm{E}-02$ & .92 & .59 \\
\hline 1.7 & $-.221 \mathrm{E}-01$ & $.186 \mathrm{E}-01$ & $.291 \mathrm{E}-02$ & $.190 \mathrm{E}-04$ & $.394 \mathrm{E}-03$ & $.249 \mathrm{E}-03$ & $.358 \mathrm{E}-02$ & $.351 \mathrm{E}-02$ & 1.12 & .60 \\
\hline 2.0 & $-.303 \mathrm{E}-01$ & $.249 \mathrm{E}-01$ & $.439 \mathrm{E}-02$ & $.215 \mathrm{E}-04$ & $.576 \mathrm{E}-03$ & $.254 \mathrm{E}-03$ & $.524 \mathrm{E}-02$ & $.543 \mathrm{E}-02$ & 1.39 & .61 \\
\hline 2.5 & $-.391 \mathrm{E}-01$ & $.325 \mathrm{E}-01$ & $.553 \mathrm{E}-02$ & $.236 \mathrm{E}-04$ & $.733 \mathrm{E}-03$ & $.235 \mathrm{E}-03$ & $.653 \mathrm{E}-02$ & $.658 \mathrm{E}-02$ & 1.87 & .63 \\
\hline 3.0 & $-.422 \mathrm{E}-01$ & $.342 \mathrm{E}-01$ & $.681 \mathrm{E}-02$ & $.245 \mathrm{E}-04$ & $.784 \mathrm{E}-03$ & $.305 \mathrm{E}-03$ & $.793 \mathrm{E}-02$ & $.798 \mathrm{E}-02$ & 2.36 & .64 \\
\hline 4.0 & $-.316 \mathrm{E}-01$ & $.262 \mathrm{E}-01$ & $.658 \mathrm{E}-03$ & $.300 \mathrm{E}-03$ & $.443 \mathrm{E}-02$ & $.572 \mathrm{E}-04$ & $.544 \mathrm{E}-02$ & $.544 \mathrm{E}-02$ & 3.10 & .90 \\
\hline 5.0 & $-.331 \mathrm{E}-01$ & $.265 \mathrm{E}-01$ & $.104 \mathrm{E}-05$ & $.971 \mathrm{E}-04$ & $.643 \mathrm{E}-02$ & $.660 \mathrm{E}-04$ & $.659 \mathrm{E}-02$ & $.659 \mathrm{E}-02$ & 4.03 & .97 \\
\hline 7.0 & $-.395 \mathrm{E}-01$ & $.311 \mathrm{E}-01$ & $.458 \mathrm{E}-04$ & $.130 \mathrm{E}-03$ & $.881 \mathrm{E}-02$ & $-.632 \mathrm{E}-03$ & $.835 \mathrm{E}-02$ & $.835 \mathrm{E}-02$ & 5.89 & 1.11 \\
\hline 8.0 & $-.508 \mathrm{E}-01$ & $.406 \mathrm{E}-01$ & $-.520 \mathrm{E}-04$ & $.158 \mathrm{E}-03$ & $.111 \mathrm{E}-01$ & $-.992 \mathrm{E}-03$ & $.102 \mathrm{E}-01$ & $.102 \mathrm{E}-01$ & 6.81 & 1.20 \\
\hline
\end{tabular}


Table 14. Pre-AGB yields for $Z_{\mathrm{ini}}=0.020, \eta_{\mathrm{AGB}}=4$, and $m_{\mathrm{HBB}}=0.8$

\begin{tabular}{|c|c|c|c|c|c|c|c|c|c|c|}
\hline$m_{\text {ini }}$ & $\mathrm{H}$ & ${ }^{4} \mathrm{He}$ & ${ }^{12} \mathrm{C}$ & ${ }^{13} \mathrm{C}$ & ${ }^{14} \mathrm{~N}$ & ${ }^{16} \mathrm{O}$ & $Y_{\mathrm{CNO}}$ & $Y_{\mathrm{TOT}}$ & $\Delta m_{\mathrm{ej}}$ & $m_{\text {end }}$ \\
\hline .8 & $.000 \mathrm{E}+00$ & $.000 \mathrm{E}+00$ & $.000 \mathrm{E}+00$ & $.000 \mathrm{E}+00$ & $.000 \mathrm{E}+00$ & $.000 \mathrm{E}+00$ & $.000 \mathrm{E}+00$ & $.000 \mathrm{E}+00$ & .00 & .80 \\
\hline .9 & $.000 \mathrm{E}+00$ & $.000 \mathrm{E}+00$ & $.000 \mathrm{E}+00$ & $.000 \mathrm{E}+00$ & $.000 \mathrm{E}+00$ & $.000 \mathrm{E}+00$ & $.000 \mathrm{E}+00$ & $.000 \mathrm{E}+00$ & .00 & .90 \\
\hline 1.0 & $-.100 \mathrm{E}-01$ & $.781 \mathrm{E}-02$ & $.371 \mathrm{E}-03$ & $.124 \mathrm{E}-04$ & $.197 \mathrm{E}-03$ & $.103 \mathrm{E}-02$ & $.161 \mathrm{E}-02$ & $.161 \mathrm{E}-02$ & .10 & .90 \\
\hline 1.3 & $-.181 \mathrm{E}-01$ & $.144 \mathrm{E}-01$ & $.614 \mathrm{E}-03$ & $.239 \mathrm{E}-04$ & $.465 \mathrm{E}-03$ & $.192 \mathrm{E}-02$ & $.303 \mathrm{E}-02$ & $.303 \mathrm{E}-02$ & .24 & 1.01 \\
\hline 1.3 & $-.440 \mathrm{E}-02$ & $.349 \mathrm{E}-02$ & $.153 \mathrm{E}-03$ & $.595 \mathrm{E}-05$ & $.111 \mathrm{E}-03$ & $.473 \mathrm{E}-03$ & $.744 \mathrm{E}-03$ & $.744 \mathrm{E}-03$ & .06 & 1.19 \\
\hline 1.5 & $-.334 \mathrm{E}-02$ & $.264 \mathrm{E}-02$ & $.110 \mathrm{E}-03$ & $.453 \mathrm{E}-05$ & $.994 \mathrm{E}-04$ & $.371 \mathrm{E}-03$ & $.586 \mathrm{E}-03$ & $.586 \mathrm{E}-03$ & .06 & 1.44 \\
\hline 1.7 & $-.143 \mathrm{E}-02$ & $.112 \mathrm{E}-02$ & $.447 \mathrm{E}-04$ & $.189 \mathrm{E}-05$ & $.453 \mathrm{E}-04$ & $.155 \mathrm{E}-03$ & $.248 \mathrm{E}-03$ & $.248 \mathrm{E}-03$ & .03 & 1.67 \\
\hline 2.0 & $-.143 \mathrm{E}-02$ & $.111 \mathrm{E}-02$ & $.428 \mathrm{E}-04$ & $.174 \mathrm{E}-05$ & $.466 \mathrm{E}-04$ & $.147 \mathrm{E}-03$ & $.239 \mathrm{E}-03$ & $.239 \mathrm{E}-03$ & .03 & 1.97 \\
\hline 2.5 & $-.119 \mathrm{E}-02$ & $.962 \mathrm{E}-03$ & $.342 \mathrm{E}-04$ & $.145 \mathrm{E}-05$ & $.415 \mathrm{E}-04$ & $.118 \mathrm{E}-03$ & $.196 \mathrm{E}-03$ & $.196 \mathrm{E}-03$ & .03 & 2.47 \\
\hline 3.0 & $-.234 \mathrm{E}-02$ & $.190 \mathrm{E}-02$ & $.645 \mathrm{E}-04$ & $.282 \mathrm{E}-05$ & $.840 \mathrm{E}-04$ & $.222 \mathrm{E}-03$ & $.375 \mathrm{E}-03$ & $.375 \mathrm{E}-03$ & .07 & 2.93 \\
\hline 4.0 & $-.127 \mathrm{E}-02$ & $.101 \mathrm{E}-02$ & $.354 \mathrm{E}-04$ & $.157 \mathrm{E}-05$ & $.459 \mathrm{E}-04$ & $.120 \mathrm{E}-03$ & $.203 \mathrm{E}-03$ & $.203 \mathrm{E}-03$ & .05 & 3.95 \\
\hline 5.0 & $-.145 \mathrm{E}-02$ & $.116 \mathrm{E}-02$ & $.419 \mathrm{E}-04$ & $.188 \mathrm{E}-05$ & $.539 \mathrm{E}-04$ & $.141 \mathrm{E}-03$ & $.239 \mathrm{E}-03$ & $.239 \mathrm{E}-03$ & .08 & 4.92 \\
\hline 7.0 & $-.274 \mathrm{E}-02$ & $.221 \mathrm{E}-02$ & $.799 \mathrm{E}-04$ & $.366 \mathrm{E}-05$ & $.104 \mathrm{E}-03$ & $.265 \mathrm{E}-03$ & $.453 \mathrm{E}-03$ & $.453 \mathrm{E}-03$ & .20 & 6.80 \\
\hline
\end{tabular}

Table 15. AGB yields for $Z_{\mathrm{ini}}=0.020, \eta_{\mathrm{AGB}}=4$, and $m_{\mathrm{HBB}}=0.8$

\begin{tabular}{|c|c|c|c|c|c|c|c|c|c|c|}
\hline$m_{\text {ini }}$ & $\mathrm{H}$ & ${ }^{4} \mathrm{He}$ & ${ }^{12} \mathrm{C}$ & ${ }^{13} \mathrm{C}$ & ${ }^{14} \mathrm{~N}$ & ${ }^{16} \mathrm{O}$ & $Y_{\mathrm{CNO}}$ & $Y_{\mathrm{TOT}}$ & $\Delta m_{\mathrm{ej}}$ & $m_{\mathrm{end}}$ \\
\hline .8 & $-.986 \mathrm{E}-02$ & $.986 \mathrm{E}-02$ & $-.389 \mathrm{E}-03$ & $.296 \mathrm{E}-04$ & $.454 \mathrm{E}-03$ & $-.368 \mathrm{E}-04$ & $.579 \mathrm{E}-04$ & $.563 \mathrm{E}-09$ & .29 & .54 \\
\hline .9 & $-.853 \mathrm{E}-02$ & $.853 \mathrm{E}-02$ & $-.357 \mathrm{E}-03$ & $.266 \mathrm{E}-04$ & $.417 \mathrm{E}-03$ & $-.333 \mathrm{E}-04$ & $.530 \mathrm{E}-04$ & $-.139 \mathrm{E}-07$ & .28 & .62 \\
\hline 1.0 & $-.918 \mathrm{E}-02$ & $.918 \mathrm{E}-02$ & $-.418 \mathrm{E}-03$ & $.301 \mathrm{E}-04$ & $.488 \mathrm{E}-03$ & $-.382 \mathrm{E}-04$ & $.617 \mathrm{E}-04$ & $-.244 \mathrm{E}-07$ & .36 & .64 \\
\hline 1.3 & $-.937 \mathrm{E}-02$ & $.937 \mathrm{E}-02$ & $-.537 \mathrm{E}-03$ & $.357 \mathrm{E}-04$ & $.627 \mathrm{E}-03$ & $-.468 \mathrm{E}-04$ & $.787 \mathrm{E}-04$ & $.557 \mathrm{E}-07$ & .55 & .70 \\
\hline 1.5 & $-.986 \mathrm{E}-02$ & $.948 \mathrm{E}-02$ & $-.268 \mathrm{E}-03$ & $.398 \mathrm{E}-04$ & $.755 \mathrm{E}-03$ & $-.375 \mathrm{E}-04$ & $.489 \mathrm{E}-03$ & $.389 \mathrm{E}-03$ & .77 & .73 \\
\hline 1.7 & $-.112 \mathrm{E}-01$ & $.101 \mathrm{E}-01$ & $.351 \mathrm{E}-03$ & $.429 \mathrm{E}-04$ & $.864 \mathrm{E}-03$ & $-.123 \mathrm{E}-04$ & $.125 \mathrm{E}-02$ & $.112 \mathrm{E}-02$ & .97 & .73 \\
\hline 2.0 & $-.176 \mathrm{E}-01$ & $.151 \mathrm{E}-01$ & $.132 \mathrm{E}-02$ & $.510 \mathrm{E}-04$ & $.108 \mathrm{E}-02$ & $-.914 \mathrm{E}-04$ & $.235 \mathrm{E}-02$ & $.252 \mathrm{E}-02$ & 1.20 & .77 \\
\hline 2.5 & $-.258 \mathrm{E}-01$ & $.219 \mathrm{E}-01$ & $.264 \mathrm{E}-02$ & $.567 \mathrm{E}-04$ & $.135 \mathrm{E}-02$ & $-.185 \mathrm{E}-03$ & $.386 \mathrm{E}-02$ & $.389 \mathrm{E}-02$ & 1.67 & .80 \\
\hline 3.0 & $-.321 \mathrm{E}-01$ & $.268 \mathrm{E}-01$ & $.391 \mathrm{E}-02$ & $.588 \mathrm{E}-04$ & $.151 \mathrm{E}-02$ & $-.235 \mathrm{E}-03$ & $.525 \mathrm{E}-02$ & $.527 \mathrm{E}-02$ & 2.11 & .82 \\
\hline 3.5 & $-.304 \mathrm{E}-01$ & $.256 \mathrm{E}-01$ & $.351 \mathrm{E}-02$ & $.591 \mathrm{E}-04$ & $.153 \mathrm{E}-02$ & $-.283 \mathrm{E}-03$ & $.481 \mathrm{E}-02$ & $.480 \mathrm{E}-02$ & 2.42 & 1.02 \\
\hline 4.0 & $-.291 \mathrm{E}-01$ & $.247 \mathrm{E}-01$ & $.318 \mathrm{E}-02$ & $.599 \mathrm{E}-04$ & $.156 \mathrm{E}-02$ & $-.329 \mathrm{E}-03$ & $.446 \mathrm{E}-02$ & $.443 \mathrm{E}-02$ & 2.74 & 1.21 \\
\hline 4.5 & $-.288 \mathrm{E}-01$ & $.245 \mathrm{E}-01$ & $-.562 \mathrm{E}-03$ & $.159 \mathrm{E}-03$ & $.511 \mathrm{E}-02$ & $-.366 \mathrm{E}-03$ & $.434 \mathrm{E}-02$ & $.428 \mathrm{E}-02$ & 3.07 & 1.37 \\
\hline 5.0 & $-.296 \mathrm{E}-01$ & $.250 \mathrm{E}-01$ & $-.726 \mathrm{E}-03$ & $.115 \mathrm{E}-03$ & $.576 \mathrm{E}-02$ & $-.394 \mathrm{E}-03$ & $.476 \mathrm{E}-02$ & $.466 \mathrm{E}-02$ & 3.48 & 1.44 \\
\hline 6.0 & $-.320 \mathrm{E}-01$ & $.268 \mathrm{E}-01$ & $-.744 \mathrm{E}-03$ & $.127 \mathrm{E}-03$ & $.695 \mathrm{E}-02$ & $-.944 \mathrm{E}-03$ & $.539 \mathrm{E}-02$ & $.529 \mathrm{E}-02$ & 4.27 & 1.59 \\
\hline 7.0 & $-.341 \mathrm{E}-01$ & $.283 \mathrm{E}-01$ & $-.805 \mathrm{E}-03$ & $.139 \mathrm{E}-03$ & $.791 \mathrm{E}-02$ & $-.132 \mathrm{E}-02$ & $.593 \mathrm{E}-02$ & $.582 \mathrm{E}-02$ & 5.06 & 1.74 \\
\hline 8.0 & $-.363 \mathrm{E}-01$ & $.301 \mathrm{E}-01$ & $-.957 \mathrm{E}-03$ & $.144 \mathrm{E}-03$ & $.881 \mathrm{E}-02$ & $-.171 \mathrm{E}-02$ & $.629 \mathrm{E}-02$ & $.621 \mathrm{E}-02$ & 5.81 & 1.89 \\
\hline
\end{tabular}

Table 16. Final AGB yields for $Z_{\mathrm{ini}}=0.020, \eta_{\mathrm{AGB}}=4$, and $m_{\mathrm{HBB}}=0.8$

\begin{tabular}{|c|c|c|c|c|c|c|c|c|c|c|}
\hline$m_{\text {ini }}$ & $\mathrm{H}$ & ${ }^{4} \mathrm{He}$ & ${ }^{12} \mathrm{C}$ & ${ }^{13} \mathrm{C}$ & ${ }^{14} \mathrm{~N}$ & ${ }^{16} \mathrm{O}$ & $Y_{\mathrm{CNO}}$ & $Y_{\mathrm{TOT}}$ & $\Delta m_{\mathrm{ej}}$ & $m_{\text {end }}$ \\
\hline .8 & $.000 \mathrm{E}+00$ & $.000 \mathrm{E}+00$ & $.000 \mathrm{E}+00$ & $.000 \mathrm{E}+00$ & $.000 \mathrm{E}+00$ & $.000 \mathrm{E}+00$ & $.000 \mathrm{E}+00$ & $.000 \mathrm{E}+00$ & .00 & .54 \\
\hline .9 & $-.139 \mathrm{E}-02$ & $.139 \mathrm{E}-02$ & $-.582 \mathrm{E}-04$ & $.433 \mathrm{E}-05$ & $.679 \mathrm{E}-04$ & $-.542 \mathrm{E}-05$ & $.863 \mathrm{E}-05$ & $-.110 \mathrm{E}-08$ & .05 & .57 \\
\hline 1.0 & $-.165 \mathrm{E}-02$ & $.165 \mathrm{E}-02$ & $-.753 \mathrm{E}-04$ & $.542 \mathrm{E}-05$ & $.878 \mathrm{E}-04$ & $-.687 \mathrm{E}-05$ & $.111 \mathrm{E}-04$ & $.396 \mathrm{E}-08$ & .06 & .58 \\
\hline 1.3 & $-.193 \mathrm{E}-02$ & $.193 \mathrm{E}-02$ & $-.110 \mathrm{E}-03$ & $.735 \mathrm{E}-05$ & $.129 \mathrm{E}-03$ & $-.963 \mathrm{E}-05$ & $.162 \mathrm{E}-04$ & $-.801 \mathrm{E}-08$ & .11 & .59 \\
\hline 1.5 & $-.500 \mathrm{E}-02$ & $.390 \mathrm{E}-02$ & $.962 \mathrm{E}-03$ & $.696 \mathrm{E}-05$ & $.132 \mathrm{E}-03$ & $.372 \mathrm{E}-04$ & $.114 \mathrm{E}-02$ & $.110 \mathrm{E}-02$ & .15 & .59 \\
\hline 1.7 & $-.415 \mathrm{E}-02$ & $.315 \mathrm{E}-02$ & $.881 \mathrm{E}-03$ & $.557 \mathrm{E}-05$ & $.113 \mathrm{E}-03$ & $.346 \mathrm{E}-04$ & $.103 \mathrm{E}-02$ & $.100 \mathrm{E}-02$ & .14 & .59 \\
\hline 2.0 & $-.503 \mathrm{E}-02$ & $.386 \mathrm{E}-02$ & $.991 \mathrm{E}-03$ & $.698 \mathrm{E}-05$ & $.148 \mathrm{E}-03$ & $.220 \mathrm{E}-04$ & $.117 \mathrm{E}-02$ & $.118 \mathrm{E}-02$ & .18 & .60 \\
\hline 2.5 & $-.619 \mathrm{E}-02$ & $.468 \mathrm{E}-02$ & $.135 \mathrm{E}-02$ & $.595 \mathrm{E}-05$ & $.143 \mathrm{E}-03$ & $.253 \mathrm{E}-04$ & $.152 \mathrm{E}-02$ & $.151 \mathrm{E}-02$ & .20 & .60 \\
\hline 3.0 & $-.543 \mathrm{E}-02$ & $.415 \mathrm{E}-02$ & $.114 \mathrm{E}-02$ & $.522 \mathrm{E}-05$ & $.136 \mathrm{E}-03$ & $.118 \mathrm{E}-04$ & $.129 \mathrm{E}-02$ & $.128 \mathrm{E}-02$ & .21 & .62 \\
\hline 3.5 & $-.627 \mathrm{E}-02$ & $.488 \mathrm{E}-02$ & $.121 \mathrm{E}-02$ & $.728 \mathrm{E}-05$ & $.190 \mathrm{E}-03$ & $-.298 \mathrm{E}-05$ & $.140 \mathrm{E}-02$ & $.139 \mathrm{E}-02$ & .32 & .70 \\
\hline 4.0 & $-.720 \mathrm{E}-02$ & $.560 \mathrm{E}-02$ & $.141 \mathrm{E}-02$ & $.836 \mathrm{E}-05$ & $.219 \mathrm{E}-03$ & $-.657 \mathrm{E}-05$ & $.163 \mathrm{E}-02$ & $.161 \mathrm{E}-02$ & .42 & .79 \\
\hline 4.5 & $-.661 \mathrm{E}-02$ & $.529 \mathrm{E}-02$ & $-.181 \mathrm{E}-04$ & $.379 \mathrm{E}-04$ & $.135 \mathrm{E}-02$ & $-.321 \mathrm{E}-04$ & $.134 \mathrm{E}-02$ & $.132 \mathrm{E}-02$ & .48 & .88 \\
\hline 5.0 & $-.666 \mathrm{E}-02$ & $.528 \mathrm{E}-02$ & $-.569 \mathrm{E}-04$ & $.246 \mathrm{E}-04$ & $.148 \mathrm{E}-02$ & $-.383 \mathrm{E}-04$ & $.141 \mathrm{E}-02$ & $.138 \mathrm{E}-02$ & .53 & .92 \\
\hline 6.0 & $-.667 \mathrm{E}-02$ & $.525 \mathrm{E}-02$ & $-.529 \mathrm{E}-04$ & $.257 \mathrm{E}-04$ & $.164 \mathrm{E}-02$ & $-.170 \mathrm{E}-03$ & $.144 \mathrm{E}-02$ & $.142 \mathrm{E}-02$ & .60 & .99 \\
\hline 7.0 & $-.673 \mathrm{E}-02$ & $.527 \mathrm{E}-02$ & $-.612 \mathrm{E}-04$ & $.267 \mathrm{E}-04$ & $.175 \mathrm{E}-02$ & $-.234 \mathrm{E}-03$ & $.148 \mathrm{E}-02$ & $.146 \mathrm{E}-02$ & .67 & 1.07 \\
\hline 8.0 & $-.693 \mathrm{E}-02$ & $.543 \mathrm{E}-02$ & $-.906 \mathrm{E}-04$ & $.270 \mathrm{E}-04$ & $.188 \mathrm{E}-02$ & $-.296 \mathrm{E}-03$ & $.152 \mathrm{E}-02$ & $.150 \mathrm{E}-02$ & .74 & 1.15 \\
\hline
\end{tabular}


Table 17. Total yields for $Z_{\mathrm{ini}}=0.020, \eta_{\mathrm{AGB}}=4$, and $m_{\mathrm{HBB}}=0.8$

\begin{tabular}{|c|c|c|c|c|c|c|c|c|c|c|}
\hline$m_{\text {ini }}$ & $\overline{\mathrm{H}}$ & ${ }^{4} \mathrm{He}$ & ${ }^{12} \mathrm{C}$ & ${ }^{13} \mathrm{C}$ & ${ }^{14} \mathrm{~N}$ & ${ }^{16} \mathrm{O}$ & $\overline{Y_{\mathrm{CNO}}}$ & $\overline{Y_{\text {TOT }}}$ & $\Delta m_{\mathrm{ej}}$ & $m_{\text {end }}$ \\
\hline .9 & $-.992 \mathrm{E}-02$ & $.992 \mathrm{E}-02$ & $-.415 \mathrm{E}-03$ & $.309 \mathrm{E}-04$ & $.485 \mathrm{E}-03$ & $-.387 \mathrm{E}-04$ & $.616 \mathrm{E}-04$ & $-.150 \mathrm{E}-07$ & .33 & .57 \\
\hline 1.0 & $-.208 \mathrm{E}-01$ & $.186 \mathrm{E}-01$ & $-.123 \mathrm{E}-03$ & $.480 \mathrm{E}-04$ & $.773 \mathrm{E}-03$ & $.981 \mathrm{E}-03$ & $.168 \mathrm{E}-02$ & $.161 \mathrm{E}-02$ & .53 & .58 \\
\hline 1.3 & $-.294 \mathrm{E}-01$ & $.257 \mathrm{E}-01$ & $-.334 \mathrm{E}-04$ & $.670 \mathrm{E}-04$ & $.122 \mathrm{E}-02$ & $.187 \mathrm{E}-02$ & $.313 \mathrm{E}-02$ & $.303 \mathrm{E}-02$ & .90 & .59 \\
\hline 1.3 & $-.157 \mathrm{E}-01$ & $.148 \mathrm{E}-01$ & $-.494 \mathrm{E}-03$ & $.491 \mathrm{E}-04$ & $.867 \mathrm{E}-03$ & $416 \mathrm{E}-03$ & $.839 \mathrm{E}-03$ & $.744 \mathrm{E}-03$ & .72 & .59 \\
\hline 1.5 & $-.182 \mathrm{E}-01$ & $.160 \mathrm{E}-01$ & $.804 \mathrm{E}-03$ & $.513 \mathrm{E}-04$ & $.986 \mathrm{E}-03$ & $.371 \mathrm{E}-03$ & $.221 \mathrm{E}-02$ & $.208 \mathrm{E}-02$ & .97 & .59 \\
\hline 1.7 & $-.167 \mathrm{E}-01$ & $.143 \mathrm{E}-01$ & $.128 \mathrm{E}-02$ & $.503 \mathrm{E}-04$ & $.102 \mathrm{E}-02$ & $.178 \mathrm{E}-03$ & $.253 \mathrm{E}-02$ & $.237 \mathrm{E}-02$ & 1.14 & .59 \\
\hline 2.0 & $-.240 \mathrm{E}-01$ & $.200 \mathrm{E}-01$ & $.235 \mathrm{E}-02$ & $.597 \mathrm{E}-04$ & $.127 \mathrm{E}-02$ & $.777 \mathrm{E}-04$ & $.376 \mathrm{E}-02$ & $.394 \mathrm{E}-02$ & 1.40 & .60 \\
\hline 2.5 & $-.332 \mathrm{E}-01$ & $.276 \mathrm{E}-01$ & $.402 \mathrm{E}-02$ & $.641 \mathrm{E}-04$ & $.154 \mathrm{E}-02$ & $-.419 \mathrm{E}-04$ & $.558 \mathrm{E}-02$ & $.560 \mathrm{E}-02$ & 1.90 & .60 \\
\hline 3.0 & $-.399 \mathrm{E}-01$ & $.329 \mathrm{E}-01$ & $.511 \mathrm{E}-02$ & $.668 \mathrm{E}-04$ & $.173 \mathrm{E}-02$ & $-.147 \mathrm{E}-05$ & $.692 \mathrm{E}-02$ & $.692 \mathrm{E}-02$ & 2.38 & .62 \\
\hline 4.0 & $-.376 \mathrm{E}-01$ & $.313 \mathrm{E}-01$ & $.462 \mathrm{E}-02$ & $.698 \mathrm{E}-04$ & $.182 \mathrm{E}-02$ & $-.216 \mathrm{E}-03$ & $.629 \mathrm{E}-02$ & $.624 \mathrm{E}-02$ & 3.21 & .79 \\
\hline 5.0 & $-.377 \mathrm{E}-01$ & $.314 \mathrm{E}-01$ & $-.741 \mathrm{E}-03$ & $.141 \mathrm{E}-03$ & $.729 \mathrm{E}-02$ & $-.291 \mathrm{E}-03$ & $.640 \mathrm{E}-02$ & $.628 \mathrm{E}-02$ & 4.08 & .92 \\
\hline 7.0 & $-.436 \mathrm{E}-01$ & $.358 \mathrm{E}-01$ & $-.786 \mathrm{E}-03$ & $.170 \mathrm{E}-03$ & $.976 \mathrm{E}-02$ & $-.128 \mathrm{E}-02$ & $.786 \mathrm{E}-02$ & $.774 \mathrm{E}-02$ & 5.93 & 1.07 \\
\hline 8.0 & $-.474 \mathrm{E}-01$ & $.390 \mathrm{E}-01$ & $-.923 \mathrm{E}-03$ & $.176 \mathrm{E}-03$ & $.108 \mathrm{E}-01$ & $-.160 \mathrm{E}-02$ & $.850 \mathrm{E}-02$ & $.841 \mathrm{E}-02$ & 6.85 & 1.15 \\
\hline
\end{tabular}

Table 18. Pre-AGB yields for $Z_{\mathrm{ini}}=0.040, \eta_{\mathrm{AGB}}=4$, and $m_{\mathrm{HBB}}=0.8$

\begin{tabular}{|c|c|c|c|c|c|c|c|c|c|c|}
\hline$m_{\text {ini }}$ & $\mathrm{H}$ & ${ }^{4} \mathrm{He}$ & ${ }^{12} \mathrm{C}$ & ${ }^{13} \mathrm{C}$ & ${ }^{14} \mathrm{~N}$ & ${ }^{16} \mathrm{O}$ & $Y_{\mathrm{CNO}}$ & $Y_{\mathrm{TOT}}$ & $\Delta m_{\mathrm{ej}}$ & $m_{\text {end }}$ \\
\hline .8 & $-.170 \mathrm{E}-04$ & $.121 \mathrm{E}-04$ & $.119 \mathrm{E}-05$ & $.145 \mathrm{E}-07$ & $.300 \mathrm{E}-06$ & $.257 \mathrm{E}-05$ & $.408 \mathrm{E}-05$ & $.408 \mathrm{E}-05$ & .00 & .80 \\
\hline .9 & $-.151 \mathrm{E}-04$ & $.108 \mathrm{E}-04$ & $.106 \mathrm{E}-05$ & $.129 \mathrm{E}-07$ & $.267 \mathrm{E}-06$ & $.229 \mathrm{E}-05$ & $.363 \mathrm{E}-05$ & $.363 \mathrm{E}-05$ & .00 & .90 \\
\hline 1.0 & $-.151 \mathrm{E}-01$ & $.112 \mathrm{E}-01$ & $.790 \mathrm{E}-03$ & $.309 \mathrm{E}-04$ & $.379 \mathrm{E}-03$ & $.201 \mathrm{E}-02$ & $.321 \mathrm{E}-02$ & $.321 \mathrm{E}-02$ & .10 & .90 \\
\hline 1.3 & $-.138 \mathrm{E}-01$ & $.101 \mathrm{E}-01$ & $.661 \mathrm{E}-03$ & $.286 \mathrm{E}-04$ & $.432 \mathrm{E}-03$ & $.186 \mathrm{E}-02$ & $.298 \mathrm{E}-02$ & $.298 \mathrm{E}-02$ & .11 & 1.14 \\
\hline 1.3 & $-.693 \mathrm{E}-04$ & $.506 \mathrm{E}-04$ & $.400 \mathrm{E}-05$ & $.168 \mathrm{E}-06$ & $.170 \mathrm{E}-05$ & $.983 \mathrm{E}-05$ & $.157 \mathrm{E}-04$ & $.157 \mathrm{E}-04$ & .00 & 1.25 \\
\hline 1.5 & $-.110 \mathrm{E}-02$ & $.799 \mathrm{E}-03$ & $.517 \mathrm{E}-04$ & $.241 \mathrm{E}-05$ & $.389 \mathrm{E}-04$ & $.153 \mathrm{E}-03$ & $.247 \mathrm{E}-03$ & $.247 \mathrm{E}-03$ & .01 & 1.49 \\
\hline 1.7 & $-.247 \mathrm{E}-02$ & $.179 \mathrm{E}-02$ & $.112 \mathrm{E}-03$ & $.528 \mathrm{E}-05$ & $.918 \mathrm{E}-04$ & $.340 \mathrm{E}-03$ & $.551 \mathrm{E}-03$ & $.551 \mathrm{E}-03$ & .03 & 1.67 \\
\hline 2.0 & $-.238 \mathrm{E}-02$ & $.175 \mathrm{E}-02$ & $.104 \mathrm{E}-03$ & $.502 \mathrm{E}-05$ & $.924 \mathrm{E}-04$ & $.320 \mathrm{E}-03$ & $.524 \mathrm{E}-03$ & $.524 \mathrm{E}-03$ & .03 & 1.97 \\
\hline 2.5 & $-.255 \mathrm{E}-02$ & $.189 \mathrm{E}-02$ & $.111 \mathrm{E}-03$ & $.528 \mathrm{E}-05$ & $.102 \mathrm{E}-03$ & $.339 \mathrm{E}-03$ & $.560 \mathrm{E}-03$ & $.560 \mathrm{E}-03$ & .04 & 2.46 \\
\hline 3.0 & $-.546 \mathrm{E}-02$ & $.406 \mathrm{E}-02$ & $.226 \mathrm{E}-03$ & $.110 \mathrm{E}-04$ & $.223 \mathrm{E}-03$ & $.691 \mathrm{E}-03$ & $.116 \mathrm{E}-02$ & $.116 \mathrm{E}-02$ & .10 & 2.89 \\
\hline 4.0 & $-.266 \mathrm{E}-02$ & $.200 \mathrm{E}-02$ & $.112 \mathrm{E}-03$ & $.549 \mathrm{E}-05$ & $.110 \mathrm{E}-03$ & $.338 \mathrm{E}-03$ & $.568 \mathrm{E}-03$ & $.568 \mathrm{E}-03$ & .07 & 3.93 \\
\hline 5.0 & $-.293 \mathrm{E}-02$ & $.219 \mathrm{E}-02$ & $.124 \mathrm{E}-03$ & $.621 \mathrm{E}-05$ & $.121 \mathrm{E}-03$ & $.368 \mathrm{E}-03$ & $.621 \mathrm{E}-03$ & $.621 \mathrm{E}-03$ & .09 & 4.91 \\
\hline 7.0 & $-.698 \mathrm{E}-02$ & $.517 \mathrm{E}-02$ & $.296 \mathrm{E}-03$ & $.148 \mathrm{E}-04$ & $.290 \mathrm{E}-03$ & $.866 \mathrm{E}-03$ & $.147 \mathrm{E}-02$ & $.147 \mathrm{E}-02$ & .31 & 6.69 \\
\hline
\end{tabular}

Table 19. AGB yields for $Z_{\mathrm{ini}}=0.040, \eta_{\mathrm{AGB}}=4$, and $m_{\mathrm{HBB}}=0.8$

\begin{tabular}{|c|c|c|c|c|c|c|c|c|c|c|}
\hline$m_{\text {ini }}$ & $\mathrm{H}$ & ${ }^{4} \mathrm{He}$ & ${ }^{12} \mathrm{C}$ & ${ }^{13} \mathrm{C}$ & ${ }^{14} \mathrm{~N}$ & ${ }^{16} \mathrm{O}$ & $Y_{\mathrm{CNO}}$ & $Y_{\mathrm{TOT}}$ & $\Delta m_{\mathrm{ej}}$ & $m_{\text {end }}$ \\
\hline .8 & $-.833 \mathrm{E}-02$ & $.833 \mathrm{E}-02$ & $-.890 \mathrm{E}-03$ & $.681 \mathrm{E}-04$ & $.104 \mathrm{E}-02$ & $-.767 \mathrm{E}-04$ & $.140 \mathrm{E}-03$ & $.484 \mathrm{E}-07$ & .30 & .53 \\
\hline .9 & $-.758 \mathrm{E}-02$ & $.758 \mathrm{E}-02$ & $-.863 \mathrm{E}-03$ & $.645 \mathrm{E}-04$ & $.101 \mathrm{E}-02$ & $-.733 \mathrm{E}-04$ & $.135 \mathrm{E}-03$ & $-.294 \mathrm{E}-07$ & .31 & .59 \\
\hline 1.0 & $-.806 \mathrm{E}-02$ & $.806 \mathrm{E}-02$ & $-.100 \mathrm{E}-02$ & $.728 \mathrm{E}-04$ & $.117 \mathrm{E}-02$ & $-.837 \mathrm{E}-04$ & $.157 \mathrm{E}-03$ & $-.761 \mathrm{E}-07$ & .40 & .60 \\
\hline 1.3 & $-.763 \mathrm{E}-02$ & $.763 \mathrm{E}-02$ & $-.122 \mathrm{E}-02$ & $.818 \mathrm{E}-04$ & $.143 \mathrm{E}-02$ & $-.972 \mathrm{E}-04$ & $.189 \mathrm{E}-03$ & $.648 \mathrm{E}-07$ & .58 & .67 \\
\hline 1.5 & $-.656 \mathrm{E}-02$ & $.657 \mathrm{E}-02$ & $-.142 \mathrm{E}-02$ & $.880 \mathrm{E}-04$ & $.166 \mathrm{E}-02$ & $-.108 \mathrm{E}-03$ & $.218 \mathrm{E}-03$ & $.262 \mathrm{E}-06$ & .77 & .73 \\
\hline 1.7 & $-.543 \mathrm{E}-02$ & $.543 \mathrm{E}-02$ & $-.159 \mathrm{E}-02$ & $.926 \mathrm{E}-04$ & $.186 \mathrm{E}-02$ & $-.117 \mathrm{E}-03$ & $.241 \mathrm{E}-03$ & $.983 \mathrm{E}-07$ & .94 & .76 \\
\hline 2.0 & $-.906 \mathrm{E}-02$ & $.827 \mathrm{E}-02$ & $-.132 \mathrm{E}-02$ & $.116 \mathrm{E}-03$ & $.199 \mathrm{E}-02$ & $-.195 \mathrm{E}-03$ & $.595 \mathrm{E}-03$ & $.781 \mathrm{E}-03$ & 1.16 & .80 \\
\hline 2.5 & $-.152 \mathrm{E}-01$ & $.133 \mathrm{E}-01$ & $-.259 \mathrm{E}-03$ & $.128 \mathrm{E}-03$ & $.236 \mathrm{E}-02$ & $-.362 \mathrm{E}-03$ & $.187 \mathrm{E}-02$ & $.191 \mathrm{E}-02$ & 1.62 & .84 \\
\hline 3.0 & $-.213 \mathrm{E}-01$ & $.183 \mathrm{E}-01$ & $.830 \mathrm{E}-03$ & $.130 \mathrm{E}-03$ & $.260 \mathrm{E}-02$ & $-.521 \mathrm{E}-03$ & $.304 \mathrm{E}-02$ & $.304 \mathrm{E}-02$ & 2.01 & .89 \\
\hline 3.5 & $-.282 \mathrm{E}-01$ & $.231 \mathrm{E}-01$ & $.288 \mathrm{E}-02$ & $.134 \mathrm{E}-03$ & $.270 \mathrm{E}-02$ & $-.596 \mathrm{E}-03$ & $.512 \mathrm{E}-02$ & $.502 \mathrm{E}-02$ & 2.44 & .97 \\
\hline 4.0 & $-.284 \mathrm{E}-01$ & $.234 \mathrm{E}-01$ & $.282 \mathrm{E}-02$ & $.136 \mathrm{E}-03$ & $.278 \mathrm{E}-02$ & $-.650 \mathrm{E}-03$ & $.508 \mathrm{E}-02$ & $.495 \mathrm{E}-02$ & 2.80 & 1.13 \\
\hline 4.5 & $-.313 \mathrm{E}-01$ & $.258 \mathrm{E}-01$ & $.290 \mathrm{E}-02$ & $.140 \mathrm{E}-03$ & $.292 \mathrm{E}-02$ & $-.744 \mathrm{E}-03$ & $.522 \mathrm{E}-02$ & $.552 \mathrm{E}-02$ & 3.21 & 1.21 \\
\hline 5.0 & $-.342 \mathrm{E}-01$ & $.280 \mathrm{E}-01$ & $.305 \mathrm{E}-02$ & $.142 \mathrm{E}-03$ & $.304 \mathrm{E}-02$ & $-.832 \mathrm{E}-03$ & $.540 \mathrm{E}-02$ & $.615 \mathrm{E}-02$ & 3.59 & 1.32 \\
\hline 6.0 & $-.338 \mathrm{E}-01$ & $.280 \mathrm{E}-01$ & $-.162 \mathrm{E}-02$ & $.202 \mathrm{E}-03$ & $.819 \mathrm{E}-02$ & $-.119 \mathrm{E}-02$ & $.558 \mathrm{E}-02$ & $.584 \mathrm{E}-02$ & 4.30 & 1.50 \\
\hline 7.0 & $-.322 \mathrm{E}-01$ & $.267 \mathrm{E}-01$ & $-.195 \mathrm{E}-02$ & $.222 \mathrm{E}-03$ & $.921 \mathrm{E}-02$ & $-.177 \mathrm{E}-02$ & $.572 \mathrm{E}-02$ & $.549 \mathrm{E}-02$ & 5.02 & 1.67 \\
\hline 8.0 & $-.322 \mathrm{E}-01$ & $.270 \mathrm{E}-01$ & $-.216 \mathrm{E}-02$ & $.212 \mathrm{E}-03$ & $.965 \mathrm{E}-02$ & $-.230 \mathrm{E}-02$ & $.541 \mathrm{E}-02$ & $.522 \mathrm{E}-02$ & 5.59 & 1.91 \\
\hline
\end{tabular}


Table 20. Final AGB yields for $Z_{\mathrm{ini}}=0.040, \eta_{\mathrm{AGB}}=4$, and $m_{\mathrm{HBB}}=0.8$

\begin{tabular}{|c|c|c|c|c|c|c|c|c|c|c|}
\hline$m_{\text {ini }}$ & $\overline{\mathrm{H}}$ & ${ }^{4} \mathrm{He}$ & ${ }^{12} \mathrm{C}$ & ${ }^{13} \mathrm{C}$ & ${ }^{14} \mathrm{~N}$ & ${ }^{16} \mathrm{O}$ & $Y_{\mathrm{CNO}}$ & $\overline{Y_{\mathrm{TOT}}}$ & $\Delta m_{\mathrm{ej}}$ & $m_{\text {end }}$ \\
\hline .8 & $.000 \mathrm{E}+00$ & $.000 \mathrm{E}+00$ & $.000 \mathrm{E}+00$ & $.000 \mathrm{E}+00$ & $.000 \mathrm{E}+00$ & $.000 \mathrm{E}+00$ & $.000 \mathrm{E}+00$ & $.000 \mathrm{E}+00$ & .00 & .53 \\
\hline .9 & $-.985 \mathrm{E}-03$ & $.985 \mathrm{E}-03$ & $-.112 \mathrm{E}-03$ & $.838 \mathrm{E}-05$ & $.131 \mathrm{E}-03$ & $-.952 \mathrm{E}-05$ & $.176 \mathrm{E}-04$ & $.453 \mathrm{E}-08$ & .04 & .55 \\
\hline 1.0 & $-.106 \mathrm{E}-02$ & $.106 \mathrm{E}-02$ & $-.132 \mathrm{E}-03$ & $.956 \mathrm{E}-05$ & $.154 \mathrm{E}-03$ & $-.110 \mathrm{E}-04$ & $.206 \mathrm{E}-04$ & $-.396 \mathrm{E}-08$ & .05 & .55 \\
\hline 1.3 & $-.151 \mathrm{E}-02$ & $.151 \mathrm{E}-02$ & $-.242 \mathrm{E}-03$ & $.162 \mathrm{E}-04$ & $.282 \mathrm{E}-03$ & $-.192 \mathrm{E}-04$ & $.373 \mathrm{E}-04$ & $-.156 \mathrm{E}-07$ & .11 & .56 \\
\hline 1.5 & $-.137 \mathrm{E}-02$ & $.137 \mathrm{E}-02$ & $-.297 \mathrm{E}-03$ & $.184 \mathrm{E}-04$ & $.347 \mathrm{E}-03$ & $-.226 \mathrm{E}-04$ & $.455 \mathrm{E}-04$ & $-.133 \mathrm{E}-07$ & .16 & .57 \\
\hline 1.7 & $-.103 \mathrm{E}-02$ & $.103 \mathrm{E}-02$ & $-.303 \mathrm{E}-03$ & $.176 \mathrm{E}-04$ & $.353 \mathrm{E}-03$ & $-.222 \mathrm{E}-04$ & $.460 \mathrm{E}-04$ & $.274 \mathrm{E}-09$ & .18 & .58 \\
\hline 2.0 & $-.273 \mathrm{E}-02$ & $.224 \mathrm{E}-02$ & $.136 \mathrm{E}-03$ & $.207 \mathrm{E}-04$ & $.354 \mathrm{E}-03$ & $-.371 \mathrm{E}-04$ & $.474 \mathrm{E}-03$ & $.496 \mathrm{E}-03$ & .21 & .59 \\
\hline 2.5 & $-.455 \mathrm{E}-02$ & $.352 \mathrm{E}-02$ & $.757 \mathrm{E}-03$ & $.180 \mathrm{E}-04$ & $.334 \mathrm{E}-03$ & $-.565 \mathrm{E}-04$ & $.105 \mathrm{E}-02$ & $.103 \mathrm{E}-02$ & .24 & .60 \\
\hline 3.0 & $-.501 \mathrm{E}-02$ & $.391 \mathrm{E}-02$ & $.835 \mathrm{E}-03$ & $.171 \mathrm{E}-04$ & $.343 \mathrm{E}-03$ & $-.741 \mathrm{E}-04$ & $.112 \mathrm{E}-02$ & $.110 \mathrm{E}-02$ & .28 & .61 \\
\hline 3.5 & $-.632 \mathrm{E}-02$ & $.482 \mathrm{E}-02$ & $.126 \mathrm{E}-02$ & $.171 \mathrm{E}-04$ & $.349 \mathrm{E}-03$ & $-.838 \mathrm{E}-04$ & $.154 \mathrm{E}-02$ & $.150 \mathrm{E}-02$ & .34 & .63 \\
\hline 4.0 & $-.781 \mathrm{E}-02$ & $.593 \mathrm{E}-02$ & $.161 \mathrm{E}-02$ & $.199 \mathrm{E}-04$ & $.411 \mathrm{E}-03$ & $-.105 \mathrm{E}-03$ & $.193 \mathrm{E}-02$ & $.188 \mathrm{E}-02$ & .45 & .68 \\
\hline 4.5 & $-.768 \mathrm{E}-02$ & $.586 \mathrm{E}-02$ & $.149 \mathrm{E}-02$ & $.194 \mathrm{E}-04$ & $.410 \mathrm{E}-03$ & $-.113 \mathrm{E}-03$ & $.181 \mathrm{E}-02$ & $.182 \mathrm{E}-02$ & .49 & .72 \\
\hline 5.0 & $-.809 \mathrm{E}-02$ & $.618 \mathrm{E}-02$ & $.151 \mathrm{E}-02$ & $.198 \mathrm{E}-04$ & $.427 \mathrm{E}-03$ & $-.126 \mathrm{E}-03$ & $.183 \mathrm{E}-02$ & $.190 \mathrm{E}-02$ & .54 & .77 \\
\hline 6.0 & $-.739 \mathrm{E}-02$ & $.577 \mathrm{E}-02$ & $-.187 \mathrm{E}-03$ & $.371 \mathrm{E}-04$ & $.198 \mathrm{E}-02$ & $-.229 \mathrm{E}-03$ & $.160 \mathrm{E}-02$ & $.161 \mathrm{E}-02$ & .62 & .88 \\
\hline 7.0 & $-.682 \mathrm{E}-02$ & $.533 \mathrm{E}-02$ & $-.229 \mathrm{E}-03$ & $.394 \mathrm{E}-04$ & $.208 \mathrm{E}-02$ & $-.351 \mathrm{E}-03$ & $.154 \mathrm{E}-02$ & $.149 \mathrm{E}-02$ & .69 & .98 \\
\hline 8.0 & $-.707 \mathrm{E}-02$ & $.559 \mathrm{E}-02$ & $-.302 \mathrm{E}-03$ & $.394 \mathrm{E}-04$ & $.228 \mathrm{E}-02$ & $-.489 \mathrm{E}-03$ & $.153 \mathrm{E}-02$ & $.149 \mathrm{E}-02$ & .82 & 1.09 \\
\hline
\end{tabular}

Table 21. Total yields for $Z_{\mathrm{ini}}=0.040, \eta_{\mathrm{AGB}}=4$, and $m_{\mathrm{HBB}}=0.8$

\begin{tabular}{|c|c|c|c|c|c|c|c|c|c|c|}
\hline$m_{\text {ini }}$ & $\mathrm{H}$ & ${ }^{4} \mathrm{He}$ & ${ }^{12} \mathrm{C}$ & ${ }^{13} \mathrm{C}$ & ${ }^{14} \mathrm{~N}$ & ${ }^{16} \mathrm{O}$ & $Y_{\mathrm{CNO}}$ & $\overline{Y_{\mathrm{TOT}}}$ & $\Delta m_{\mathrm{ej}}$ & $m_{\mathrm{end}}$ \\
\hline .9 & $-.858 \mathrm{E}-02$ & $.858 \mathrm{E}-02$ & $-.974 \mathrm{E}-03$ & $.729 \mathrm{E}-04$ & $.114 \mathrm{E}-02$ & $-.805 \mathrm{E}-04$ & $.157 \mathrm{E}-03$ & $.360 \mathrm{E}-05$ & .35 & .55 \\
\hline 1.0 & $-.243 \mathrm{E}-01$ & $.204 \mathrm{E}-01$ & $-.347 \mathrm{E}-03$ & $.113 \mathrm{E}-03$ & $.171 \mathrm{E}-02$ & $.191 \mathrm{E}-02$ & $.339 \mathrm{E}-02$ & $.321 \mathrm{E}-02$ & .55 & .55 \\
\hline 1.3 & $-.229 \mathrm{E}-01$ & $.193 \mathrm{E}-01$ & $-.804 \mathrm{E}-03$ & $.127 \mathrm{E}-03$ & $.214 \mathrm{E}-02$ & $.174 \mathrm{E}-02$ & $.321 \mathrm{E}-02$ & $.298 \mathrm{E}-02$ & .80 & .56 \\
\hline 1.3 & $-.921 \mathrm{E}-02$ & $.919 \mathrm{E}-02$ & $-.146 \mathrm{E}-02$ & $.982 \mathrm{E}-04$ & $.171 \mathrm{E}-02$ & $-.107 \mathrm{E}-03$ & $.242 \mathrm{E}-03$ & $.158 \mathrm{E}-04$ & .69 & .56 \\
\hline 1.5 & $-.903 \mathrm{E}-02$ & $.874 \mathrm{E}-02$ & $-.167 \mathrm{E}-02$ & $.109 \mathrm{E}-03$ & $.205 \mathrm{E}-02$ & $.228 \mathrm{E}-04$ & $.510 \mathrm{E}-03$ & $.247 \mathrm{E}-03$ & .94 & .57 \\
\hline 1.7 & $-.893 \mathrm{E}-02$ & $.825 \mathrm{E}-02$ & $-.178 \mathrm{E}-02$ & $.115 \mathrm{E}-03$ & $.230 \mathrm{E}-02$ & $.201 \mathrm{E}-03$ & $.838 \mathrm{E}-03$ & $.551 \mathrm{E}-03$ & 1.15 & .58 \\
\hline 2.0 & $-.142 \mathrm{E}-01$ & $.123 \mathrm{E}-01$ & $-.108 \mathrm{E}-02$ & $.142 \mathrm{E}-03$ & $.244 \mathrm{E}-02$ & $.878 \mathrm{E}-04$ & $.159 \mathrm{E}-02$ & $.180 \mathrm{E}-02$ & 1.41 & .59 \\
\hline 2.5 & $-.223 \mathrm{E}-01$ & $.187 \mathrm{E}-01$ & $.609 \mathrm{E}-03$ & $.152 \mathrm{E}-03$ & $.280 \mathrm{E}-02$ & $-.798 \mathrm{E}-04$ & $.348 \mathrm{E}-02$ & $.350 \mathrm{E}-02$ & 1.90 & .60 \\
\hline 3.0 & $-.318 \mathrm{E}-01$ & $.262 \mathrm{E}-01$ & $.189 \mathrm{E}-02$ & $.158 \mathrm{E}-03$ & $.317 \mathrm{E}-02$ & $.964 \mathrm{E}-04$ & $.532 \mathrm{E}-02$ & $.529 \mathrm{E}-02$ & 2.39 & .61 \\
\hline 4.0 & $-.388 \mathrm{E}-01$ & $.314 \mathrm{E}-01$ & $.454 \mathrm{E}-02$ & $.161 \mathrm{E}-03$ & $.330 \mathrm{E}-02$ & $-.417 \mathrm{E}-03$ & $.758 \mathrm{E}-02$ & $.739 \mathrm{E}-02$ & 3.32 & .68 \\
\hline 5.0 & $-.452 \mathrm{E}-01$ & $.364 \mathrm{E}-01$ & $.468 \mathrm{E}-02$ & $.168 \mathrm{E}-03$ & $.359 \mathrm{E}-02$ & $-.590 \mathrm{E}-03$ & $.785 \mathrm{E}-02$ & $.867 \mathrm{E}-02$ & 4.23 & .77 \\
\hline 7.0 & $-.460 \mathrm{E}-01$ & $.372 \mathrm{E}-01$ & $-.188 \mathrm{E}-02$ & $.276 \mathrm{E}-03$ & $.116 \mathrm{E}-01$ & $-.125 \mathrm{E}-02$ & $.873 \mathrm{E}-02$ & $.845 \mathrm{E}-02$ & 6.02 & .98 \\
\hline 8.0 & $-.513 \mathrm{E}-01$ & $.416 \mathrm{E}-01$ & $-.195 \mathrm{E}-02$ & $.277 \mathrm{E}-03$ & $.124 \mathrm{E}-01$ & $-.130 \mathrm{E}-02$ & $.947 \mathrm{E}-02$ & $.924 \mathrm{E}-02$ & 6.91 & 1.09 \\
\hline
\end{tabular}


Table 22. AGB yields for $Z_{\mathrm{ini}}=0.001, \eta_{\mathrm{AGB}}=4$, and $m_{\mathrm{HBB}}=0.9$

\begin{tabular}{lcrcc}
\hline$M_{\text {ini }}$ & ${ }^{12} \mathrm{C}$ & ${ }^{13} \mathrm{C}$ & ${ }^{14} \mathrm{~N}$ & ${ }^{16} \mathrm{O}$ \\
\hline 3.0 & $.379 \mathrm{E}-02$ & $-.203 \mathrm{E}-04$ & $.699 \mathrm{E}-04$ & $.335 \mathrm{E}-03$ \\
3.5 & $.420 \mathrm{E}-02$ & $-.210 \mathrm{E}-04$ & $.759 \mathrm{E}-04$ & $.365 \mathrm{E}-03$ \\
4.0 & $.474 \mathrm{E}-02$ & $-.218 \mathrm{E}-04$ & $.823 \mathrm{E}-04$ & $.408 \mathrm{E}-03$ \\
4.5 & $.197 \mathrm{E}-02$ & $.250 \mathrm{E}-04$ & $.334 \mathrm{E}-02$ & $.426 \mathrm{E}-03$ \\
5.0 & $.472 \mathrm{E}-03$ & $.414 \mathrm{E}-04$ & $.541 \mathrm{E}-02$ & $.338 \mathrm{E}-03$ \\
6.0 & $.571 \mathrm{E}-03$ & $.625 \mathrm{E}-04$ & $.655 \mathrm{E}-02$ & $.355 \mathrm{E}-04$ \\
7.0 & $.613 \mathrm{E}-03$ & $.748 \mathrm{E}-04$ & $.731 \mathrm{E}-02$ & $.465 \mathrm{E}-04$ \\
8.0 & $.603 \mathrm{E}-03$ & $.859 \mathrm{E}-04$ & $.794 \mathrm{E}-02$ & $.960 \mathrm{E}-04$ \\
\hline
\end{tabular}

Table 23. Final AGB yields for $Z_{\text {ini }}=0.001, \eta_{\mathrm{AGB}}=4$, and $m_{\mathrm{HBB}}=0.9$

\begin{tabular}{lcrcc}
\hline$M_{\text {ini }}$ & ${ }^{12} \mathrm{C}$ & \multicolumn{1}{c}{${ }^{13} \mathrm{C}$} & ${ }^{14} \mathrm{~N}$ & ${ }^{16} \mathrm{O}$ \\
\hline 3.0 & $.137 \mathrm{E}-02$ & $-.309 \mathrm{E}-05$ & $.984 \mathrm{E}-05$ & $.121 \mathrm{E}-03$ \\
3.5 & $.156 \mathrm{E}-02$ & $-.318 \mathrm{E}-05$ & $.105 \mathrm{E}-04$ & $.137 \mathrm{E}-03$ \\
4.0 & $.140 \mathrm{E}-02$ & $-.306 \mathrm{E}-05$ & $.108 \mathrm{E}-04$ & $.122 \mathrm{E}-03$ \\
4.5 & $.311 \mathrm{E}-03$ & $.100 \mathrm{E}-04$ & $.899 \mathrm{E}-03$ & $.983 \mathrm{E}-04$ \\
5.0 & $.108 \mathrm{E}-03$ & $.112 \mathrm{E}-04$ & $.116 \mathrm{E}-02$ & $.736 \mathrm{E}-04$ \\
6.0 & $.120 \mathrm{E}-03$ & $.147 \mathrm{E}-04$ & $.130 \mathrm{E}-02$ & $.109 \mathrm{E}-04$ \\
7.0 & $.121 \mathrm{E}-03$ & $.163 \mathrm{E}-04$ & $.137 \mathrm{E}-02$ & $.165 \mathrm{E}-04$ \\
\hline
\end{tabular}

Table 24. AGB yields for $Z_{\mathrm{ini}}=0.004, \eta_{\mathrm{AGB}}=4$, and $m_{\mathrm{HBB}}=0.9$

\begin{tabular}{lcccr}
\hline$M_{\text {ini }}$ & ${ }^{12} \mathrm{C}$ & ${ }^{13} \mathrm{C}$ & ${ }^{14} \mathrm{~N}$ & ${ }^{16} \mathrm{O}$ \\
\hline 3.0 & $.583 \mathrm{E}-02$ & $.117 \mathrm{E}-04$ & $.400 \mathrm{E}-03$ & $.380 \mathrm{E}-03$ \\
3.5 & $.393 \mathrm{E}-02$ & $.119 \mathrm{E}-04$ & $.361 \mathrm{E}-03$ & $.243 \mathrm{E}-03$ \\
4.0 & $.402 \mathrm{E}-02$ & $.127 \mathrm{E}-04$ & $.343 \mathrm{E}-03$ & $.264 \mathrm{E}-03$ \\
4.5 & $.159 \mathrm{E}-02$ & $.576 \mathrm{E}-04$ & $.325 \mathrm{E}-02$ & $.274 \mathrm{E}-03$ \\
5.0 & $.215 \mathrm{E}-03$ & $.724 \mathrm{E}-04$ & $.522 \mathrm{E}-02$ & $.194 \mathrm{E}-03$ \\
6.0 & $.284 \mathrm{E}-03$ & $.916 \mathrm{E}-04$ & $.636 \mathrm{E}-02$ & $-.166 \mathrm{E}-03$ \\
7.0 & $.297 \mathrm{E}-03$ & $.103 \mathrm{E}-03$ & $.718 \mathrm{E}-02$ & $-.242 \mathrm{E}-03$ \\
8.0 & $.248 \mathrm{E}-03$ & $.113 \mathrm{E}-03$ & $.791 \mathrm{E}-02$ & $-.316 \mathrm{E}-03$ \\
\hline
\end{tabular}

Table 25. Final AGB yields for $Z_{\text {ini }}=0.004, \eta_{\mathrm{AGB}}=4$, and $m_{\mathrm{HBB}}=0.9$

\begin{tabular}{lcccr}
\hline$M_{\text {ini }}$ & ${ }^{12} \mathrm{C}$ & ${ }^{13} \mathrm{C}$ & ${ }^{14} \mathrm{~N}$ & ${ }^{16} \mathrm{O}$ \\
\hline 3.0 & $.154 \mathrm{E}-02$ & $.101 \mathrm{E}-05$ & $.358 \mathrm{E}-04$ & $.117 \mathrm{E}-03$ \\
3.5 & $.142 \mathrm{E}-02$ & $.156 \mathrm{E}-05$ & $.483 \mathrm{E}-04$ & $.105 \mathrm{E}-03$ \\
4.0 & $.152 \mathrm{E}-02$ & $.172 \mathrm{E}-05$ & $.473 \mathrm{E}-04$ & $.115 \mathrm{E}-03$ \\
4.5 & $.277 \mathrm{E}-03$ & $.148 \mathrm{E}-04$ & $.907 \mathrm{E}-03$ & $.777 \mathrm{E}-04$ \\
5.0 & $.775 \mathrm{E}-04$ & $.154 \mathrm{E}-04$ & $.118 \mathrm{E}-02$ & $.552 \mathrm{E}-04$ \\
6.0 & $.872 \mathrm{E}-04$ & $.184 \mathrm{E}-04$ & $.132 \mathrm{E}-02$ & $-.217 \mathrm{E}-04$ \\
7.0 & $.842 \mathrm{E}-04$ & $.195 \mathrm{E}-04$ & $.140 \mathrm{E}-02$ & $-.292 \mathrm{E}-04$ \\
8.0 & $.724 \mathrm{E}-04$ & $.208 \mathrm{E}-04$ & $.147 \mathrm{E}-02$ & $-.329 \mathrm{E}-04$ \\
\hline
\end{tabular}

Table 26. AGB yields for $Z_{\mathrm{ini}}=0.008, \eta_{\mathrm{AGB}}=4$, and $m_{\mathrm{HBB}}=0.9$

\begin{tabular}{lrccr}
\hline$M_{\text {ini }}$ & \multicolumn{1}{c}{${ }^{12} \mathrm{C}$} & ${ }^{13} \mathrm{C}$ & ${ }^{14} \mathrm{~N}$ & ${ }^{16} \mathrm{O}$ \\
\hline 3.0 & $.537 \mathrm{E}-02$ & $.223 \mathrm{E}-04$ & $.706 \mathrm{E}-03$ & $.185 \mathrm{E}-03$ \\
3.5 & $.351 \mathrm{E}-02$ & $.219 \mathrm{E}-04$ & $.666 \mathrm{E}-03$ & $.628 \mathrm{E}-04$ \\
4.0 & $.343 \mathrm{E}-02$ & $.226 \mathrm{E}-04$ & $.664 \mathrm{E}-03$ & $.568 \mathrm{E}-04$ \\
4.5 & $.179 \mathrm{E}-02$ & $.580 \mathrm{E}-04$ & $.279 \mathrm{E}-02$ & $.732 \mathrm{E}-04$ \\
5.0 & $-.521 \mathrm{E}-04$ & $.798 \mathrm{E}-04$ & $.519 \mathrm{E}-02$ & $.211 \mathrm{E}-05$ \\
6.0 & $-.781 \mathrm{E}-05$ & $.976 \mathrm{E}-04$ & $.639 \mathrm{E}-02$ & $-.428 \mathrm{E}-03$ \\
7.0 & $-.173 \mathrm{E}-04$ & $.109 \mathrm{E}-03$ & $.730 \mathrm{E}-02$ & $-.599 \mathrm{E}-03$ \\
8.0 & $-.101 \mathrm{E}-03$ & $.134 \mathrm{E}-03$ & $.934 \mathrm{E}-02$ & $-.926 \mathrm{E}-03$ \\
\hline
\end{tabular}

Table 27. Final AGB yields for $Z_{\mathrm{ini}}=0.008, \eta_{\mathrm{AGB}}=4$, and $m_{\mathrm{HBB}}=0.9$

\begin{tabular}{lcccc}
\hline \multicolumn{1}{c}{$M_{\text {ini }}$} & ${ }^{12} \mathrm{C}$ & ${ }^{13} \mathrm{C}$ & ${ }^{14} \mathrm{~N}$ & ${ }^{16} \mathrm{O}$ \\
\hline 3.0 & $.144 \mathrm{E}-02$ & $.193 \mathrm{E}-05$ & $.626 \mathrm{E}-04$ & $.854 \mathrm{E}-04$ \\
3.5 & $.142 \mathrm{E}-02$ & $.313 \mathrm{E}-05$ & $.966 \mathrm{E}-04$ & $.741 \mathrm{E}-04$ \\
4.0 & $.149 \mathrm{E}-02$ & $.334 \mathrm{E}-05$ & $.993 \mathrm{E}-04$ & $.784 \mathrm{E}-04$ \\
4.5 & $.344 \mathrm{E}-03$ & $.158 \mathrm{E}-04$ & $.877 \mathrm{E}-03$ & $.490 \mathrm{E}-04$ \\
5.0 & $.431 \mathrm{E}-04$ & $.171 \mathrm{E}-04$ & $.123 \mathrm{E}-02$ & $.277 \mathrm{E}-04$ \\
6.0 & $.521 \mathrm{E}-04$ & $.199 \mathrm{E}-04$ & $.140 \mathrm{E}-02$ & $-.668 \mathrm{E}-04$ \\
7.0 & $.475 \mathrm{E}-04$ & $.209 \mathrm{E}-04$ & $.148 \mathrm{E}-02$ & $-.886 \mathrm{E}-04$ \\
8.0 & $.336 \mathrm{E}-04$ & $.240 \mathrm{E}-04$ & $.172 \mathrm{E}-02$ & $-.121 \mathrm{E}-03$ \\
\hline
\end{tabular}

Table 28. AGB yields for $Z_{\text {ini }}=0.020, \eta_{\text {AGB }}=4$, and $m_{\mathrm{HBB}}=0.9$

\begin{tabular}{lcccc}
\hline$M_{\text {ini }}$ & ${ }^{12} \mathrm{C}$ & ${ }^{13} \mathrm{C}$ & ${ }^{14} \mathrm{~N}$ & ${ }^{16} \mathrm{O}$ \\
\hline 3.0 & $.391 \mathrm{E}-02$ & $.588 \mathrm{E}-04$ & $.151 \mathrm{E}-02$ & $-.235 \mathrm{E}-03$ \\
3.5 & $.351 \mathrm{E}-02$ & $.591 \mathrm{E}-04$ & $.153 \mathrm{E}-02$ & $-.283 \mathrm{E}-03$ \\
4.0 & $.318 \mathrm{E}-02$ & $.599 \mathrm{E}-04$ & $.156 \mathrm{E}-02$ & $-.329 \mathrm{E}-03$ \\
4.5 & $.309 \mathrm{E}-02$ & $.607 \mathrm{E}-04$ & $.155 \mathrm{E}-02$ & $-.334 \mathrm{E}-03$ \\
5.0 & $.302 \mathrm{E}-02$ & $.681 \mathrm{E}-04$ & $.201 \mathrm{E}-02$ & $-.337 \mathrm{E}-03$ \\
6.0 & $-.744 \mathrm{E}-03$ & $.127 \mathrm{E}-03$ & $.695 \mathrm{E}-02$ & $-.944 \mathrm{E}-03$ \\
7.0 & $-.805 \mathrm{E}-03$ & $.139 \mathrm{E}-03$ & $.791 \mathrm{E}-02$ & $-.132 \mathrm{E}-02$ \\
8.0 & $-.957 \mathrm{E}-03$ & $.144 \mathrm{E}-03$ & $.881 \mathrm{E}-02$ & $-.171 \mathrm{E}-02$ \\
\hline
\end{tabular}

Table 29. Final AGB yields for $Z_{\text {ini }}=0.020, \eta_{\mathrm{AGB}}=4$, and $m_{\mathrm{HBB}}=0.9$

\begin{tabular}{lcccr}
\hline$M_{\text {ini }}$ & ${ }^{12} \mathrm{C}$ & ${ }^{13} \mathrm{C}$ & ${ }^{14} \mathrm{~N}$ & ${ }^{16} \mathrm{O}$ \\
\hline 3.0 & $.114 \mathrm{E}-02$ & $.522 \mathrm{E}-05$ & $.136 \mathrm{E}-03$ & $.118 \mathrm{E}-04$ \\
3.5 & $.121 \mathrm{E}-02$ & $.728 \mathrm{E}-05$ & $.190 \mathrm{E}-03$ & $-.298 \mathrm{E}-05$ \\
4.0 & $.141 \mathrm{E}-02$ & $.836 \mathrm{E}-05$ & $.219 \mathrm{E}-03$ & $-.657 \mathrm{E}-05$ \\
4.5 & $.149 \mathrm{E}-02$ & $.895 \mathrm{E}-05$ & $.231 \mathrm{E}-03$ & $-.696 \mathrm{E}-05$ \\
5.0 & $.782 \mathrm{E}-03$ & $.141 \mathrm{E}-04$ & $.633 \mathrm{E}-03$ & $-.252 \mathrm{E}-04$ \\
6.0 & $-.529 \mathrm{E}-04$ & $.257 \mathrm{E}-04$ & $.164 \mathrm{E}-02$ & $-.170 \mathrm{E}-03$ \\
7.0 & $-.612 \mathrm{E}-04$ & $.267 \mathrm{E}-04$ & $.175 \mathrm{E}-02$ & $-.234 \mathrm{E}-03$ \\
8.0 & $-.906 \mathrm{E}-04$ & $.270 \mathrm{E}-04$ & $.188 \mathrm{E}-02$ & $-.296 \mathrm{E}-03$ \\
\hline
\end{tabular}


Table 30. AGB yields for $Z_{\text {ini }}=0.040, \eta_{\text {AGB }}=4$, and $m_{\mathrm{HBB}}=0.9$

\begin{tabular}{lcccc}
\hline$M_{\text {ini }}$ & ${ }^{12} \mathrm{C}$ & ${ }^{13} \mathrm{C}$ & ${ }^{14} \mathrm{~N}$ & ${ }^{16} \mathrm{O}$ \\
\hline 3.0 & $.830 \mathrm{E}-03$ & $.130 \mathrm{E}-03$ & $.260 \mathrm{E}-02$ & $-.521 \mathrm{E}-03$ \\
3.5 & $.288 \mathrm{E}-02$ & $.134 \mathrm{E}-03$ & $.270 \mathrm{E}-02$ & $-.596 \mathrm{E}-03$ \\
4.0 & $.282 \mathrm{E}-02$ & $.136 \mathrm{E}-03$ & $.278 \mathrm{E}-02$ & $-.650 \mathrm{E}-03$ \\
4.5 & $.290 \mathrm{E}-02$ & $.140 \mathrm{E}-03$ & $.292 \mathrm{E}-02$ & $-.744 \mathrm{E}-03$ \\
5.0 & $.305 \mathrm{E}-02$ & $.142 \mathrm{E}-03$ & $.304 \mathrm{E}-02$ & $-.832 \mathrm{E}-03$ \\
6.0 & $.327 \mathrm{E}-02$ & $.147 \mathrm{E}-03$ & $.298 \mathrm{E}-02$ & $-.816 \mathrm{E}-03$ \\
7.0 & $-.582 \mathrm{E}-03$ & $.204 \mathrm{E}-03$ & $.759 \mathrm{E}-02$ & $-.150 \mathrm{E}-02$ \\
8.0 & $-.216 \mathrm{E}-02$ & $.212 \mathrm{E}-03$ & $.965 \mathrm{E}-02$ & $-.230 \mathrm{E}-02$ \\
\hline
\end{tabular}

Table 31. Final AGB yields for $Z_{\text {ini }}=0.040, \eta_{\text {AGB }}=4$, and $m_{\mathrm{HBB}}=0.9$

\begin{tabular}{lcccc}
\hline$M_{\text {ini }}$ & ${ }^{12} \mathrm{C}$ & ${ }^{13} \mathrm{C}$ & ${ }^{14} \mathrm{~N}$ & ${ }^{16} \mathrm{O}$ \\
\hline 3.0 & $.835 \mathrm{E}-03$ & $.171 \mathrm{E}-04$ & $.343 \mathrm{E}-03$ & $-.741 \mathrm{E}-04$ \\
3.5 & $.126 \mathrm{E}-02$ & $.171 \mathrm{E}-04$ & $.349 \mathrm{E}-03$ & $-.838 \mathrm{E}-04$ \\
4.0 & $.161 \mathrm{E}-02$ & $.199 \mathrm{E}-04$ & $.411 \mathrm{E}-03$ & $-.105 \mathrm{E}-03$ \\
4.5 & $.149 \mathrm{E}-02$ & $.194 \mathrm{E}-04$ & $.410 \mathrm{E}-03$ & $-.113 \mathrm{E}-03$ \\
5.0 & $.151 \mathrm{E}-02$ & $.198 \mathrm{E}-04$ & $.427 \mathrm{E}-03$ & $-.126 \mathrm{E}-03$ \\
6.0 & $.154 \mathrm{E}-02$ & $.195 \mathrm{E}-04$ & $.401 \mathrm{E}-03$ & $-.119 \mathrm{E}-03$ \\
7.0 & $-.387 \mathrm{E}-04$ & $.369 \mathrm{E}-04$ & $.186 \mathrm{E}-02$ & $-.314 \mathrm{E}-03$ \\
8.0 & $-.302 \mathrm{E}-03$ & $.394 \mathrm{E}-04$ & $.228 \mathrm{E}-02$ & $-.489 \mathrm{E}-03$ \\
\hline
\end{tabular}

Table 32. Total AGB yields for $\mathrm{H}$, He for synthetic evolution model

\begin{tabular}{|c|c|c|c|c|c|c|c|c|c|c|}
\hline \multirow[b]{2}{*}{$m_{\text {ini }}$} & \multicolumn{2}{|c|}{$Z_{\text {ini }}=0.001$} & \multicolumn{2}{|c|}{$Z_{\text {ini }}=0.004$} & \multicolumn{2}{|c|}{$Z_{\text {ini }}=0.008$} & \multicolumn{2}{|c|}{$Z_{\text {ini }}=0.020$} & \multicolumn{2}{|c|}{$Z_{\text {ini }}=0.040$} \\
\hline & $\mathrm{H}$ & ${ }^{4} \mathrm{He}$ & $\mathrm{H}$ & ${ }^{4} \mathrm{He}$ & $\mathrm{H}$ & ${ }^{4} \mathrm{He}$ & $\mathrm{H}$ & ${ }^{4} \mathrm{He}$ & $\mathrm{H}$ & ${ }^{4} \mathrm{He}$ \\
\hline .8 & $-.12 \mathrm{E}-01$ & $.12 \mathrm{E}-01$ & $.11 \mathrm{E}-01$ & $.11 \mathrm{E}-01$ & $-.11 \mathrm{E}-01$ & $.11 \mathrm{E}-01$ & $-.99 \mathrm{E}-02$ & $.99 \mathrm{E}-02$ & $-.83 \mathrm{E}-02$ & $.83 \mathrm{E}-02$ \\
\hline .9 & $-.13 \mathrm{E}-01$ & $.13 \mathrm{E}-01$ & $-.12 \mathrm{E}-01$ & $.12 \mathrm{E}-01$ & $-.12 \mathrm{E}-01$ & $.12 \mathrm{E}-01$ & $-.99 \mathrm{E}-02$ & $.99 \mathrm{E}-02$ & $-.86 \mathrm{E}-02$ & $.86 \mathrm{E}-02$ \\
\hline 1.0 & $-.14 \mathrm{E}-01$ & $.14 \mathrm{E}-01$ & $-.16 \mathrm{E}-01$ & $.15 \mathrm{E}-01$ & $-.13 \mathrm{E}-01$ & $.13 \mathrm{E}-01$ & $-.11 \mathrm{E}-01$ & $.11 \mathrm{E}-01$ & $-.91 \mathrm{E}-02$ & $.91 \mathrm{E}-02$ \\
\hline 1.3 & $-.24 \mathrm{E}-01$ & $.21 \mathrm{E}-01$ & $-.20 \mathrm{E}-01$ & $.18 \mathrm{E}-01$ & $-.18 \mathrm{E}-01$ & $.17 \mathrm{E}-01$ & $-.11 \mathrm{E}-01$ & $.11 \mathrm{E}-01$ & $-.91 \mathrm{E}-02$ & $.91 \mathrm{E}-02$ \\
\hline 1.5 & $-.24 \mathrm{E}-01$ & $.21 \mathrm{E}-01$ & $-.21 \mathrm{E}-01$ & $.18 \mathrm{E}-01$ & $-.22 \mathrm{E}-01$ & $.19 \mathrm{E}-01$ & $-.15 \mathrm{E}-01$ & $.13 \mathrm{E}-01$ & $-.79 \mathrm{E}-02$ & $.79 \mathrm{E}-02$ \\
\hline 1.7 & $-.23 \mathrm{E}-01$ & $.20 \mathrm{E}-01$ & $-.24 \mathrm{E}-01$ & $.20 \mathrm{E}-01$ & $-.22 \mathrm{E}-01$ & $.18 \mathrm{E}-01$ & $-.15 \mathrm{E}-01$ & $.13 \mathrm{E}-01$ & $-.65 \mathrm{E}-02$ & $.65 \mathrm{E}-02$ \\
\hline 2.0 & $-.23 \mathrm{E}-01$ & $.18 \mathrm{E}-01$ & $-.23 \mathrm{E}-01$ & $.19 \mathrm{E}-01$ & $-.21 \mathrm{E}-01$ & $.17 \mathrm{E}-01$ & $-.16 \mathrm{E}-01$ & $.13 \mathrm{E}-01$ & $-.61 \mathrm{E}-02$ & $.53 \mathrm{E}-02$ \\
\hline 2.5 & $-.22 \mathrm{E}-01$ & $.17 \mathrm{E}-01$ & $-.27 \mathrm{E}-01$ & $.20 \mathrm{E}-01$ & $-.24 \mathrm{E}-01$ & $.18 \mathrm{E}-01$ & $-.19 \mathrm{E}-01$ & $.14 \mathrm{E}-01$ & $-.12 \mathrm{E}-01$ & $.88 \mathrm{E}-02$ \\
\hline 3.0 & $-.19 \mathrm{E}-01$ & $.14 \mathrm{E}-01$ & $-.28 \mathrm{E}-01$ & $.20 \mathrm{E}-01$ & $-.27 \mathrm{E}-01$ & $.19 \mathrm{E}-01$ & $-.22 \mathrm{E}-01$ & $.15 \mathrm{E}-01$ & $-.14 \mathrm{E}-01$ & $.94 \mathrm{E}-02$ \\
\hline 3.5 & $-.19 \mathrm{E}-01$ & $.13 \mathrm{E}-01$ & $-.18 \mathrm{E}-01$ & $.12 \mathrm{E}-01$ & $-.18 \mathrm{E}-01$ & $.12 \mathrm{E}-01$ & $-.19 \mathrm{E}-01$ & $.13 \mathrm{E}-01$ & $-.20 \mathrm{E}-01$ & $.14 \mathrm{E}-01$ \\
\hline 4.0 & $-.36 \mathrm{E}-01$ & $.30 \mathrm{E}-01$ & $-.32 \mathrm{E}-01$ & $.27 \mathrm{E}-01$ & $-.27 \mathrm{E}-01$ & $.22 \mathrm{E}-01$ & $-.17 \mathrm{E}-01$ & $.12 \mathrm{E}-01$ & $-.20 \mathrm{E}-01$ & $.13 \mathrm{E}-01$ \\
\hline 4.5 & $-.53 \mathrm{E}-01$ & $.46 \mathrm{E}-01$ & $-.50 \mathrm{E}-01$ & $.44 \mathrm{E}-01$ & $-.46 \mathrm{E}-01$ & $.41 \mathrm{E}-01$ & $-.21 \mathrm{E}-01$ & $.16 \mathrm{E}-01$ & $-.19 \mathrm{E}-01$ & $.13 \mathrm{E}-01$ \\
\hline 5.0 & $-.68 \mathrm{E}-01$ & $.60 \mathrm{E}-01$ & $-.65 \mathrm{E}-01$ & $.58 \mathrm{E}-01$ & $-.61 \mathrm{E}-01$ & $.55 \mathrm{E}-01$ & $-.38 \mathrm{E}-01$ & $.32 \mathrm{E}-01$ & $-.19 \mathrm{E}-01$ & $.13 \mathrm{E}-01$ \\
\hline 6.0 & $-.89 \mathrm{E}-01$ & $.80 \mathrm{E}-01$ & $-.87 \mathrm{E}-01$ & $.79 \mathrm{E}-01$ & $-.84 \mathrm{E}-01$ & $.77 \mathrm{E}-01$ & $-.63 \mathrm{E}-01$ & $.57 \mathrm{E}-01$ & $-.19 \mathrm{E}-01$ & $.14 \mathrm{E}-01$ \\
\hline 7.0 & $-.10 \mathrm{E}+00$ & $.95 \mathrm{E}-01$ & $-.10 \mathrm{E}+00$ & $.94 \mathrm{E}-01$ & $-.10 \mathrm{E}+00$ & $.92 \mathrm{E}-01$ & $-.81 \mathrm{E}-01$ & $.75 \mathrm{E}-01$ & $-.18 \mathrm{E}-01$ & $.13 \mathrm{E}-01$ \\
\hline 8.0 & $-.10 \mathrm{E}+00$ & $.94 \mathrm{E}-01$ & $-.11 \mathrm{E}+00$ & $.11 \mathrm{E}+00$ & $-.11 \mathrm{E}+00$ & $.10 \mathrm{E}+00$ & $-.94 \mathrm{E}-01$ & $.87 \mathrm{E}-01$ & $-.28 \mathrm{E}-01$ & $.23 \mathrm{E}-01$ \\
\hline
\end{tabular}

Table 33. AGB yields for $Z_{\mathrm{ini}}=0.004, \eta_{\mathrm{AGB}}=2$, and $m_{\mathrm{HBB}}=0.8$

\begin{tabular}{|c|c|c|c|c|c|c|c|c|c|c|}
\hline$m_{\text {ini }}$ & $\overline{\mathrm{H}}$ & ${ }^{4} \mathrm{He}$ & ${ }^{12} \mathrm{C}$ & ${ }^{13} \mathrm{C}$ & ${ }^{14} \mathrm{~N}$ & ${ }^{16} \mathrm{O}$ & $\overline{Y_{\mathrm{CNO}}}$ & $\overline{Y_{\mathrm{TOT}}}$ & $\Delta m_{\mathrm{ej}}$ & $m_{\text {end }}$ \\
\hline .8 & $-.108 \mathrm{E}-01$ & $.108 \mathrm{E}-01$ & $-.753 \mathrm{E}-04$ & $.564 \mathrm{E}-05$ & $.879 \mathrm{E}-04$ & $-.649 \mathrm{E}-05$ & $.117 \mathrm{E}-04$ & $-.145 \mathrm{E}-07$ & .25 & .57 \\
\hline .9 & $-.113 \mathrm{E}-01$ & $.113 \mathrm{E}-01$ & $-.832 \mathrm{E}-04$ & $.609 \mathrm{E}-05$ & $.971 \mathrm{E}-04$ & $-.707 \mathrm{E}-05$ & $.129 \mathrm{E}-04$ & $.428 \mathrm{E}-09$ & .30 & .60 \\
\hline 1.0 & $-.139 \mathrm{E}-01$ & $.133 \mathrm{E}-01$ & $.415 \mathrm{E}-03$ & $.681 \mathrm{E}-05$ & $.112 \mathrm{E}-03$ & $.338 \mathrm{E}-04$ & $.568 \mathrm{E}-03$ & $.551 \mathrm{E}-03$ & .38 & .62 \\
\hline 1.3 & $-.208 \mathrm{E}-01$ & $.182 \mathrm{E}-01$ & $.222 \mathrm{E}-02$ & $.808 \mathrm{E}-05$ & $.145 \mathrm{E}-03$ & $.181 \mathrm{E}-03$ & $.255 \mathrm{E}-02$ & $253 \mathrm{E}-02$ & .61 & .64 \\
\hline 1.5 & $-.273 \mathrm{E}-01$ & $.225 \mathrm{E}-01$ & $.427 \mathrm{E}-02$ & $.902 \mathrm{E}-05$ & $.175 \mathrm{E}-03$ & $.350 \mathrm{E}-03$ & $.480 \mathrm{E}-02$ & $.477 \mathrm{E}-02$ & .87 & .63 \\
\hline 1.7 & $-.281 \mathrm{E}-01$ & $.225 \mathrm{E}-01$ & $.502 \mathrm{E}-02$ & $.901 \mathrm{E}-05$ & $.187 \mathrm{E}-03$ & $.411 \mathrm{E}-03$ & $.563 \mathrm{E}-02$ & $.559 \mathrm{E}-02$ & 1.02 & .68 \\
\hline 2.0 & $-.401 \mathrm{E}-01$ & $.315 \mathrm{E}-01$ & $.757 \mathrm{E}-02$ & $.969 \mathrm{E}-05$ & $.300 \mathrm{E}-03$ & $.571 \mathrm{E}-03$ & $.846 \mathrm{E}-02$ & $.865 \mathrm{E}-02$ & 1.28 & .71 \\
\hline 2.5 & $-.491 \mathrm{E}-01$ & $.382 \mathrm{E}-01$ & $.972 \mathrm{E}-02$ & $.110 \mathrm{E}-04$ & $.375 \mathrm{E}-03$ & $.705 \mathrm{E}-03$ & $.108 \mathrm{E}-01$ & $.109 \mathrm{E}-01$ & 1.74 & .74 \\
\hline 3.0 & $-.521 \mathrm{E}-01$ & $.394 \mathrm{E}-01$ & $.114 \mathrm{E}-01$ & $.112 \mathrm{E}-04$ & $.392 \mathrm{E}-03$ & $.831 \mathrm{E}-03$ & $.126 \mathrm{E}-01$ & $.127 \mathrm{E}-01$ & 2.17 & .80 \\
\hline 3.5 & $-.366 \mathrm{E}-01$ & $.278 \mathrm{E}-01$ & $.756 \mathrm{E}-02$ & $.306 \mathrm{E}-03$ & $.406 \mathrm{E}-03$ & $.566 \mathrm{E}-03$ & $.884 \mathrm{E}-02$ & $.888 \mathrm{E}-02$ & 2.40 & 1.06 \\
\hline 4.0 & $-.354 \mathrm{E}-01$ & $.264 \mathrm{E}-01$ & $.129 \mathrm{E}-02$ & $.349 \mathrm{E}-03$ & $.685 \mathrm{E}-02$ & $.486 \mathrm{E}-03$ & $.897 \mathrm{E}-02$ & $.899 \mathrm{E}-02$ & 2.78 & 1.19 \\
\hline 4.5 & $-.399 \mathrm{E}-01$ & $.299 \mathrm{E}-01$ & $.634 \mathrm{E}-03$ & $.137 \mathrm{E}-03$ & $.862 \mathrm{E}-02$ & $.593 \mathrm{E}-03$ & $.999 \mathrm{E}-02$ & $.100 \mathrm{E}-01$ & 3.22 & 1.25 \\
\hline 5.0 & $-.437 \mathrm{E}-01$ & $.328 \mathrm{E}-01$ & $.624 \mathrm{E}-03$ & $.128 \mathrm{E}-03$ & $.969 \mathrm{E}-02$ & $.416 \mathrm{E}-03$ & $.109 \mathrm{E}-01$ & $109 \mathrm{E}-01$ & 3.65 & 1.32 \\
\hline 6.0 & $-.483 \mathrm{E}-01$ & $.359 \mathrm{E}-01$ & $.717 \mathrm{E}-03$ & $.163 \mathrm{E}-03$ & $.117 \mathrm{E}-01$ & $-.219 \mathrm{E}-03$ & $.123 \mathrm{E}-01$ & $.124 \mathrm{E}-01$ & 4.49 & 1.46 \\
\hline 7.0 & $-.511 \mathrm{E}-02$ & $.537 \mathrm{E}-01$ & $.712 \mathrm{E}-03$ & $.182 \mathrm{E}-03$ & $.128 \mathrm{E}-01$ & $-.165 \mathrm{E}-03$ & $.136 \mathrm{E}-01$ & $.137 \mathrm{E}-01$ & 4.84 & 1.64 \\
\hline
\end{tabular}


Table 34. Final AGB yields for $Z_{\mathrm{ini}}=0.004, \eta_{\mathrm{AGB}}=2$, and $m_{\mathrm{HBB}}=0.8$

\begin{tabular}{|c|c|c|c|c|c|c|c|c|c|c|}
\hline$m_{\text {ini }}$ & $\mathrm{H}$ & ${ }^{4} \mathrm{He}$ & ${ }^{12} \mathrm{C}$ & ${ }^{13} \mathrm{C}$ & ${ }^{14} \mathrm{~N}$ & ${ }^{16} \mathrm{O}$ & $Y_{\mathrm{CNO}}$ & $Y_{\mathrm{TOT}}$ & $\Delta m_{\mathrm{ej}}$ & $m_{\text {end }}$ \\
\hline .8 & $-.494 \mathrm{E}-04$ & $.494 \mathrm{E}-04$ & $-.344 \mathrm{E}-06$ & $.258 \mathrm{E}-07$ & $.402 \mathrm{E}-06$ & $-.297 \mathrm{E}-07$ & $.536 \mathrm{E}-07$ & $-.967 \mathrm{E}-10$ & .00 & .57 \\
\hline .9 & $-.670 \mathrm{E}-03$ & $.670 \mathrm{E}-03$ & $-.493 \mathrm{E}-05$ & $.361 \mathrm{E}-06$ & $.576 \mathrm{E}-05$ & $-.419 \mathrm{E}-06$ & $.766 \mathrm{E}-06$ & $.218 \mathrm{E}-09$ & .02 & .58 \\
\hline 1.0 & $-.179 \mathrm{E}-02$ & $.152 \mathrm{E}-02$ & $.246 \mathrm{E}-03$ & $.508 \mathrm{E}-06$ & $.839 \mathrm{E}-05$ & $.201 \mathrm{E}-04$ & $.275 \mathrm{E}-03$ & $.273 \mathrm{E}-03$ & .03 & .59 \\
\hline 1.3 & $-.265 \mathrm{E}-02$ & $.210 \mathrm{E}-02$ & $.496 \mathrm{E}-03$ & $.564 \mathrm{E}-06$ & $.101 \mathrm{E}-04$ & $.405 \mathrm{E}-04$ & $.547 \mathrm{E}-03$ & $.544 \mathrm{E}-03$ & .05 & .60 \\
\hline 1.5 & $-.313 \mathrm{E}-02$ & $.226 \mathrm{E}-02$ & $.806 \mathrm{E}-03$ & $.228 \mathrm{E}-06$ & $.463 \mathrm{E}-05$ & $.659 \mathrm{E}-04$ & $.877 \mathrm{E}-03$ & $.873 \mathrm{E}-03$ & .03 & .60 \\
\hline 1.7 & $-.414 \mathrm{E}-02$ & $.302 \mathrm{E}-02$ & $.102 \mathrm{E}-02$ & $.489 \mathrm{E}-06$ & $.104 \mathrm{E}-04$ & $.836 \mathrm{E}-04$ & $.112 \mathrm{E}-02$ & $.111 \mathrm{E}-02$ & .07 & .61 \\
\hline 2.0 & $-.552 \mathrm{E}-02$ & $.399 \mathrm{E}-02$ & $.140 \mathrm{E}-02$ & $.449 \mathrm{E}-06$ & $.150 \mathrm{E}-04$ & $.112 \mathrm{E}-03$ & $.152 \mathrm{E}-02$ & $.153 \mathrm{E}-02$ & .08 & .63 \\
\hline 2.5 & $-.453 \mathrm{E}-02$ & $.329 \mathrm{E}-02$ & $.114 \mathrm{E}-02$ & $.394 \mathrm{E}-06$ & $.144 \mathrm{E}-04$ & $.897 \mathrm{E}-04$ & $.125 \mathrm{E}-02$ & $.125 \mathrm{E}-02$ & .08 & .66 \\
\hline 3.0 & $-.510 \mathrm{E}-02$ & $.366 \mathrm{E}-02$ & $.132 \mathrm{E}-02$ & $.447 \mathrm{E}-06$ & $.168 \mathrm{E}-04$ & $.104 \mathrm{E}-03$ & $.144 \mathrm{E}-02$ & $.144 \mathrm{E}-02$ & .11 & .69 \\
\hline 3.5 & $-.481 \mathrm{E}-02$ & $.350 \mathrm{E}-02$ & $.112 \mathrm{E}-02$ & $.567 \mathrm{E}-04$ & $.385 \mathrm{E}-04$ & $.902 \mathrm{E}-04$ & $.130 \mathrm{E}-02$ & $.130 \mathrm{E}-02$ & .20 & .86 \\
\hline 4.0 & $-.494 \mathrm{E}-02$ & $.360 \mathrm{E}-02$ & $.195 \mathrm{E}-03$ & $.470 \mathrm{E}-04$ & $.102 \mathrm{E}-02$ & $.801 \mathrm{E}-04$ & $.134 \mathrm{E}-02$ & $.134 \mathrm{E}-02$ & .24 & .95 \\
\hline 4.5 & $-.521 \mathrm{E}-02$ & $.381 \mathrm{E}-02$ & $.104 \mathrm{E}-03$ & $.182 \mathrm{E}-04$ & $.119 \mathrm{E}-02$ & $.887 \mathrm{E}-04$ & $.141 \mathrm{E}-02$ & $.141 \mathrm{E}-02$ & .26 & .99 \\
\hline 5.0 & $-.549 \mathrm{E}-02$ & $.401 \mathrm{E}-02$ & $.998 \mathrm{E}-04$ & $.167 \mathrm{E}-04$ & $.130 \mathrm{E}-02$ & $.598 \mathrm{E}-04$ & $.147 \mathrm{E}-02$ & $.147 \mathrm{E}-02$ & .29 & 1.03 \\
\hline 6.0 & $-.571 \mathrm{E}-02$ & $.416 \mathrm{E}-02$ & $.104 \mathrm{E}-03$ & $.200 \mathrm{E}-04$ & $.145 \mathrm{E}-02$ & $-.165 \mathrm{E}-04$ & $.156 \mathrm{E}-02$ & $.156 \mathrm{E}-02$ & .33 & 1.12 \\
\hline 7.0 & $-.464 \mathrm{E}-01$ & $-.156 \mathrm{E}-01$ & $-.594 \mathrm{E}-04$ & $-.714 \mathrm{E}-06$ & $.453 \mathrm{E}-05$ & $-.131 \mathrm{E}-03$ & $-.187 \mathrm{E}-03$ & $-.228 \mathrm{E}-03$ & .44 & 1.20 \\
\hline
\end{tabular}

Table 35. Total yields for $Z_{\mathrm{ini}}=0.004, \eta_{\mathrm{AGB}}=2$, and $m_{\mathrm{HBB}}=0.8$

\begin{tabular}{|c|c|c|c|c|c|c|c|c|c|c|}
\hline$m_{\text {ini }}$ & $\mathrm{H}$ & ${ }^{4} \mathrm{He}$ & ${ }^{12} \mathrm{C}$ & ${ }^{13} \mathrm{C}$ & ${ }^{14} \mathrm{~N}$ & ${ }^{16} \mathrm{O}$ & $Y_{\mathrm{CNO}}$ & $Y_{\mathrm{TOT}}$ & $\Delta m_{\mathrm{ej}}$ & $m_{\text {end }}$ \\
\hline .9 & $-.121 \mathrm{E}-01$ & $.121 \mathrm{E}-01$ & $-.853 \mathrm{E}-04$ & $.643 \mathrm{E}-05$ & $.104 \mathrm{E}-03$ & $-.652 \mathrm{E}-06$ & $.245 \mathrm{E}-04$ & $.108 \mathrm{E}-04$ & .32 & .58 \\
\hline 1.0 & $-.158 \mathrm{E}-01$ & $.150 \mathrm{E}-01$ & $.665 \mathrm{E}-03$ & $.729 \mathrm{E}-05$ & $.122 \mathrm{E}-03$ & $.626 \mathrm{E}-04$ & $.857 \mathrm{E}-03$ & $.839 \mathrm{E}-03$ & .42 & .59 \\
\hline 1.3 & $-.235 \mathrm{E}-01$ & $.204 \mathrm{E}-01$ & $.271 \mathrm{E}-02$ & $.863 \mathrm{E}-05$ & $.156 \mathrm{E}-03$ & $.226 \mathrm{E}-03$ & $.311 \mathrm{E}-02$ & $.308 \mathrm{E}-02$ & .66 & .60 \\
\hline 1.3 & $-.235 \mathrm{E}-01$ & $.204 \mathrm{E}-01$ & $.271 \mathrm{E}-02$ & $.864 \mathrm{E}-05$ & $.156 \mathrm{E}-03$ & $.226 \mathrm{E}-03$ & $.310 \mathrm{E}-02$ & $.307 \mathrm{E}-02$ & .66 & .60 \\
\hline 1.5 & $-.310 \mathrm{E}-01$ & $.253 \mathrm{E}-01$ & $.508 \mathrm{E}-02$ & $.914 \mathrm{E}-05$ & $.190 \mathrm{E}-03$ & $.444 \mathrm{E}-03$ & $.573 \mathrm{E}-02$ & $.569 \mathrm{E}-02$ & .92 & .60 \\
\hline 1.7 & $-.327 \mathrm{E}-01$ & $.259 \mathrm{E}-01$ & $.605 \mathrm{E}-02$ & $.940 \mathrm{E}-05$ & $.206 \mathrm{E}-03$ & $.517 \mathrm{E}-03$ & $.678 \mathrm{E}-02$ & $.674 \mathrm{E}-02$ & 1.11 & .61 \\
\hline 2.0 & $-.459 \mathrm{E}-01$ & $.357 \mathrm{E}-01$ & $.897 \mathrm{E}-02$ & $.101 \mathrm{E}-04$ & $.320 \mathrm{E}-03$ & $.694 \mathrm{E}-03$ & $.100 \mathrm{E}-01$ & $.102 \mathrm{E}-01$ & 1.37 & .63 \\
\hline 2.5 & $-.539 \mathrm{E}-01$ & $.417 \mathrm{E}-01$ & $.109 \mathrm{E}-01$ & $.114 \mathrm{E}-04$ & $.395 \mathrm{E}-03$ & $.806 \mathrm{E}-03$ & $.121 \mathrm{E}-01$ & $.121 \mathrm{E}-01$ & 1.84 & .66 \\
\hline 3.0 & $-.575 \mathrm{E}-01$ & $.434 \mathrm{E}-01$ & $.127 \mathrm{E}-01$ & $.116 \mathrm{E}-04$ & $.417 \mathrm{E}-03$ & $.950 \mathrm{E}-03$ & $.141 \mathrm{E}-01$ & $.141 \mathrm{E}-01$ & 2.31 & .69 \\
\hline 4.0 & $-.405 \mathrm{E}-01$ & $.301 \mathrm{E}-01$ & $.149 \mathrm{E}-02$ & $.396 \mathrm{E}-03$ & $.787 \mathrm{E}-02$ & $.578 \mathrm{E}-03$ & $.103 \mathrm{E}-01$ & $.103 \mathrm{E}-01$ & 3.05 & .95 \\
\hline 5.0 & $-.492 \mathrm{E}-01$ & $.369 \mathrm{E}-01$ & $.726 \mathrm{E}-03$ & $.145 \mathrm{E}-03$ & $.110 \mathrm{E}-01$ & $.484 \mathrm{E}-03$ & $.123 \mathrm{E}-01$ & $.124 \mathrm{E}-01$ & 3.97 & 1.03 \\
\hline 7.0 & $-.517 \mathrm{E}-01$ & $.382 \mathrm{E}-01$ & $.657 \mathrm{E}-03$ & $.181 \mathrm{E}-03$ & $.128 \mathrm{E}-01$ & $-.279 \mathrm{E}-03$ & $.134 \mathrm{E}-01$ & $.135 \mathrm{E}-01$ & 5.79 & 1.20 \\
\hline
\end{tabular}

Table 36. AGB yields for $Z_{\mathrm{ini}}=0.001, \eta_{\mathrm{AGB}}=1$, and $m_{\mathrm{HBB}}=0.8$

\begin{tabular}{|c|c|c|c|c|c|c|c|c|c|c|}
\hline$m_{\text {ini }}$ & $\mathrm{H}$ & ${ }^{4} \mathrm{He}$ & ${ }^{12} \mathrm{C}$ & ${ }^{13} \mathrm{C}$ & ${ }^{14} \mathrm{~N}$ & ${ }^{16} \mathrm{O}$ & $Y_{\mathrm{CNO}}$ & $Y_{\mathrm{TOT}}$ & $\Delta m_{\mathrm{ej}}$ & $m_{\mathrm{end}}$ \\
\hline 8 & $-.118 \mathrm{E}-01$ & $.118 \mathrm{E}-01$ & $-.183 \mathrm{E}-04$ & $-.104 \mathrm{E}-04$ & $214 \mathrm{E}-04$ & $-.173 \mathrm{E}-05$ & $-.911 \mathrm{E}-05$ & $-.147 \mathrm{E}-07$ & .27 & .56 \\
\hline 1.0 & $-.168 \mathrm{E}-01$ & $.155 \mathrm{E}-01$ & $.118 \mathrm{E}-02$ & $-.126 \mathrm{E}-04$ & $.258 \mathrm{E}-04$ & $.104 \mathrm{E}-03$ & $.129 \mathrm{E}-02$ & $.130 \mathrm{E}-02$ & .39 & .61 \\
\hline 1.3 & $-.339 \mathrm{E}-01$ & $.273 \mathrm{E}-01$ & $.603 \mathrm{E}-02$ & $-.162 \mathrm{E}-04$ & $.314 \mathrm{E}-04$ & $.534 \mathrm{E}-03$ & $.658 \mathrm{E}-02$ & $.659 \mathrm{E}-02$ & .62 & .63 \\
\hline 1.7 & $-.426 \mathrm{E}-01$ & $.324 \mathrm{E}-01$ & $.936 \mathrm{E}-02$ & $-.193 \mathrm{E}-04$ & $.387 \mathrm{E}-04$ & $.829 \mathrm{E}-03$ & $.102 \mathrm{E}-01$ & $.102 \mathrm{E}-01$ & .99 & .71 \\
\hline 2.0 & $-.530 \mathrm{E}-01$ & $.398 \mathrm{E}-01$ & $.120 \mathrm{E}-01$ & $-.207 \mathrm{E}-04$ & $.684 \mathrm{E}-04$ & $.105 \mathrm{E}-02$ & $.131 \mathrm{E}-01$ & $.132 \mathrm{E}-01$ & 1.23 & .77 \\
\hline 2.5 & $-.512 \mathrm{E}-01$ & $.368 \mathrm{E}-01$ & $.130 \mathrm{E}-01$ & $-.212 \mathrm{E}-04$ & $.736 \mathrm{E}-04$ & $.114 \mathrm{E}-02$ & $.142 \mathrm{E}-01$ & $.143 \mathrm{E}-01$ & 1.62 & .87 \\
\hline 4.0 & $-.614 \mathrm{E}-01$ & $.443 \mathrm{E}-01$ & $.230 \mathrm{E}-02$ & $.433 \mathrm{E}-03$ & $.130 \mathrm{E}-01$ & $.123 \mathrm{E}-02$ & $.170 \mathrm{E}-01$ & $.171 \mathrm{E}-01$ & 2.81 & 1.17 \\
\hline 4.5 & $-.669 \mathrm{E}-01$ & $.483 \mathrm{E}-01$ & $.155 \mathrm{E}-02$ & $.190 \mathrm{E}-03$ & $.154 \mathrm{E}-01$ & $.131 \mathrm{E}-02$ & $.185 \mathrm{E}-01$ & $.186 \mathrm{E}-01$ & 3.24 & 1.25 \\
\hline 5.0 & $-.716 \mathrm{E}-01$ & $.517 \mathrm{E}-01$ & $.156 \mathrm{E}-02$ & $.194 \mathrm{E}-03$ & $.172 \mathrm{E}-01$ & $.893 \mathrm{E}-03$ & $.198 \mathrm{E}-01$ & $.200 \mathrm{E}-01$ & 3.66 & 1.33 \\
\hline 6.0 & $-.599 \mathrm{E}-01$ & $.436 \mathrm{E}-01$ & $.118 \mathrm{E}-02$ & $.184 \mathrm{E}-03$ & $.146 \mathrm{E}-01$ & $.204 \mathrm{E}-03$ & $.162 \mathrm{E}-01$ & $.163 \mathrm{E}-01$ & 3.74 & 2.25 \\
\hline 7.0 & $-.148 \mathrm{E}-01$ & $.112 \mathrm{E}-01$ & $.247 \mathrm{E}-03$ & $.365 \mathrm{E}-04$ & $.325 \mathrm{E}-02$ & $.246 \mathrm{E}-04$ & $.356 \mathrm{E}-02$ & $.357 \mathrm{E}-02$ & 1.82 & 5.16 \\
\hline
\end{tabular}


Table 37. Final AGB yields for $Z_{\mathrm{ini}}=0.001, \eta_{\mathrm{AGB}}=1$, and $m_{\mathrm{HBB}}=0.8$

\begin{tabular}{|c|c|c|c|c|c|c|c|c|c|c|}
\hline$m_{\text {ini }}$ & $\mathrm{H}$ & ${ }^{4} \mathrm{He}$ & ${ }^{12} \mathrm{C}$ & ${ }^{13} \mathrm{C}$ & ${ }^{14} \mathrm{~N}$ & ${ }^{16} \mathrm{O}$ & $Y_{\mathrm{CNO}}$ & $Y_{\mathrm{TOT}}$ & $\Delta m_{\mathrm{ej}}$ & $m_{\mathrm{end}}$ \\
\hline .8 & $-.108 \mathrm{E}-03$ & $.108 \mathrm{E}-03$ & $-.167 \mathrm{E}-06$ & $-.952 \mathrm{E}-07$ & $.195 \mathrm{E}-06$ & $-.158 \mathrm{E}-07$ & $-.831 \mathrm{E}-07$ & $-.133 \mathrm{E}-09$ & .00 & .56 \\
\hline .9 & $-.263 \mathrm{E}-03$ & $.263 \mathrm{E}-03$ & $-.431 \mathrm{E}-06$ & $-.243 \mathrm{E}-06$ & $.503 \mathrm{E}-06$ & $-.401 \mathrm{E}-07$ & $-.211 \mathrm{E}-06$ & $-.322 \mathrm{E}-09$ & .01 & .58 \\
\hline 1.0 & $-.235 \mathrm{E}-02$ & $.179 \mathrm{E}-02$ & $.515 \mathrm{E}-03$ & $-.657 \mathrm{E}-06$ & $.103 \mathrm{E}-05$ & $.456 \mathrm{E}-04$ & $.560 \mathrm{E}-03$ & $.561 \mathrm{E}-03$ & .02 & .59 \\
\hline 1.3 & $-.414 \mathrm{E}-02$ & $.298 \mathrm{E}-02$ & $.106 \mathrm{E}-02$ & $-.746 \mathrm{E}-06$ & $.879 \mathrm{E}-06$ & $.941 \mathrm{E}-04$ & $.116 \mathrm{E}-02$ & $.116 \mathrm{E}-02$ & .03 & .60 \\
\hline 1.5 & $-.311 \mathrm{E}-02$ & $.220 \mathrm{E}-02$ & $.841 \mathrm{E}-03$ & $-.465 \mathrm{E}-06$ & $.447 \mathrm{E}-06$ & $.745 \mathrm{E}-04$ & $.915 \mathrm{E}-03$ & $.915 \mathrm{E}-03$ & .02 & .64 \\
\hline 1.7 & $-.519 \mathrm{E}-02$ & $.367 \mathrm{E}-02$ & $.140 \mathrm{E}-02$ & $-.904 \mathrm{E}-06$ & $.109 \mathrm{E}-05$ & $.124 \mathrm{E}-03$ & $.152 \mathrm{E}-02$ & $.152 \mathrm{E}-02$ & .04 & .66 \\
\hline 2.0 & $-.542 \mathrm{E}-02$ & $.384 \mathrm{E}-02$ & $.144 \mathrm{E}-02$ & $-.960 \mathrm{E}-06$ & $.226 \mathrm{E}-05$ & $.128 \mathrm{E}-03$ & $.157 \mathrm{E}-02$ & $.158 \mathrm{E}-02$ & .06 & .71 \\
\hline 2.5 & $-.630 \mathrm{E}-02$ & $.439 \mathrm{E}-02$ & $.175 \mathrm{E}-02$ & $-.116 \mathrm{E}-05$ & $.289 \mathrm{E}-05$ & $.155 \mathrm{E}-03$ & $.191 \mathrm{E}-02$ & $.191 \mathrm{E}-02$ & .09 & .79 \\
\hline 3.0 & $-.405 \mathrm{E}-02$ & $.281 \mathrm{E}-02$ & $.112 \mathrm{E}-02$ & $.482 \mathrm{E}-06$ & $.318 \mathrm{E}-05$ & $.997 \mathrm{E}-04$ & $.123 \mathrm{E}-02$ & $.123 \mathrm{E}-02$ & .11 & .89 \\
\hline 3.5 & $-.438 \mathrm{E}-02$ & $.308 \mathrm{E}-02$ & $.804 \mathrm{E}-03$ & $.145 \mathrm{E}-03$ & $.240 \mathrm{E}-03$ & $.105 \mathrm{E}-03$ & $.129 \mathrm{E}-02$ & $.130 \mathrm{E}-02$ & .13 & .96 \\
\hline 4.0 & $-.500 \mathrm{E}-02$ & $.357 \mathrm{E}-02$ & $.180 \mathrm{E}-03$ & $.327 \mathrm{E}-04$ & $.111 \mathrm{E}-02$ & $.105 \mathrm{E}-03$ & $.142 \mathrm{E}-02$ & $.143 \mathrm{E}-02$ & .15 & 1.03 \\
\hline 4.5 & $-.522 \mathrm{E}-02$ & $.373 \mathrm{E}-02$ & $.125 \mathrm{E}-03$ & $.159 \mathrm{E}-04$ & $.124 \mathrm{E}-02$ & $.104 \mathrm{E}-03$ & $.149 \mathrm{E}-02$ & $.149 \mathrm{E}-02$ & .16 & 1.09 \\
\hline 5.0 & $-.544 \mathrm{E}-02$ & $.389 \mathrm{E}-02$ & $.123 \mathrm{E}-03$ & $.163 \mathrm{E}-04$ & $.134 \mathrm{E}-02$ & $.651 \mathrm{E}-04$ & $.155 \mathrm{E}-02$ & $.156 \mathrm{E}-02$ & .18 & 1.15 \\
\hline
\end{tabular}

Table 38. Total yields for $Z_{\mathrm{ini}}=0.001, \eta_{\mathrm{AGB}}=1$, and $m_{\mathrm{HBB}}=0.8$

\begin{tabular}{|c|c|c|c|c|c|c|c|c|c|c|}
\hline$m_{\text {ini }}$ & $\mathrm{H}$ & ${ }^{4} \mathrm{He}$ & ${ }^{12} \mathrm{C}$ & ${ }^{13} \mathrm{C}$ & ${ }^{14} \mathrm{~N}$ & ${ }^{16} \mathrm{O}$ & $Y_{\mathrm{CNO}}$ & $Y_{\mathrm{TOT}}$ & $\Delta m_{\mathrm{ej}}$ & $m_{\text {end }}$ \\
\hline .9 & $-.132 \mathrm{E}-01$ & $.132 \mathrm{E}-01$ & $-.213 \mathrm{E}-04$ & $-.128 \mathrm{E}-04$ & $.248 \mathrm{E}-04$ & $-.185 \mathrm{E}-05$ & $-.111 \mathrm{E}-04$ & $-.108 \mathrm{E}-05$ & .36 & .58 \\
\hline 1.0 & $-.199 \mathrm{E}-01$ & $.179 \mathrm{E}-01$ & $.169 \mathrm{E}-02$ & $-.143 \mathrm{E}-04$ & $.281 \mathrm{E}-04$ & $.150 \mathrm{E}-03$ & $.185 \mathrm{E}-02$ & $.186 \mathrm{E}-02$ & .44 & .59 \\
\hline 1.3 & $-.382 \mathrm{E}-01$ & $.305 \mathrm{E}-01$ & $.709 \mathrm{E}-02$ & $-.172 \mathrm{E}-04$ & $.328 \mathrm{E}-04$ & $.628 \mathrm{E}-03$ & $.774 \mathrm{E}-02$ & $.775 \mathrm{E}-02$ & .66 & .60 \\
\hline 1.3 & $-.385 \mathrm{E}-01$ & $.307 \mathrm{E}-01$ & $.709 \mathrm{E}-02$ & $-.176 \mathrm{E}-04$ & $.334 \mathrm{E}-04$ & $.628 \mathrm{E}-03$ & $.774 \mathrm{E}-02$ & $.774 \mathrm{E}-02$ & .67 & .60 \\
\hline 1.5 & $-.452 \mathrm{E}-01$ & $.348 \mathrm{E}-01$ & $.949 \mathrm{E}-02$ & $-.193 \mathrm{E}-04$ & $.373 \mathrm{E}-04$ & $.841 \mathrm{E}-03$ & $.104 \mathrm{E}-01$ & $.104 \mathrm{E}-01$ & .88 & .64 \\
\hline 1.7 & $-.478 \mathrm{E}-01$ & $.361 \mathrm{E}-01$ & $.108 \mathrm{E}-01$ & $-.203 \mathrm{E}-04$ & $.400 \mathrm{E}-04$ & $.953 \mathrm{E}-03$ & $.117 \mathrm{E}-01$ & $.117 \mathrm{E}-01$ & 1.04 & .66 \\
\hline 2.0 & $-.585 \mathrm{E}-01$ & $.437 \mathrm{E}-01$ & $.134 \mathrm{E}-01$ & $-.217 \mathrm{E}-04$ & $.710 \mathrm{E}-04$ & $.118 \mathrm{E}-02$ & $.146 \mathrm{E}-01$ & $.148 \mathrm{E}-01$ & 1.29 & .71 \\
\hline 2.5 & $-.575 \mathrm{E}-01$ & $.413 \mathrm{E}-01$ & $.148 \mathrm{E}-01$ & $-.225 \mathrm{E}-04$ & $.769 \mathrm{E}-04$ & $.130 \mathrm{E}-02$ & $.161 \mathrm{E}-01$ & $.163 \mathrm{E}-01$ & 1.71 & .79 \\
\hline 3.0 & $-.520 \mathrm{E}-01$ & $.365 \mathrm{E}-01$ & $.140 \mathrm{E}-01$ & $-.129 \mathrm{E}-04$ & $.697 \mathrm{E}-04$ & $.124 \mathrm{E}-02$ & $.153 \mathrm{E}-01$ & $.155 \mathrm{E}-01$ & 2.11 & .89 \\
\hline 4.0 & $-.664 \mathrm{E}-01$ & $.479 \mathrm{E}-01$ & $.248 \mathrm{E}-02$ & $.466 \mathrm{E}-03$ & $.141 \mathrm{E}-01$ & $.133 \mathrm{E}-02$ & $.184 \mathrm{E}-01$ & $.185 \mathrm{E}-01$ & 2.97 & 1.03 \\
\hline 5.0 & $-.771 \mathrm{E}-01$ & $.556 \mathrm{E}-01$ & $.169 \mathrm{E}-02$ & $.210 \mathrm{E}-03$ & $.185 \mathrm{E}-01$ & $.958 \mathrm{E}-03$ & $.214 \mathrm{E}-01$ & $.215 \mathrm{E}-01$ & 3.85 & 1.15 \\
\hline 7.0 & $-.148 \mathrm{E}-01$ & $.112 \mathrm{E}-01$ & $.247 \mathrm{E}-03$ & $.364 \mathrm{E}-04$ & $.325 \mathrm{E}-02$ & $.246 \mathrm{E}-04$ & $.356 \mathrm{E}-02$ & $.357 \mathrm{E}-02$ & 1.84 & 5.16 \\
\hline
\end{tabular}

